\title{
WestVirginiaUniversity
}

THE RESEARCH REPOSITORY @ WVU

Graduate Theses, Dissertations, and Problem Reports

2012

\section{Effectiveness of a Flanged and Unflanged Small Rectangular Capturing Hood}

Stephen Philip Kasberger

West Virginia University

Follow this and additional works at: https://researchrepository.wvu.edu/etd

\section{Recommended Citation}

Kasberger, Stephen Philip, "Effectiveness of a Flanged and Unflanged Small Rectangular Capturing Hood" (2012). Graduate Theses, Dissertations, and Problem Reports. 3331.

https://researchrepository.wvu.edu/etd/3331

This Thesis is protected by copyright and/or related rights. It has been brought to you by the The Research Repository @WVU with permission from the rights-holder(s). You are free to use this Thesis in any way that is permitted by the copyright and related rights legislation that applies to your use. For other uses you must obtain permission from the rights-holder(s) directly, unless additional rights are indicated by a Creative Commons license in the record and/ or on the work itself. This Thesis has been accepted for inclusion in WVU Graduate Theses, Dissertations, and Problem Reports collection by an authorized administrator of The Research Repository @ WVU. For more information, please contact researchrepository@mail.wvu.edu. 
Effectiveness of a Flanged and Unflanged Small Rectangular Capturing Hood

Stephen Philip Kasberger

Thesis Submitted to

The Benjamin M. Statler College of Engineering and Mineral Resources

at West Virginia University

in partial fulfillment of requirements

for the degree of

Master of Science

in

Industrial Hygiene

\begin{abstract}
Steven E. Guffey, Ph.D., Chair
Wafik H. Iskander, Ph.D.

Warren R. Myers, Ph.D.
\end{abstract}

Department of Industrial and Management Systems Engineering

Morgantown, West Virginia

2012

Keywords: Capturing hood; Ventilation; Worker Protection; Capture Efficiency; Protection Efficiency; Industrial Hygiene; Occupational Safety and Health 


\section{ABSTRACT \\ Effectiveness of a Flanged and Unflanged Small Rectangular Capturing Hood \\ Stephen Philip Kasberger}

Capturing hoods are an important tool for protecting workers from hazardous airborne exposures and often preferred because their small sizes offers little interference to the worker or process. Current ventilation guidelines for capturing hood assume that exceeding a recommended capture velocity ensures an acceptable degree of effectiveness. That assumption has little basis in scientific studies. This study investigated the effectiveness of a 6 inch by 12 inch rectangular capturing hood centered on a work table with a manikin acting as a surrogate for a worker.

The study utilized a tracer gas (Freon-134a) to evaluate effectiveness of a capturing hood at three different hood airflows $(\mathrm{Q})$, two different cross draft velocities $\left(\mathrm{V}_{\text {cross }}\right)$, and with the presence or absence of a flange (Flange). The tested air flows through the hood produced velocities at the leading edge of the source $\left(V_{x}\right)$ of approximately 40,100 , and $140 \mathrm{fpm}$, as measured with a constant temperature anemometer. The study was conducted inside of a $9 \mathrm{ft}$ high, $12 \mathrm{ft}$ wide, $50 \mathrm{ft}$ long wind tunnel with the manikin's back to the cross draft. Tracer gas was released from a custom made source located 11" in front of the capturing hood. The manikin was heated and "breathed." Its hands were positioned on either side of the source.

Breathing zone samples from the nose $\left(C_{\text {nose }}\right)$ and mouth $\left(C_{\text {mouth }}\right)$ of the manikin were collected simultaneously to evaluate the protection efficiency of the hood. Samples were also taken simultaneously from inside the duct $\left(\mathrm{C}_{\text {duct }}\right)$ to evaluate the capture efficiency of the hood. Samples were collected in 5 liter Tedlar ${ }^{\circledR}$ bags at a rate of $0.2 \mathrm{lpm}$ over a period of 20 minutes for each sample. Sample bag contents were analyzed by a Gastec FT-IR.

The study used a randomized factorial design with two replications. The results showed that the capturing hood was surprisingly highly effective both in terms of minimizing manikin exposures and minimizing escape of contaminant to the room environment. The concentration of Freon measured in the breathing zone was less than $1 \mathrm{ppm}$ for all tests and mostly was below $0.2 \mathrm{ppm}$, even though the source concentration was over $370,000 \mathrm{ppm}$ and was released at $1.79 \mathrm{lpm}$. This was true even when the capture velocity was only $50 \mathrm{fpm}$ and the cross draft velocity was $60 \mathrm{fpm}$. The capture effectiveness of the hood was no less than $90 \%$ but the results may not have been reliable due to apparent measurement inaccuracies and imprecision at the Freon levels measured.

The results only apply to this hood under these conditions. Testing under broader ranges of conditions would be necessary before concluding that the capturing hood is always highly effective. 


\section{ACKNOWLEDGEMENTS}

This project was supported by the National Institute of Safety and Health through their training grant number: 5 T01 OH008431.

I am deeply indebted to my academic advisor, chair, and mentor Dr. Steven Guffey, not only for his guidance, advice, and support through the entire thesis process, but for the guidance and advice he has imparted to me regarding academic, professional, and personal life. This thesis would not have been possible without his sound advice and encouragement.

I am very grateful to Dr. Warren Myers and Dr. Wafik Iskander for their constructive comments and service as committee members.

I owe a special thanks to my colleague, Chris Warnick, who spent countless hours with me building and testing the experimental set up used in this study. Additionally, I would like to thank my girlfriend, Jennifer Meier, for her patient support throughout the years of my academic career.

Lastly, I am forever indebted to my parents, Ron and Renee Kasberger, for their limitless encouragement, support, and love. 


\section{Table of Contents}

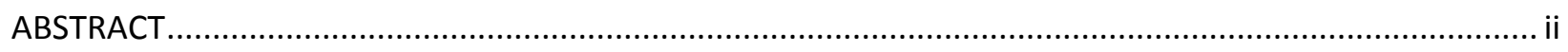

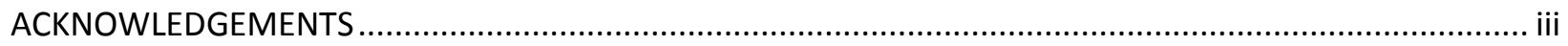

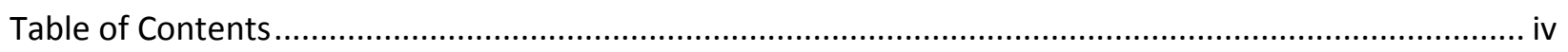

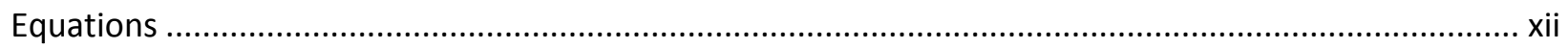

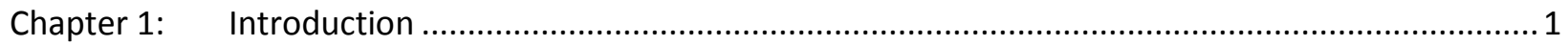

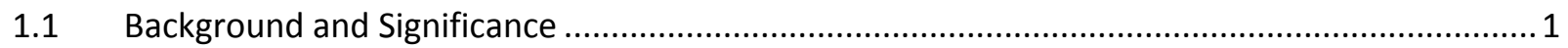

1.1.1 Velocities in Front of a Capturing Hood ......................................................................... 2

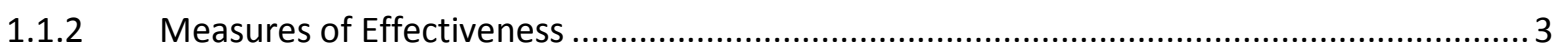

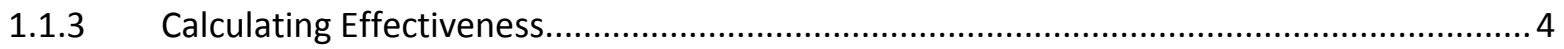

1.1.4 Studies of Actual Effectiveness of Hoods........................................................................ 6

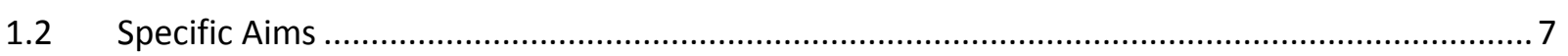

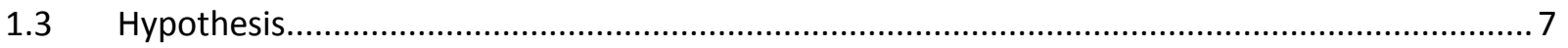

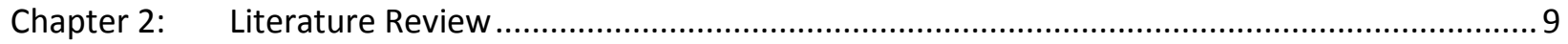

2.1. Centerline Velocity, Capture Envelopes............................................................................... 9

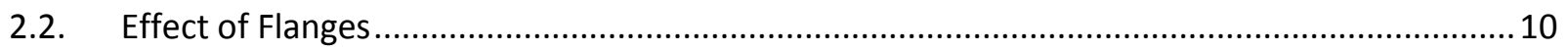

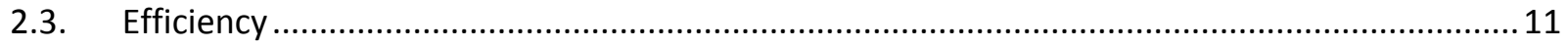

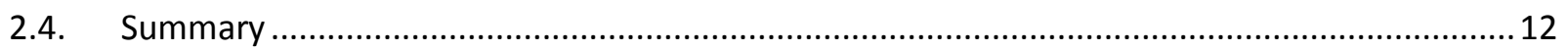

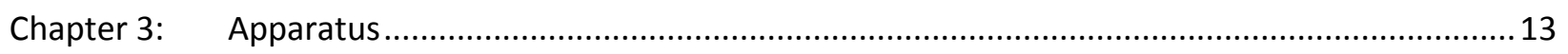

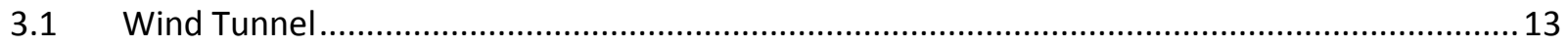

3.2 Wind Tunnel Cross Draft and Control System …................................................................. 14

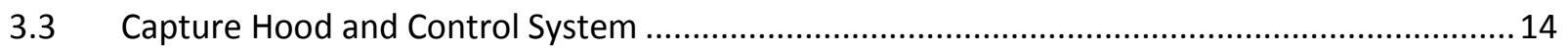

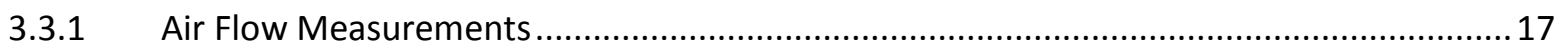

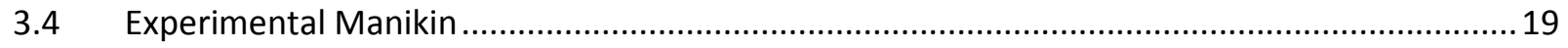

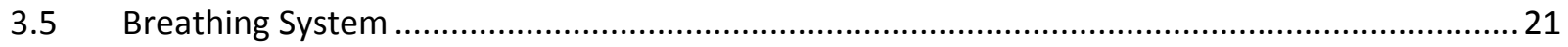

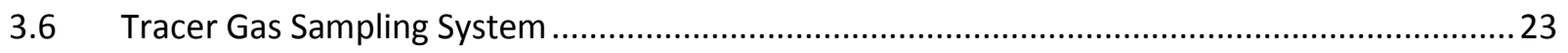

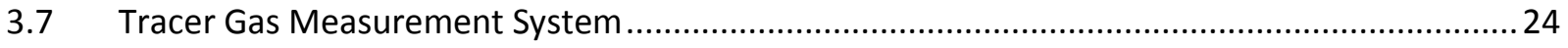

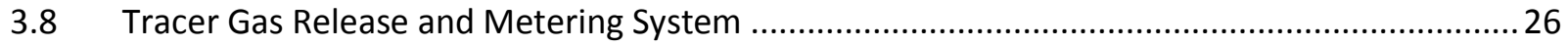

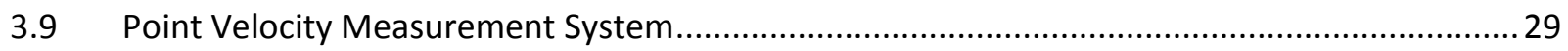

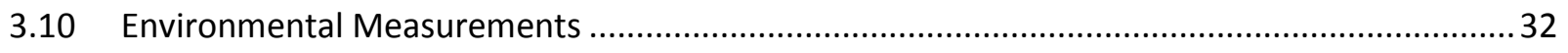

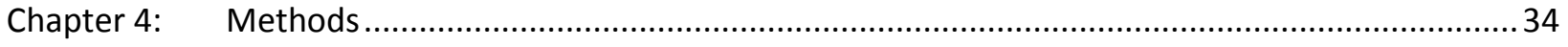




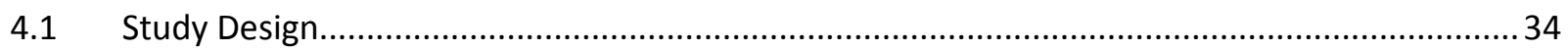

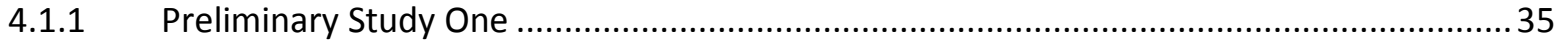

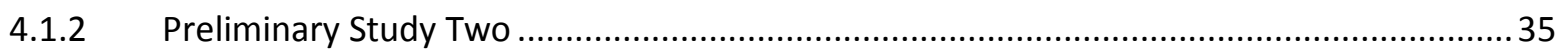

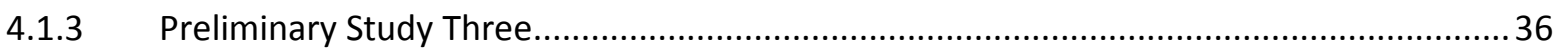

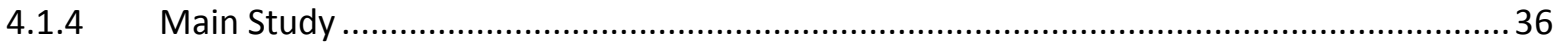

4.2 Procedure

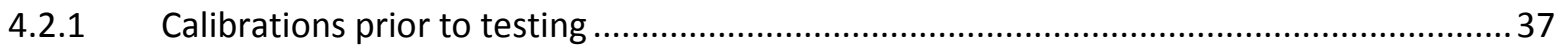

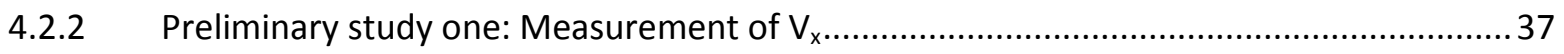

4.2.3 Preliminary study two: Measurement of $100 \%$ duct ...................................................... 38

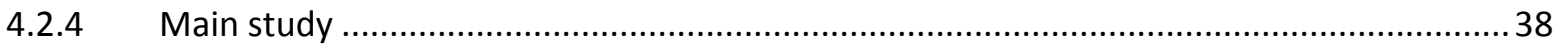

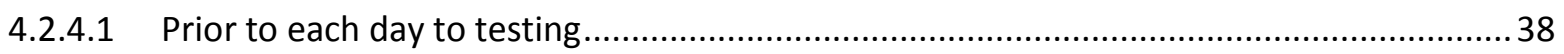

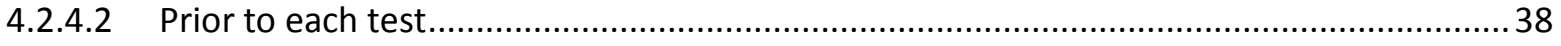

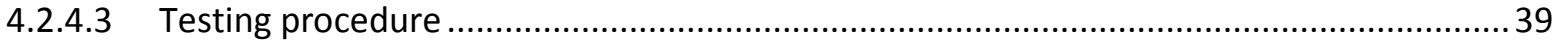

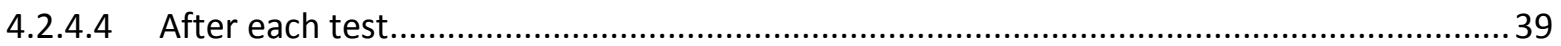

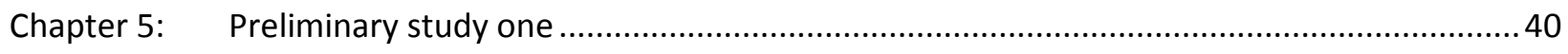

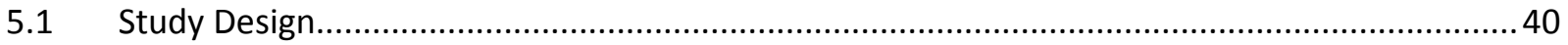

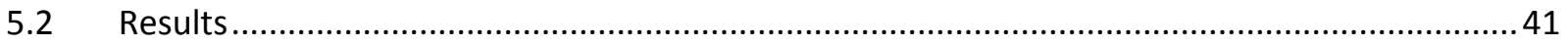

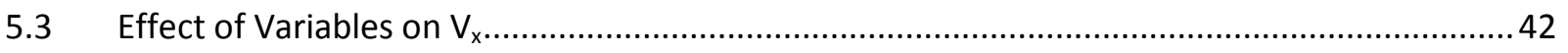

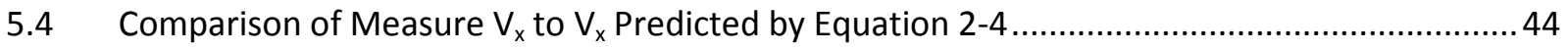

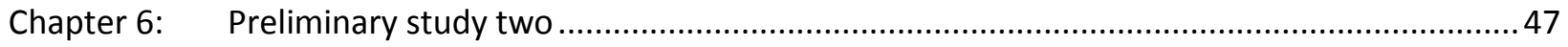

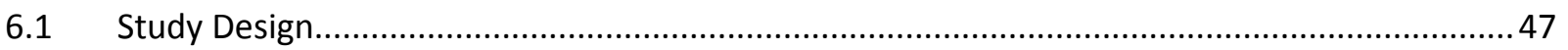

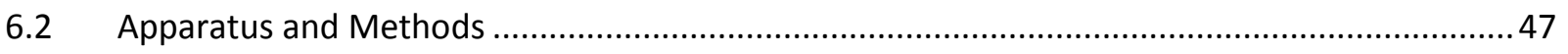

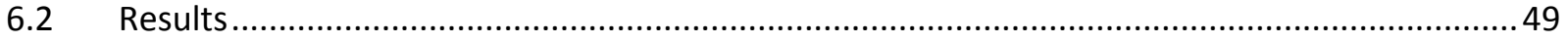

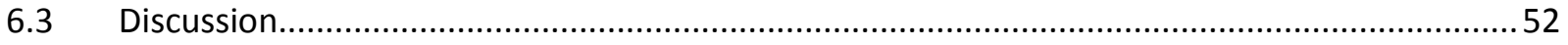

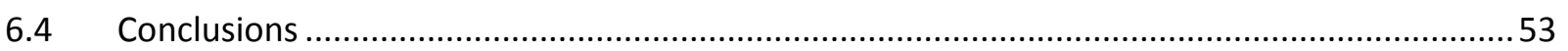

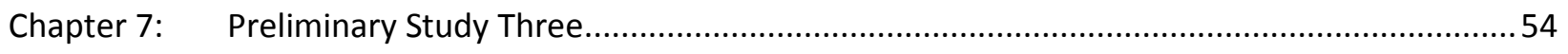

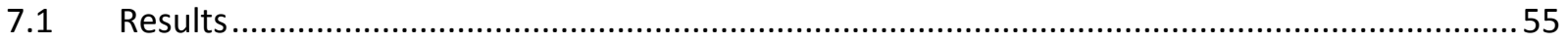

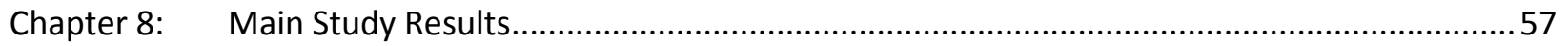

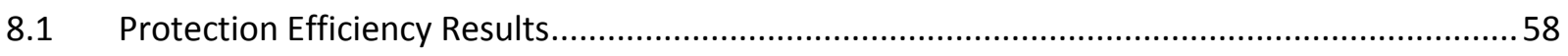

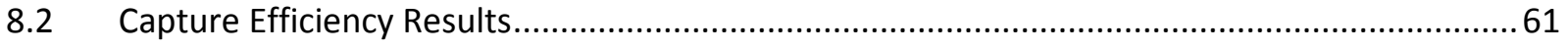

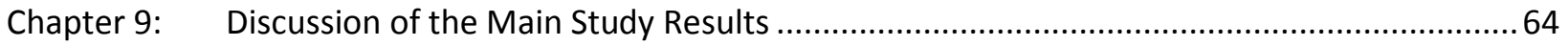

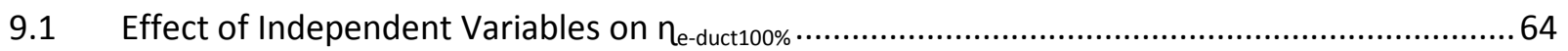




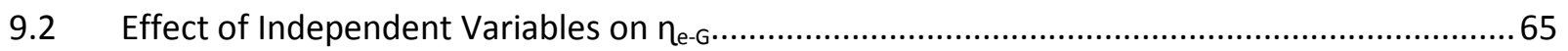

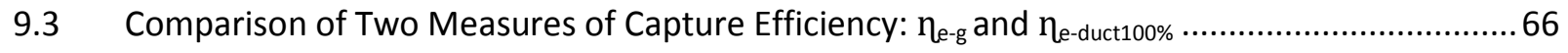

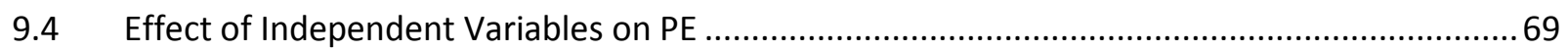

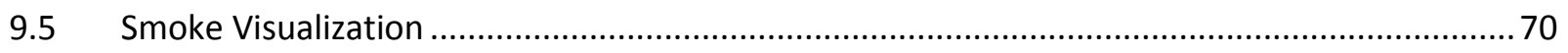

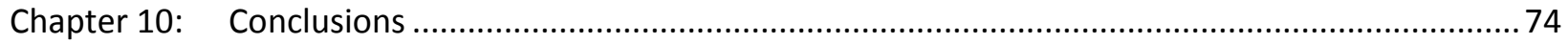

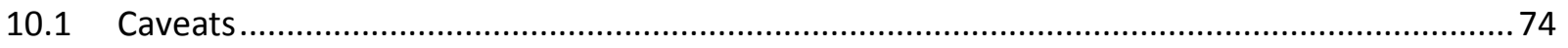

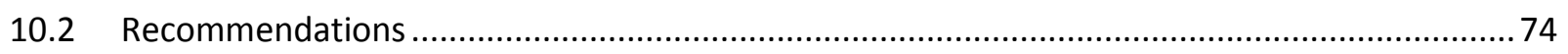

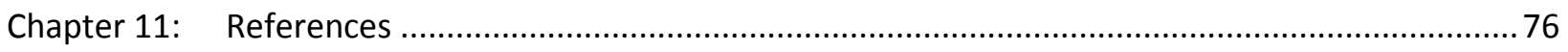

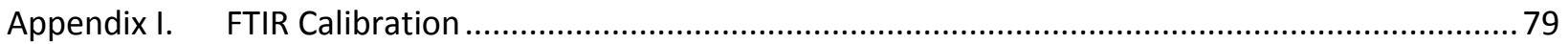

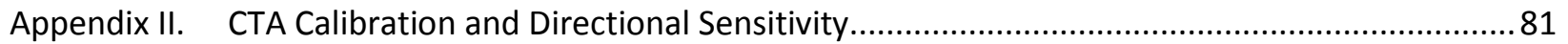




\section{Table of Figures}

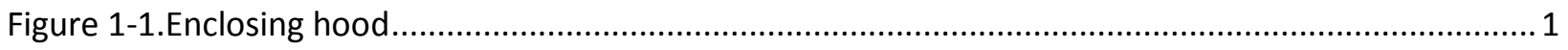

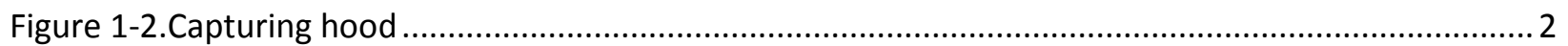

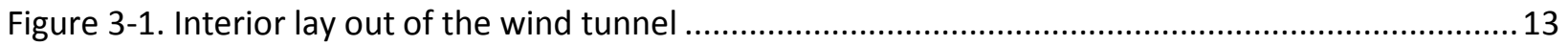

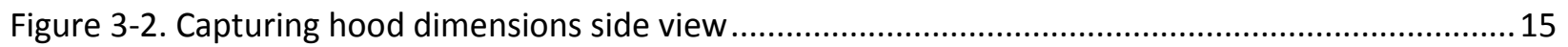

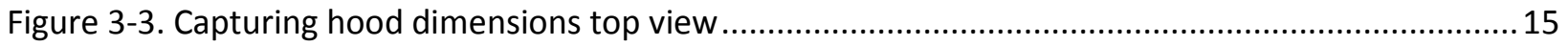

Figure 3-4. Dimensions of flanged capturing hood........................................................................... 15

Figure 3-5. Front view of the capturing hood and table dimensions .................................................... 16

Figure 3-6. Side view of the capturing hood and table dimensions ..................................................... 16

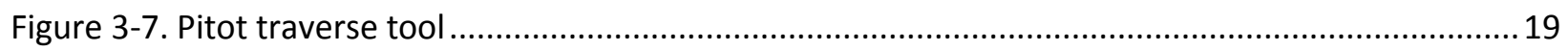

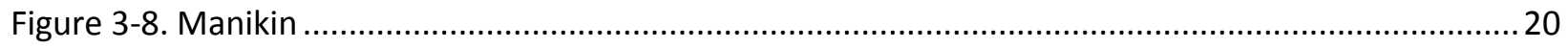

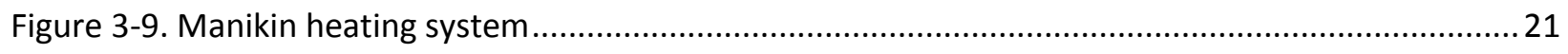

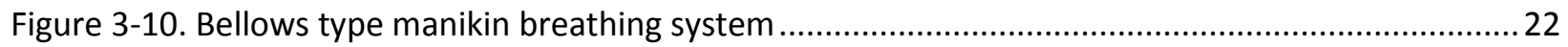

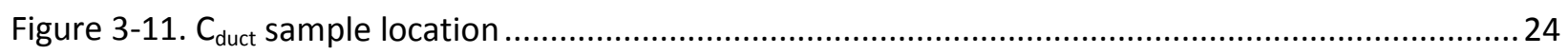

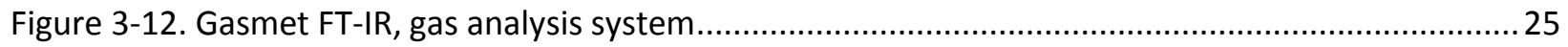

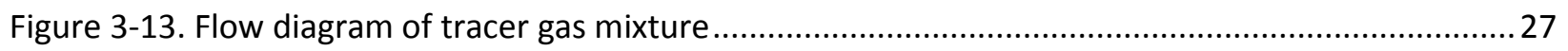

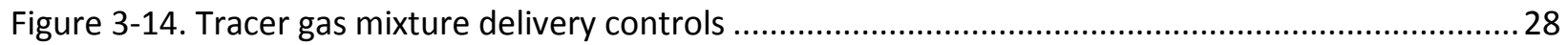

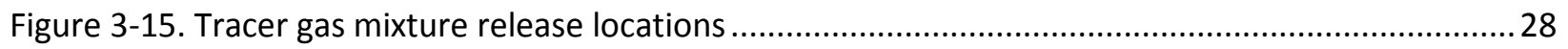

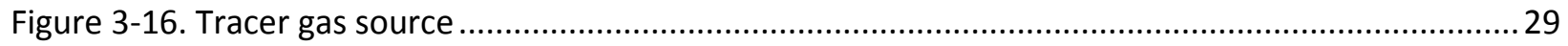

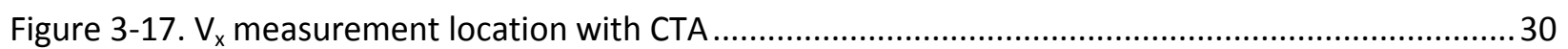

Figure 3-18. Detailed description of CTA probe used with permission by Dantec Dynamics. ...................30

Figure 3-19. CTA principle of operation used with permission by Dantec Dynamics ............................... 31

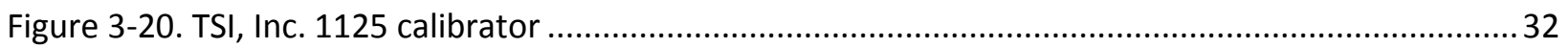

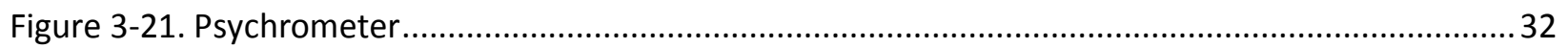

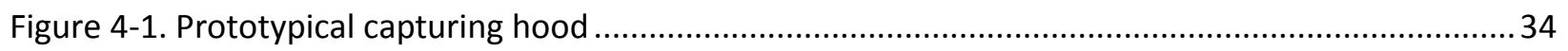

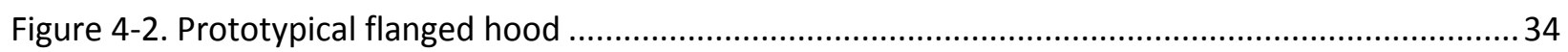

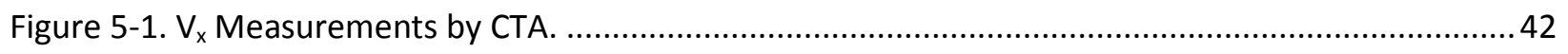

Figure 5-2. Graph of measured $V_{x}$ with a cross draft of $10 \mathrm{fpm}$ and the predicted $V_{x}$ from Equation 2-3

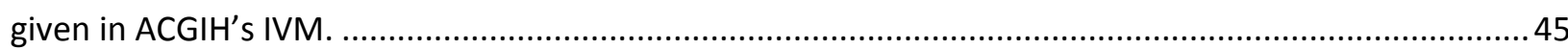

Figure 5-3. Graph of measured $V_{x}$ with a cross draft of $60 \mathrm{fpm}$ and the predicted $V_{x}$ from Equation 2-3

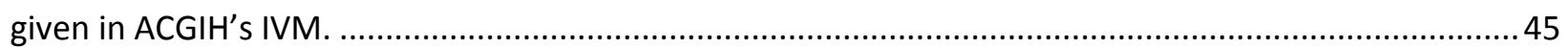

Figure 5-4. Graph of measured $V_{x}$ with a cross draft of 10 and $60 \mathrm{fpm}$ and the predicted $V_{x}$ from Equation

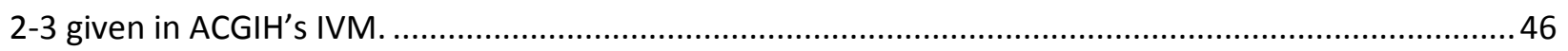

Figure 6-1. Undiluted $100 \%$ duct sample results and the corresponding residual value given by the FTIR,

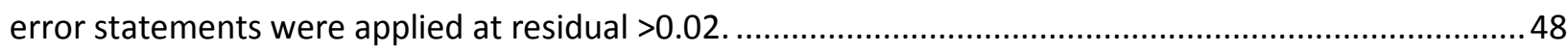

Figure 6-2. Diluted $100 \%$ duct sample results and the corresponding residual values given by the FTIR,

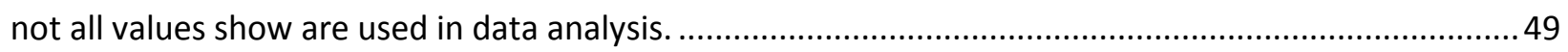

Figure 6-3. Diluted Freon duct samples from the $100 \%$ duct tests ......................................................5 51

Figure 6-4. Unadjusted capturing efficiency for the $100 \%$ duct study calculated using Equation 1-2 .......51

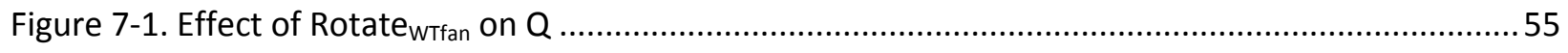


Figure 8-1. Measured Freon concentrations at the nose of the manikin and ambient locations for $Q$ and

Flange

Figure 8-2. Measured Freon concentrations at the mouth of the manikin and ambient locations for $Q$

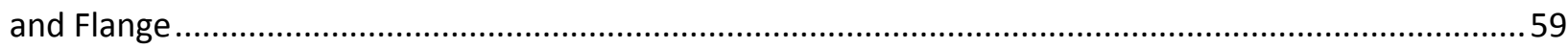

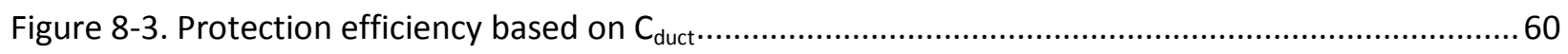

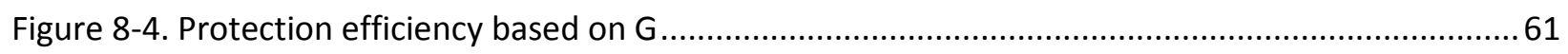

Figure 8-5. Measured Freon concentration in the duct when the tracer gas mixture was being released at

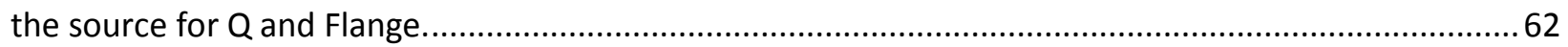

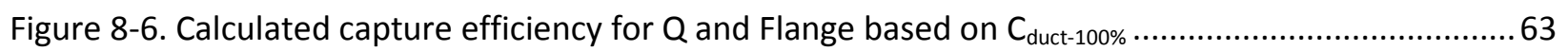

Figure 8-7. Calculated capture efficiency for $Q$ and Flange based on $G$...............................................63

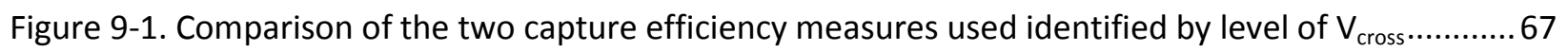

Figure 9-2. Comparison of two measures of capture efficiency...........................................................6 68

Figure 9-3. Comparison of two measure of capture efficiency with four values removed ........................68

Figure 9-4. Smoke visualization tests at Freq ${ }_{\text {HoodFan }}=23$ and Rotate ${ }_{\text {WTfan }}=930$ with no flange................ 72

Figure 9-5. Smoke Visualization at $\mathrm{Freq}_{\mathrm{HoodFan}}=23$ Rotate $_{\mathrm{WTfan}}=930$ with and without a flange..............73

Figure 9-6. Smoke visualization at Freq $_{\mathrm{HoodFan}}=40$ Rotate $_{\mathrm{Wffan}}=930$ with and without a flange.............. 73

Figure 9-7. Smoke visualization at $\mathrm{Freq}_{\text {HoodFan }}=55$ and Rotate $_{W T f a n}=930$ with and without a flange.......73

Figure 11-1. Calibration curve for the FTIR, combined pre and post calibrations...................................79

Figure 11-2. Residual values associated with the measured Freon concentrations during calibration. ..... 80

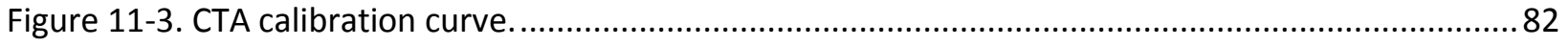

Figure 11-4. Directional sensitivity of the CTA when rotated about its axis......................................... 82 


\section{Table of Tables}

Table 3-1. Anthropometrically-scaled manikin dimensions ............................................................. 19

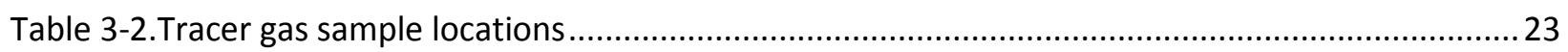

Table 4-1. Experimental Conditions for preliminary study one and the main study.................................35

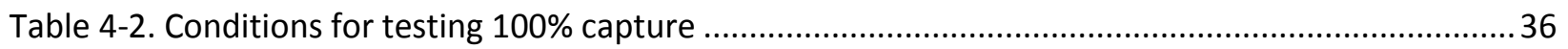

Table 5-1. Velocity measurements by CTA at the source on the centerline of the hood $\left(V_{x}\right)$ for each

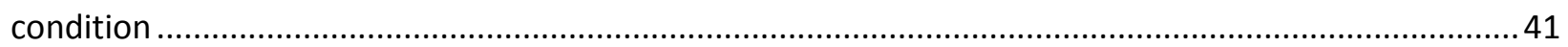

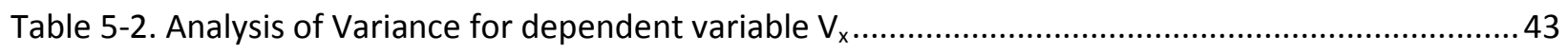

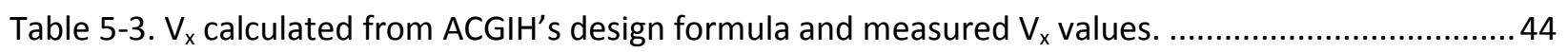

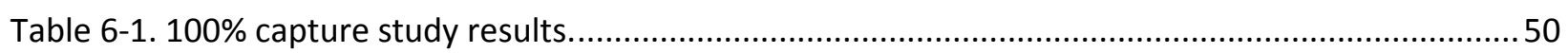

Table 6-2. Statistics for the Freon concentrations measured during the $100 \%$ capture tests ...................52

Table 7-1. Fixed-effect Analysis of Variance for dependent variable Q ...................................................55

Table 8-1. Main study Freon concentrations for each level of independent variable...............................57

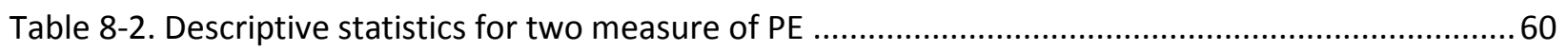

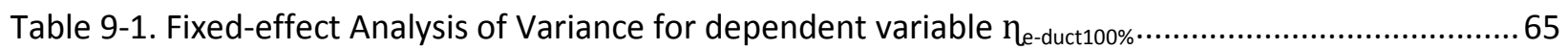

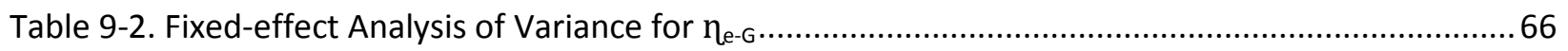

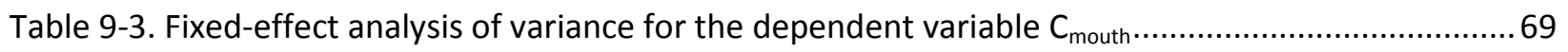

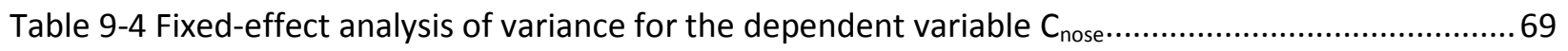

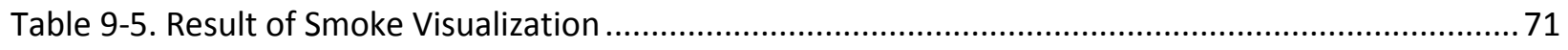

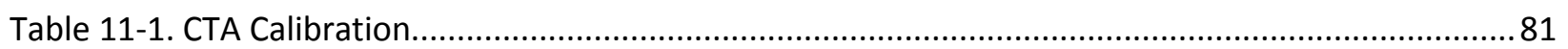




\section{Abbreviations}

ACGIH

American Conference of Governmental Industrial Hygienists

AlHA

American Industrial Hygiene Association

ANSI

American National Standards Institute

ASTM

American Society of Testing and Materials

$\mathrm{C}_{\text {ambient }}$

Concentration of Freon measured at the inlet of the wind tunnel, used to control for build up of Freon inside the laboratory

$\mathrm{C}_{\text {duct }}$

Concentration in the duct, Dependent variable

$\mathrm{C}_{\text {mouth }}$

Concentration at the mouth of the manikin, Dependent variable

$\mathrm{C}_{\text {nose }}$

Concentration at the nose of the manikin, Dependent Variable

FT-IR

Fourier transform infrared

G

Generation rate of tracer gas expressed in volume per time (Ipm)

IVM

Industrial Ventilation Manual

LEV

Local Exhaust Ventilation Ipm

Liters Per Minute

$\eta_{\text {e }}$

Capture efficiency

$\eta_{\text {e-duct } 100 \%}$

Calculated capture efficiency of the hood using the concentration in the duct when $100 \%$ capture was assured

$\eta_{\text {e-G }}$

Calculated capture efficiency using the measured generation rate of the source NIST

National Institute of Standards and Technology

NSC

Natinal Safety Council

OSHA

Occupational Safety and Health Administration $P E_{\text {duct }}$

Calculated protection efficiency based on the measured concentration of Freon in the duct 6 $\mathrm{PE}_{\mathrm{G}}$

Calculated protection efficiency based on the calculated concentration of Freon at the source 6 PPM

Parts Per Million 
$\mathrm{SF}_{6}$

Sulfur Hexafluoride used as a tracer gas

$V_{\text {face }}$

Velocity at the hood face 


\section{Equations}

$$
\begin{aligned}
& \eta_{e}=\frac{G \prime}{G} \\
& \eta_{e-G}=\frac{C_{d u c t}}{\frac{G}{Q} 10^{6}} . \\
& \eta_{e-d u c t 100 \%}=\frac{C_{d u c t}}{C_{d u c t-100 \%}} . . \\
& P F_{d u c t}=1-\frac{C_{\text {mouth }}}{C_{d u c t}} \text { or } X\left(1-\eta_{e}\right) \\
& P F_{G}=1-\frac{C_{\text {mouth }}}{C_{\text {source }}} \text { or } X\left(1-\eta_{e}\right) \\
& W=0.75 A^{1 / 2} \\
& W=A^{1 / 2} \\
& Q=C_{c a p} V\left(10 X^{2}+A\right) \\
& V_{x}=\frac{Q}{C_{c a p}\left(10 X^{2}+A\right)}
\end{aligned}
$$

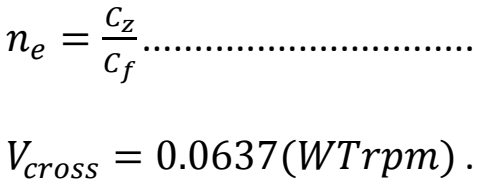

$$
\begin{aligned}
& \bar{V}_{d u c t}=\frac{1}{20} \sum_{i=1}^{20} \sqrt{\frac{V P_{i}}{d f}} . \\
& d f=\left(\frac{S P_{d u c t}+S P_{a t m}}{S P_{s t d}}\right)\left(\frac{T_{d u c t}}{T_{s t d}}\right)\left(\frac{\rho_{a i r}}{\rho_{s t d}}\right) . \\
& \bar{Q}=\bar{V}_{d u c t} A_{d u c t}
\end{aligned}
$$




\section{CHAPTER 1: INTRODUCTION}

The purpose of this study is to investigate the capture efficiency and protection efficiency for a small rectangular capturing hood and to quantify the effect a flange has on both the capture and protection efficiency. The hood's performance was quantified through the use of a tracer gas, Freon 134a.

\subsection{Background and Significance}

Engineering controls, such as local exhaust ventilation (LEV), are important tools in protecting workers from hazardous airborne exposures. In particular, LEV has long been used for controlling worker exposure to vapors, gases, fumes, and particulates and is applied in almost every industry (Dalla Valle \& Hatch, 1932). Indeed, the use of such engineering controls are preferred by the Occupational Safety and Health Administrations (OSHA), the National Safety Council (NSC), the American Industrial Hygiene Association (AIHA), the American Conference of Governmental Industrial Hygienists (ACGIH), many other consensus organizations, and governing bodies (National Safety Council, 2002). To be acceptable, LEV hoods should be designed to control the hazard while minimizing interferences to the task being performed.

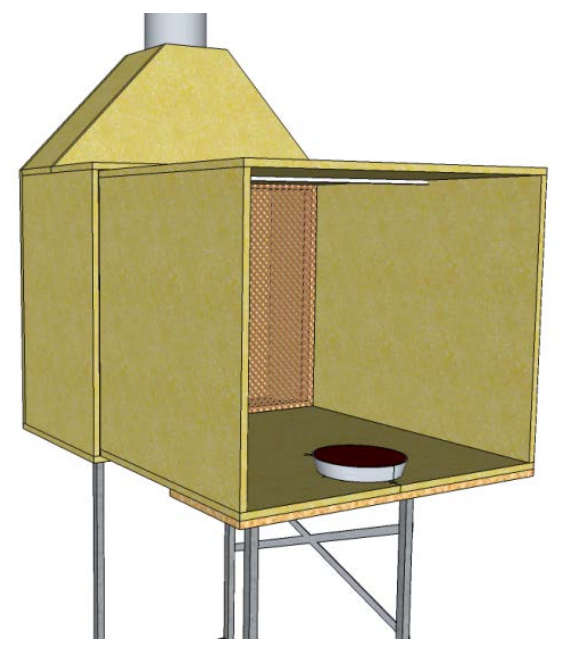

Figure 1-1.Enclosing hood

LEV hoods may be classified into two categories: "enclosing" and "capturing" hoods. Enclosing hoods completely surround the contaminant source (see Figure 1-1) while capturing hoods 
draw air past the containment source with sufficient velocity to capture the contaminant (see Figure 1-2). Each type of LEV hood has advantages and disadvantages for any given application. However, due to the ubiquitous use of capturing hoods in industry (Ellenbecker, Gampel, \& Burgess, 1983) they are the focus of this study.

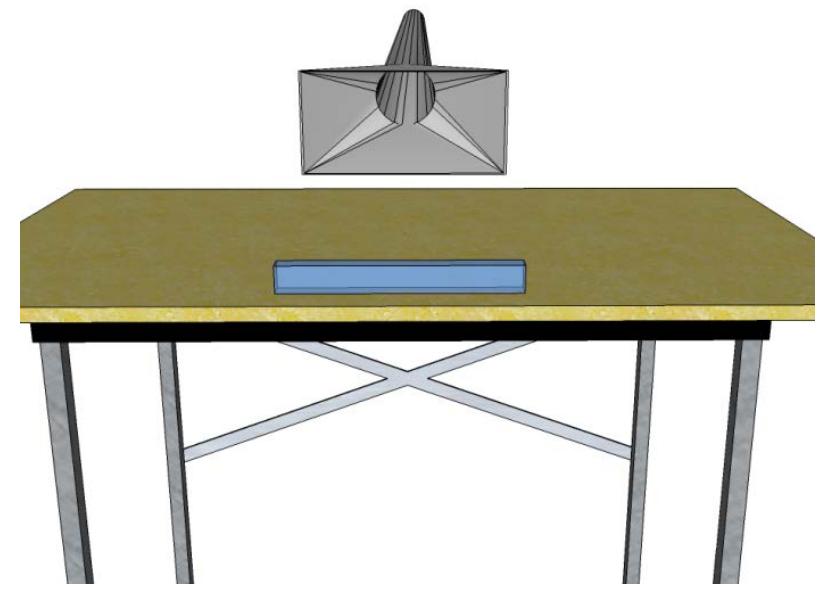

Figure 1-2.Capturing hood

\subsubsection{Velocities in Front of a Capturing Hood}

Nearly all of the relevant scientific literature published regarding the effectiveness of capturing hoods (Silverman, 1942; Fletcher B. , 1977; Fletcher B. , 1978; Garrison, 1981; Fletcher \& Johson, 1982; Flynn \& Ellenbecker, 1987; Conroy, Ellenbecker, \& Flynn, 1988) have employed the concept of "capture velocity", which is defined by ACGIH as "the minimum hood-induced air velocity necessary to capture and convey the contaminant into the hood" (ACGIH, 2007). It is assumed that meeting or exceeding recommended velocities ensures an acceptable level of contaminant capture.

These studies measured velocity or developed empirical formulas to predict the velocities induced at a distance in front of a hood $\left(\mathrm{V}_{\mathrm{x}}\right)$ with the ultimate goal of allowing practitioners to meet target velocities thought to be associated with acceptable performance, such as those given in table 6-1 of ACGIH's Industrial Ventilation Manual (IVM). These target velocities are loosely based on competing air currents, buoyancy of the contaminant and toxicity of the contaminant. Surprisingly, given their long use, these target velocities have no clear basis in 
published empirical data. The assumption that values of $\mathrm{V}_{\mathrm{x}}$ are good predictors of hood performance is long held but unsupported by current scientific literature.

Skepticism of the adequacy of control velocities as a surrogate or guidepost to effectiveness is well documented for laboratory hoods. Indeed, ANSI Z9.5 for laboratory fume hoods clearly states that "face velocities are an inadequate indicator of [laboratory] hood performance" (ANSI/AIHA, 2003). For capturing hoods Flynn and Ellenbecker (1986) argued that capture velocity is an inadequate surrogate measure of capturing hood performance. Instead, they recommended capture efficiency, which they defined as "the fraction of airborne contaminant generated per unit time that is captured per unit time" (Ellenbecker, Gampel, \& Burgess, 1983) as a more direct measure of hood performance.

\subsubsection{Measures of Effectiveness}

Clearly the effectiveness of a hood must be determined in terms of its success in reducing exposures to the contaminant it is intended to control. For all hoods, success should be considered in two ways: (1) protecting the user of the hood, and (2) preventing others in the same area from high background concentrations due to escape of contaminants to the room. The former can be described as a "protection efficiency" much like the protection factors for respirators and the latter as a "capture efficiency".

For respirators, protection factors are generally described as the ratio of the concentration outside the respirator divided by the concentration inside the respirator (TSI Incorporated, 2008). The concentration inside of the respirator is an exposure concentration (e.g., $C_{\text {mouth }}$ ). The concentration outside the respirator can be compared to any of several different concentrations, such as the concentration of the contaminant as it is released $\left(\mathrm{C}_{\text {source }}\right)$, the concentration of the cloud in the space in between the worker and the hood face $\left(\mathrm{C}_{\text {cloud }}\right)$, and the average concentration if the contaminant is mixed perfectly with the exhaust air $\left(C_{\text {duct }}\right)$. The protection factor is mathematically related to the protection efficiency. Protection efficiency $(P E)$ is presented as a percentage rather than a whole number and is the measure used in this 
study. It should be noted that the protection efficiency is equal to one minus the inverse of the protection factor.

Each of these has disadvantages:

1. $P E=1-\left(C_{\text {mouth }} / C_{\text {source }}\right):$ does not consider generation rate

2. $P E=1-\left(C_{\text {mouth }} / C_{\text {cloud }}\right)$ : the boundaries of the cloud would be difficult to specify

3. $P E=1-\left(C_{\text {mouth }} / C_{\text {duct }}\right)$ : since $C_{\text {duct }}=G / Q$ this formulation would have the paradoxical effect of at some diminishing effect level of $Q$ showing a diminishing PE as the air flow through the hood $(Q)$ increases even if the concentration at the mouth continues to fall to trivial levels.

4. $P E=1-\left(C_{\text {mouth }} / C_{\text {acceptable }}\right):$ would vary with the contaminant and with all factors affecting $\mathrm{C}_{\text {mouth }}$.

\subsubsection{Calculating Effectiveness}

A useful formulation for capture efficiency is much simpler, however may be calculated using two different techniques which both have advantages and disadvantages. The first formulation of efficiency, defined by Flynn and Ellenbecker (1986), is a measure of capture efficiency $\left(\eta_{e}\right)$, which can be stated mathematically as:

$$
\eta_{e}=\frac{G^{\prime}}{G}
$$

Where: $\quad G \quad=$ rate of contaminant released by the source (mass or volume per time)

$\mathrm{G}^{\prime}=$ rate of contaminant captured by the hood (mass or volume per time) 
This formula may be restated in terms of concentration as:

$$
\eta_{e-G}=\frac{C_{d u c t}}{\frac{G}{Q} 10^{6}}
$$

Where: $\mathrm{C}_{\text {duct }}=$ Concentration of tracer gas in the duct (ppm)

$\mathrm{G}=$ Controlled rate of release of at the source tracer gas (Ipm)

$\mathrm{Q}=$ Air flow through the hood (Ipm)

Note that $G$ and $G^{\prime}$ can be stated as either mass rates or volume rates. For the rest of this investigation it will refer only to volume rates.

Capture efficiency may also be calculated without the measure of generation rate in the equation by assuming that the generation rate is constant. This is accomplished by measuring the concentration of the contaminant in the duct (1) when all the contaminant is released directly into the duct and $100 \%$ capture is assured $\left(C_{\text {duct- }-100 \%}\right)$, and $(2)$ when the contaminant is released at some distance in front of the hood's face $\left(\mathrm{C}_{\text {duct }}\right)$. The ratio of these two measures gives the capture efficiency for the system, which can be expressed mathematically as:

$$
\eta_{e-d u c t 100 \%}=\frac{C_{d u c t}}{C_{d u c t-100 \%}}
$$

Where: $\quad C_{\text {duct }}=$ Concentration of contaminant in the duct when released at some location in front of the hood's face (ppm)

$\mathrm{C}_{\text {duct-110\% }}=$ Concentration of contaminant in the duct when released into the duct (ppm)

By comparing the capture efficiency and protection efficiency of a small rectangular hood with the measured capture velocity, one can determine if a correlation exists between capture velocities and capture effectiveness or protection efficiency. The two measures of protection efficiency chosen and are shown below: 


$$
P E_{\text {duct }}=1-\frac{C_{m o u t h}}{C_{d u c t}} \text { or } X\left(1-\eta_{e}\right)
$$

Where: $\mathrm{C}_{\text {mouth }}=$ Concentration of tracer gas at manikin's mouth

$\eta_{\mathrm{e}}=$ Capture efficiency

$\mathrm{X}=$ Fraction of tracer gas which reaches the breathing zone

$$
P E_{G}=1-\frac{C_{\text {mouth }}}{C_{\text {source }}} \text { or } X\left(1-\eta_{e}\right)
$$

Where: $\mathrm{C}_{\text {source }}=$ Concentration of tracer gas released from source, $\mathrm{ppm}$

$Q=$ Air flow through the duct

$X=$ Fraction of tracer gas which reaches the breathing zone

\subsubsection{Studies of Actual Effectiveness of Hoods}

Recently published laboratory "fume" hoods studies have found poor correlations between laboratory hoods' face velocities and their performance measured by capture efficiency, protection efficiency, and/or smoke visualization (Volin, Joao, Reiman, Party, \& Gershey, 1998; Ahn, Woskie, DiBerardinis, \& Ellenbecker, 2008). This leads one to question whether capture velocities would show a similar lack of correlation to capture hood performance in terms of capture effectiveness or protection efficiency.

Little scientific attention has been applied to determining the capture efficiency of capturing hoods (Ellenbecker, Gampel, \& Burgess, 1983; Flynn \& Ellenbecker, 1986). To the author's knowledge, no empirical studies have investigated the effect on capture efficiency given by a flange.

This study investigated capture efficiency and protection efficiencies for this particular capturing hood's performance under the conditions tested. 


\subsection{Specific Aims}

The goals of this study are to quantify the capture efficiency $\left(\eta_{e}\right)$ and protection efficiency (PE) of a particular small rectangular capturing hood of a size and type in common use and quantify the effect a flange has on its capture efficiency and protection efficiency.

\subsection{Hypothesis}

The null hypothesis is that the protection efficiency and capture efficiency for the hood studied are not affected by air flow through the hood $(Q)$, cross draft velocity $\left(V_{\text {cross }}\right)$, presence of a flange (Flange), or interactions between $Q$ and $V_{\text {cross }}$ or Flange. Conversely the alternative hypothesis is that for the hood studied the protection efficiency and capture efficiency are affected by one or more of the independent variables $\left(Q, V_{\text {cross, }}\right.$ interactions between $Q$ and $\mathrm{V}_{\text {cross }}$ or Flange).

It should be noted that cross draft velocities and capturing hood airflows were controlled by adjusting to a set of specific and predetermined fan speeds. The values of $\mathrm{V}_{\text {cross }}$ were estimated from previous Pitot traverses of the wind tunnel fan inlet duct and were not measured during this study. Hence, $V_{\text {cross }}$ was not a random variable but a fix variable with 2 specific values. On the other hand, the capturing hood fan speed was adjusted to 3 specific values during the study; the actual values of $Q$ for the hood were determined by performing Pitot traverses of the duct connected to the hood. Hence, $Q$ varied within 3 distinct and widely separated ranges. Thus $Q$ was given a nominal value equal to the average observed $Q$ at each level of Freq ${ }_{\text {Hoodfan }}$ $\left(Q_{\text {nom }}\right)$. The $Q_{\text {nom }}$ value allows $Q$ to be treated as a fixed variable.

Hypothesis Model

$$
Y=\mu+\alpha_{i}+\beta_{j}+\gamma_{k}+\alpha \beta_{i j}+\alpha \gamma_{i k}+\varepsilon_{i j k l}
$$

$$
\text { Where: } \quad \begin{array}{ll}
\alpha & =\text { Effect of } Q_{\text {nom }} \\
\beta & =\text { Effect of Rotate } \\
\nu & =\text { Effect of Flange }
\end{array}
$$




$$
\begin{gathered}
Y=C_{\text {mouth }} \\
H_{0-1}: \alpha_{\mathrm{i}}=0 \text { for } i=1,2,3 \\
\mathrm{H}_{\mathrm{a}-1}: \text { any } \alpha_{\mathrm{i}} \neq 0 \\
\mathrm{H}_{0-2}: \beta_{1}=\beta_{2}=0 \\
\mathrm{H}_{\mathrm{a}-2}: \beta_{1} \text { or } \beta_{2} \neq 0 \\
\mathrm{H}_{0-3}: \gamma_{1} \text { or } \gamma_{2}=0 \\
\mathrm{H}_{\mathrm{a}-3}: \gamma_{1} \text { or } \gamma_{2} \neq 0 \\
\mathrm{H}_{0-4}: \alpha \beta_{\mathrm{ij}}=0 \text { for all } \mathrm{ij} \\
\mathrm{H}_{\mathrm{a}-4}: \text { any } \alpha \beta_{\mathrm{ij}} \neq 0 \\
\mathrm{H}_{0-5}: \alpha \gamma_{\mathrm{ij}}=0 \text { for all } \mathrm{ij} \\
\mathrm{H}_{\mathrm{a}-5}: \text { any } \alpha \gamma_{\mathrm{ij}} \neq 0
\end{gathered}
$$$$
Y=\eta_{\text {e-duct } 100 \%} \text { and } \eta_{\text {e-G }}
$$

$\mathrm{H}_{0-1}: \alpha_{\mathrm{i}}=0$ for $i=1,2,3$

$\mathrm{H}_{\mathrm{a}-1}$ : any $\alpha_{\mathrm{i}} \neq 0$

$$
\begin{gathered}
H_{0-2}: \beta_{1}=\beta_{2}=0 \\
H_{a-2}: \beta_{1} \text { or } \beta_{2} \neq 0
\end{gathered}
$$

$$
\mathrm{H}_{0-3}: \gamma_{1} \text { or } \gamma_{2}=0
$$$$
\mathrm{H}_{\mathrm{a}-3}: \nu_{1} \text { or } \nu_{2} \neq 0
$$

$\mathrm{H}_{0-4}: \alpha \beta_{\mathrm{ij}}=0$ for all $\mathrm{ij}$ $\mathrm{H}_{\mathrm{a}-4}$ : any $\alpha \beta_{\mathrm{ij}} \neq 0$

$\mathrm{H}_{0-5}: \alpha \gamma_{\mathrm{ij}}=0$ for all ij $\mathrm{H}_{\mathrm{a}-5}$ : any $\alpha \gamma_{\mathrm{ij}} \neq 0$ 


\section{CHAPTER 2: IITERATURE REVIEW}

A review of published scientific literature pertaining to capturing hoods with emphasis on capture efficiency was performed. The following paragraphs will discuss past studies which utilized centerline velocities, velocities fields in front of hoods, capture envelopes, and hood effectiveness.

\subsection{Centerline Velocity, Capture Envelopes}

DallaValle (1930) defined velocity contour lines in front of capturing hoods. Since then, studies which measured or predicted the centerline velocity and velocities in front of capturing hoods have prevailed in literature (Silverman, 1942; Fletcher B. , 1977; Fletcher B. , 1978; Garrison, 1981; Fletcher \& Johson, 1982; Flynn \& Ellenbecker, 1987; Conroy, Ellenbecker, \& Flynn, 1988). Unfortunately, these investigators developed models that only applied to predicting values of $V_{x}$ for ideal conditions.

Advances in technology have more recently allowed investigators to make more accurate, more precise, and faster air velocity measurements than in the past. Previously researchers were limited to measuring velocities with single-direction, single point velocity devices. The development of particle image velocimetry (PIV), laser Doppler, omni-directional anemometry, and 3D constant temperature anemometry have allowed investigators to measure air movement in ways which were previously impossible. The later techniques (laser Doppler, omni-directional anemometry, and 3D constant temperature anemometry) are all bound to measuring velocities at a single point. On the other hand, PIV has allowed investigators to simultaneously measure the air velocities induced by the hood and the velocities of competing air currents in any plane in front of a hood.

The use of the PIV system allowed investigators such as Huang et al. (2001) to measure the capture envelope of various capturing hoods in less than ideal conditions (i.e. competing air currents, such as cross drafts). However, Huang et al. (2001) states the equations developed from the PIV data are reasonable for quick computations to determine the effective capture zone but cannot be used to determine the capture efficiency of the hood. 


\subsection{Effect of Flanges}

DallaValle (1930) proposed that the flange size for capturing hoods should be approximately 5 inches for hoods with a face area of $3 \mathrm{ft}^{2}$. Silverman (1942) suggested that the optimum flange width should be stated in terms of the hood face area. Alden and Kane (1982) later stated that the flange should be such that it intercepts the $5 \%$ velocity contour of an equivalent unflanged hood, as computed below.

$$
W=0.75 A^{1 / 2}
$$

$$
\begin{aligned}
& \text { Where: } \quad \mathrm{W}=\quad \text { Flange width } \\
& \text { A }=\text { Area of hood face }
\end{aligned}
$$

Fletcher (1978) measured the centerline velocities for hoods having varying flange sizes. He found that increasing the flange size reaches diminishing returns for increasing the velocity measured in front of the hood. The flange size when diminishing returns are reached was found to be equal to the square root of the hood face area:

$$
W=A^{1 / 2}
$$

$$
\begin{aligned}
& \text { Where: } \quad \mathrm{W}=\quad \text { Flange width } \\
& \text { A }=\text { Area of hood face }
\end{aligned}
$$

According to Fletcher (1978) adding a flange to a free standing LEV rectangular exhaust hood increases velocities by $33 \%$ up to a distance of $X / A^{1 / 2}$.

$$
Q=C_{\text {cap }} V\left(10 X^{2}+A\right)
$$

Where: $\quad \begin{array}{rll}\mathrm{C}_{\text {cap }} & = & 1.0 \text { for non-flanged and } 0.75 \text { for flanged hoods } \\ \mathrm{Q} & = & \text { Calculated volumetric flow } \\ \mathrm{V} & = & \text { Capture velocity, fpm, at distance } \mathrm{X} \\ \mathrm{X} & = & \begin{array}{l}\text { Distance from hood face to farthest point of } \\ \text { contamination release, Ft. }\end{array} \\ \mathrm{A} & = & \text { Hood face area, } \mathrm{ft} 2\end{array}$


In the calculation of required air flow for a rectangular hood, adding a flange decreases $C_{\text {cap }}$ from 1.0 to 0.75 , thereby reducing the recommended airflow by $25 \%$. This recommendation is consistent with Fletcher (1978) and Dalla Valle (1930).

Equation 2-3 can be solved for $\mathrm{V}_{\mathrm{x}}$ :

$$
V_{x}=\frac{Q}{C_{c a p}\left(10 X^{2}+A\right)}
$$

If $Q$ is held constant and $C_{\text {cap }}=0.75$ is used for a flange, then $V_{x}$ increases by $33 \%$, consistent with Fletcher (1978) and Dalla Valle (1930).

\subsection{Efficiency}

Equations for determining capture efficiency were proposed by Ellenbecker, Gampel, and Burgess (1983). The hypothesis was that through releasing a contaminant at a known rate and measuring the amount collected or not collected by the LEV system one could determine the capture efficiency. Ellenbecker, Gampel, and Burgess (1983) initially proposed Equation 1-1 as a calculation for capture efficiency.

Flynn and Ellenbecker (1986) used sulfur hexafluoride $\left(\mathrm{SF}_{6}\right)$ as a tracer gas to evaluate the capture efficiency of flanged capturing hoods under varied cross-drafts, flows, hood diameters, and source distance from the hood face to determine the critical distance for capture of a contaminant into the hood. In this study Flynn and Ellenbecker used the ratio of concentrations of tracer gas measured in the exhaust duct when the source was at the face of the hood $\left(C_{2}\right)$ compared to when the source was placed at varied distances in front of the hood $\left(C_{f}\right)$, to a maximum distance in front of the hood of 1.5 times the duct diameter. 


$$
n_{e}=\frac{C_{z}}{C_{f}}
$$
Where: $\quad n_{e}=$ Capture efficiency of the hood
$C_{z}=$ Tracer gas concentration measured in the duct downstream of the hood face when the source is a distance of $Z$ from the hood face
$C_{f}=$ Tracer gas concentration measured in the duct downstream of the hood face when the source is at the hood face

Flynn and Ellenbecker (1986) found capture efficiency to be highly related to the distance between the hood face and source, the air flow through the hood, and the cross drafts. However, their experiments were conducted at low air flows, 35-140 cfm, with hoods ranging from 2-6 inches in diameter. The range of air flows tested by Flynn and Ellenbecker were well below the range tested in this study. Thus, it would be difficult to compare this study to Fylnn and Ellenbecker's study. The studies present in this text range from 380-1100 cfm and were selected to reasonably represent local exhaust ventilation systems used in industry.

\subsection{Summary}

There is no clear evidence that capture velocities are an acceptable surrogate for capture efficiency or protection effectiveness, yet current guidelines are based solely on velocity measurements to judge hood performance. Little is known about the capture efficiency or protection efficiency of capturing hoods and even less is known about the effect of a flange on the capture efficiency or protection efficiency of a capturing hood. This study will contribute to current information known about capture efficiency, protection efficiency, and the relationship between capture velocity and capture efficiency for a particular small rectangular capturing hood. 


\section{CHAPTER 3: APPARATUS}

The following is a description of the apparatus used to investigate the hood effectiveness and protection efficiency of the test hood for varied flange, $Q$, and cross draft velocity conditions.

\subsection{Wind Tunnel}

The wind tunnel is located in the "High Bay laboratory" (room 157A) located in West Virginia University's Mineral Resources building. The wind tunnel's dimensions are shown in Figure 3-1. The wind tunnel is divided into three chambers: the mixing, experimental, and plenum chambers. A bank of HEPA filters backed with activated charcoal are located at the inlet to the wind tunnel and between the experimental and plenum chamber.

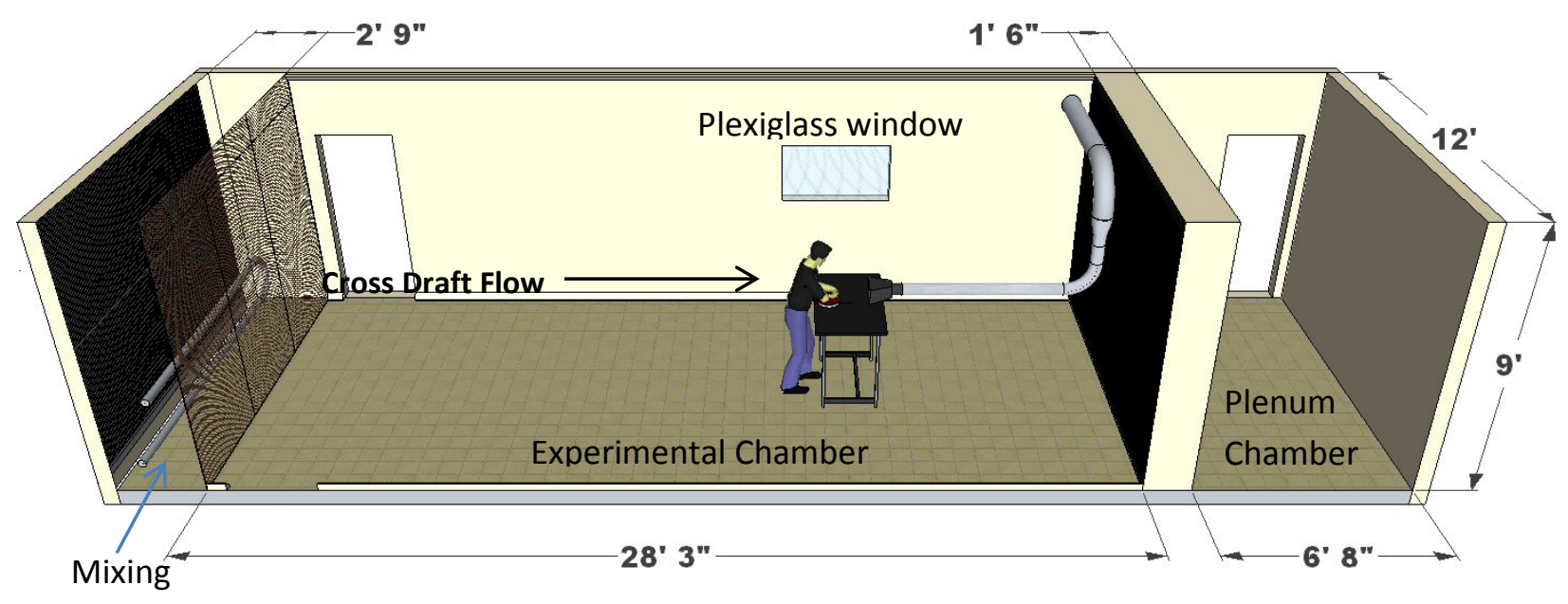

Chamber

Figure 3-1. Interior lay out of the wind tunnel

The interior is finished with dry wall on the walls and ceiling, and linoleum covers the floor. The floor is insulated with Styrofoam ${ }^{\mathrm{TM}}$ to reduce heat conduction from the cement floor. The wind tunnel has three entrances which are thirty-two inches by eighty inches. Two entrances provide access to the main "experimental area" of the wind tunnel and the other provides access to the plenum of the wind tunnel. Each entrance is fitted with two double pained glass storm doors, with one on the interior and one exterior side of the wall. The wind tunnel has two sealed Plexiglass ${ }^{\circledR}$ windows on either side of the experimental chamber’s exterior walls. One is approximately 44 inches by 26 inches and the other is approximately 44 inches by 56 inches. 


\subsection{Wind Tunnel Cross Draft and Control System}

Cross drafts through the wind tunnel are induced by a type BCV-SW size 270 large-capacity industrial fan manufactured by Twin-City Fan and Blower Minneapolis, MN. The flow of the cross draft is towards the manikin's back and the face of the capturing hood. The fan is located above the wind tunnel on a steel platform (see Figure 3-1). The fan's speed is controlled by a Baldor Series $15-\mathrm{H}$ inverter and digital control mounted at eye level on the exterior of the wind tunnel on the plenum end. The wind tunnel fan speed (Rotate WTfan $_{\text {) }}$ is adjustable in increments of 30 rpms with a range of 0 to 1,560 RPMs. Lewis (2010) found that the Rotate ${ }_{W T f a n}$ has a linear relationship to the $V_{\text {cross }}$ based on previous Pitot traverses of the inlet duct for the wind tunnel fan:

$$
\begin{array}{ll}
\qquad V_{\text {cross }} & =0.0637(\text { WTrpm }) \\
\text { Where: } \quad V_{\text {cross }} & =\quad \text { Cross draft velocity } \\
\text { Rotate } & =\quad \text { Speed of the wind tunnel fan }
\end{array}
$$

\subsection{Capture Hood and Control System}

This study utilizes one rectangular capturing hood. For some tests a flange was attached to the capturing hood (see Figure 3-4) and for others it is not (see Figure 3-3). The hood was manufactured by Nordfab Systems, Inc. (Thomasville, North Carolina) and sold as a router hood (Model No. 3231-04). The flange is custom made of Plexiglass ${ }^{\circledR}$ and was designed to be easily attached and detached from the hood. 


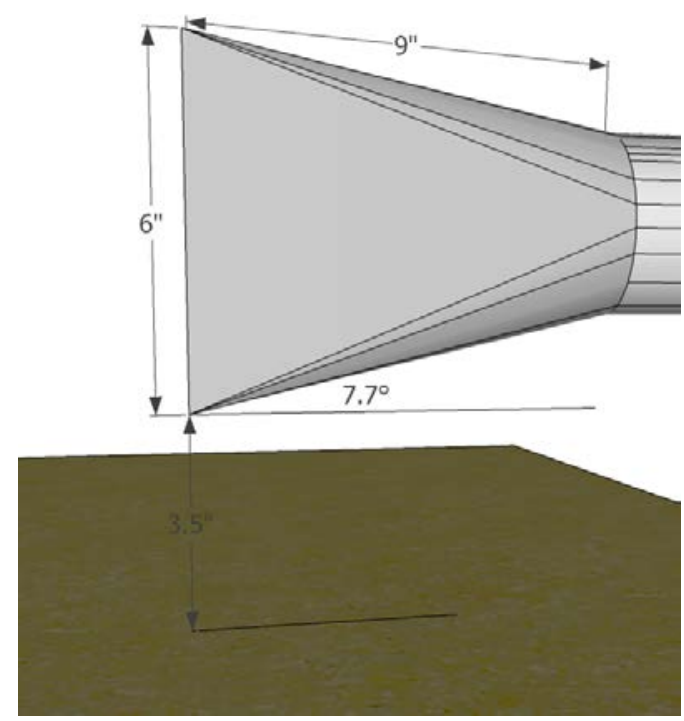

Figure 3-2. Capturing hood dimensions side view

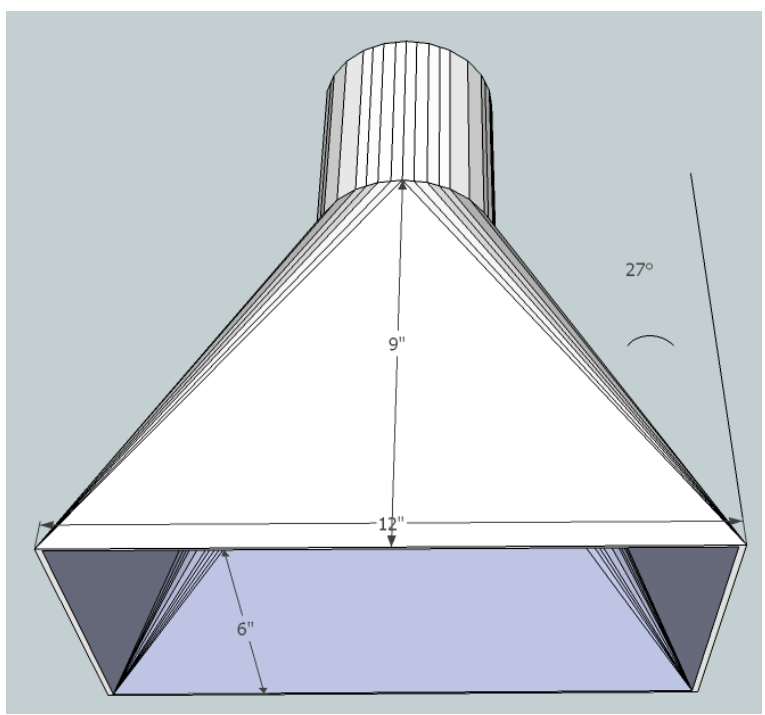

Figure 3-3. Capturing hood dimensions top view

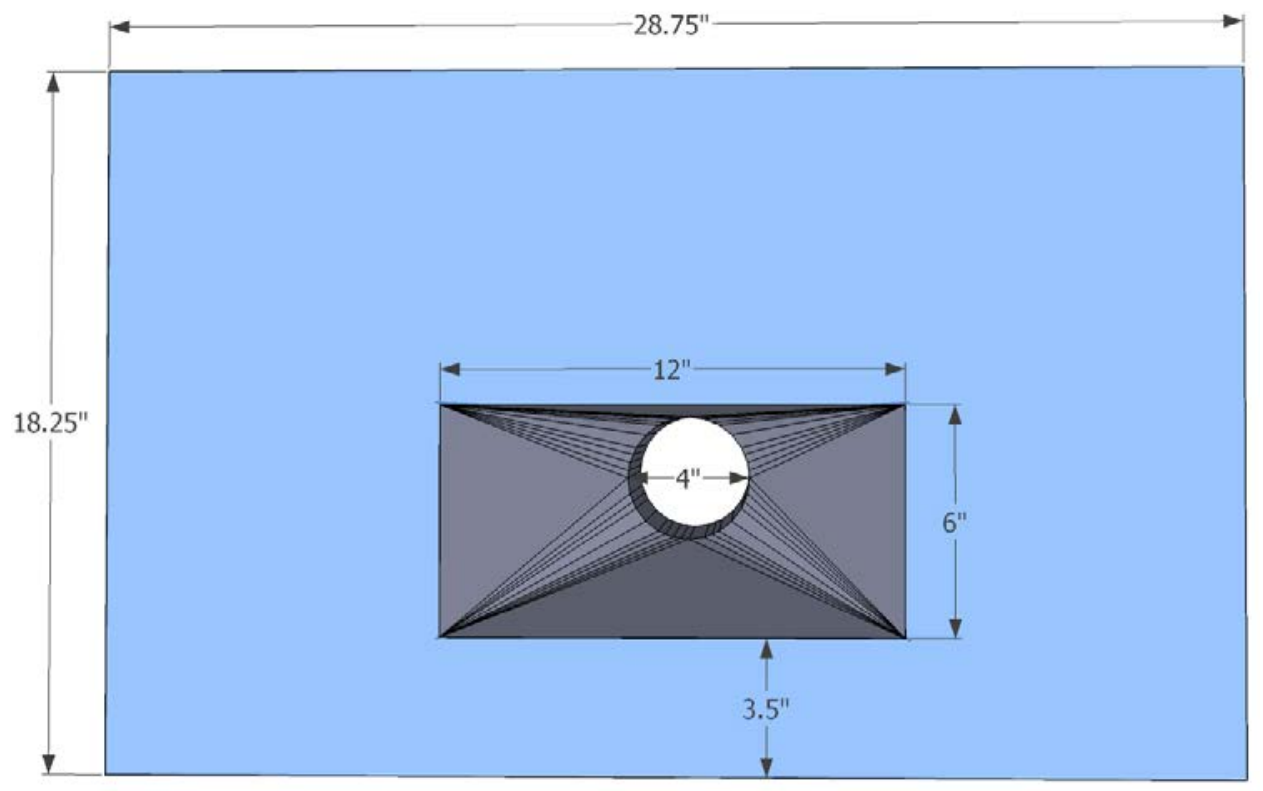

Figure 3-4. Dimensions of flanged capturing hood

The rectangular capturing hood face is 6 inches vertically by 12 inches horizontally (see Figure 3-3). The hood tapers at a $21^{\circ}$ horizontally at the sides and $7.7^{\circ}$ vertically at the bottom (see Figure 3-2) to a 4 inch in diameter circular rolled steel duct. The flange is made of 3/8" Plexiglass ${ }^{\circledR}$ and has an approximate width equivalent to the square root of the area of the face, 8.66 inches (see Figure 3-4). 
The capturing hood is held 3.5 inches above a table (see Figure 3-5) and is supported by a custom made duct stand. The face of the hood is 14.25 inches from the leading edge of the table and 11 inches from the furthest edge of the source. All dimensions of the hood in relation to the table are shown in Figure 3-5 and Figure 3-6.

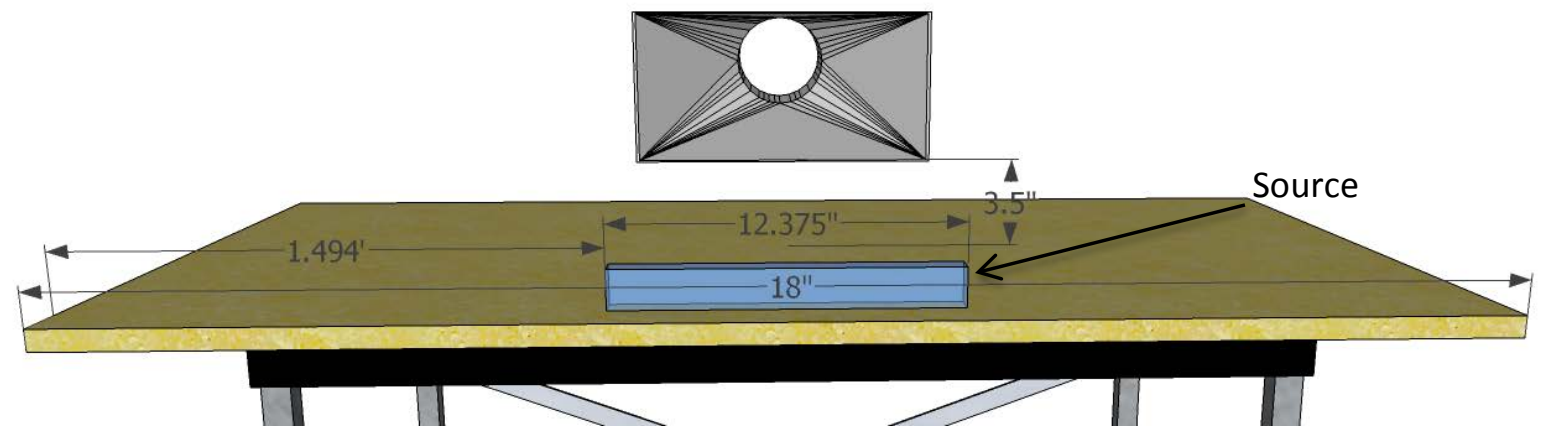

Figure 3-5. Front view of the capturing hood and table dimensions

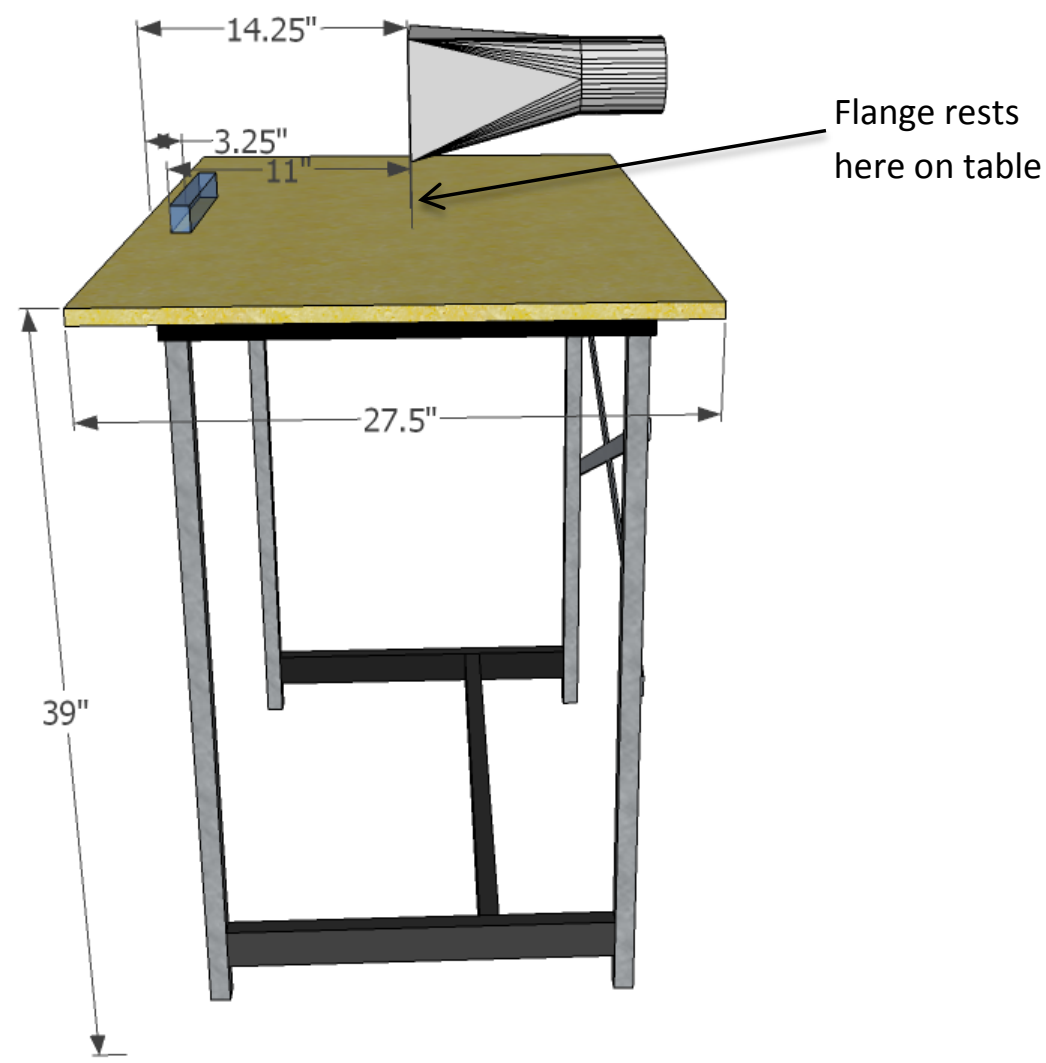

Figure 3-6. Side view of the capturing hood and table dimensions 
Air flow through the capturing hood is induced by a 200 volt three-phase BCN-SW industrial fan (Model 250 APP4 CL.L) manufactured by TCF Aerovent Company in Brookings, South Dakota. The industrial fan is controlled by a Teco N3 Inverter with a digital control that is mounted at eye level on the exterior of the wind tunnel plenum. The digital controller allows the user to adjust the electrical frequency driving the fan motor in $0.01 \mathrm{~Hz}$ increments.

\subsubsection{Air Flow Measurements}

The capturing hood is connected to the industrial fan by a system of 8 inch and 4 inch diameter circular rolled steel ducts. The 8 inch ducts are connected to a 4 inch diameter circular duct with a taper. Hood face velocities are determined by two perpendicular ten point Pitot-tube traverse readings conducted according to recommendations in appendix C of the ACGIH's Industrial Ventilation manual. Velocity pressure and static pressure readings are taken using a PVM-100 micromanometer (TSI Inc. Shoreview, MN) which is calibrated with a Dwyer Hook Gauge (model 1425). Data from the micromanometer is electronically captured by a desktop computer using a RS-232 cable through the use of a commercial software program HvMeasurement (Guffey, Morgantown, WV).

The software calculates the average velocity in the duct from the 20 individual Pitot-traverse readings (see Equation 3-2). Using the measured average duct velocity, the average air flow through the duct $(Q)$ is calculated (see Equation 3-4).

$$
\bar{V}_{d u c t}=\frac{1}{20} \sum_{i=1}^{20} \sqrt{\frac{V P_{i}}{d f}}
$$

Where: $\quad$ VP $\quad=$ Velocity pressure measured by a Pitot tube

$\bar{V}_{d u c t}=$ Average velocity in duct 


$$
d f=\left(\frac{S P_{d u c t}+S P_{a t m}}{S P_{s t d}}\right)\left(\frac{T_{d u c t}}{T_{s t d}}\right)\left(\frac{\rho_{a i r}}{\rho_{s t d}}\right)
$$

$$
\begin{aligned}
& \text { Where: } \quad \begin{array}{ll}
\mathrm{SP}_{\text {duct }} & =\text { Static pressure of duct } \\
\mathrm{SP}_{\mathrm{atm}} & =\text { Static pressure of atmosphere } \\
\mathrm{SP}_{\text {std }} & =\text { Standard static pressure } \\
\mathrm{T}_{\text {duct }} & =\text { Temperature of duct } \\
\mathrm{T}_{\text {std }} & =\text { Standard temperature } \\
\rho_{\text {air }} & =\text { Density of air } \\
\rho_{\text {std }} & =\text { Standard density of air } \\
& \\
& \\
\text { Where: } & \\
\bar{V}_{d u c t} & =\bar{V}_{d u c t} A_{d u c t} \\
\mathrm{~A}_{\text {duct }} & =\text { Average air velocity in the face of the hood, } \mathrm{fpm}
\end{array}
\end{aligned}
$$

In order to reduce errors associated with Pitot-tube traverse measurements, two fixed traverse tools (Guffey S. E., 1993) held two Pitot-tubes perpendicular to the duct and at the desired insertion depth, thereby minimizing human error associated with attempting to hold the Pitot tubes in place by hand (see Figure 3-7). 


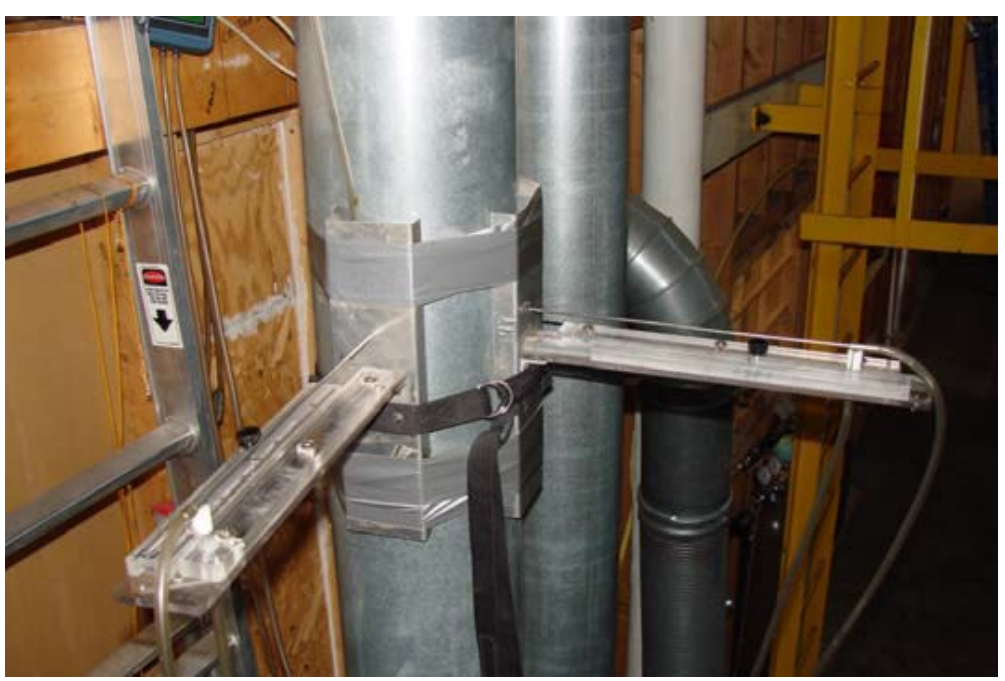

Figure 3-7. Pitot traverse tool

\subsection{Experimental Manikin}

This study used a heated anthropometrically-scaled manikin (see Figure 3-8). The manikin's dimensions are shown in Table 3-1.

Table 3-1. Anthropometrically-scaled manikin dimensions

\begin{tabular}{lc} 
Description of Measured Location & Dimensions (inches) \\
\hline Stature & $66^{\prime \prime}$ \\
Eye height & $58^{\prime \prime}$ \\
Shoulder height & $52.5^{\prime \prime}$ \\
Elbow height & $40^{\prime \prime}$ \\
Fingertip height & $23.5^{\prime \prime}$ \\
Shoulder breadth & $14^{\prime \prime}$ \\
Head length & $7 "$ \\
Head Breadth & $6 "$
\end{tabular}

The manikin was heated by two 6 meter in length fifty watt flexible heat ropes and one 4.3 meter in length twenty-five watt flexible heat rope, all manufactured by Big Apple Herpetological, Inc. (Hauppauge, NY). The temperature of the flexible heat ropes was controlled by a digital thermostat (BAH-100DC) manufactured by Big Apple Herpetology, Inc. (Hauppauge, NY) to prevent overheating. The flexible heat ropes were inserted into the manikin's head, torso, arms, thighs, and chest cavity (see Figure 3-9). The manikin's arms were heated to the wrists and the legs were heated down to the thighs. Insulation was utilized in the extremities 
and core of the manikin to prevent hot spots. The manikin required an approximate warm-up time of 90 minutes to reach final operating temperatures. The power usage of the manikin was continuously metered by a Kill-A-Watt ${ }^{\mathrm{TM}}$ power meter (Model P4400 Manufactured by the P4 International Corporation) and periodically checked to ensure consistent power consumption.

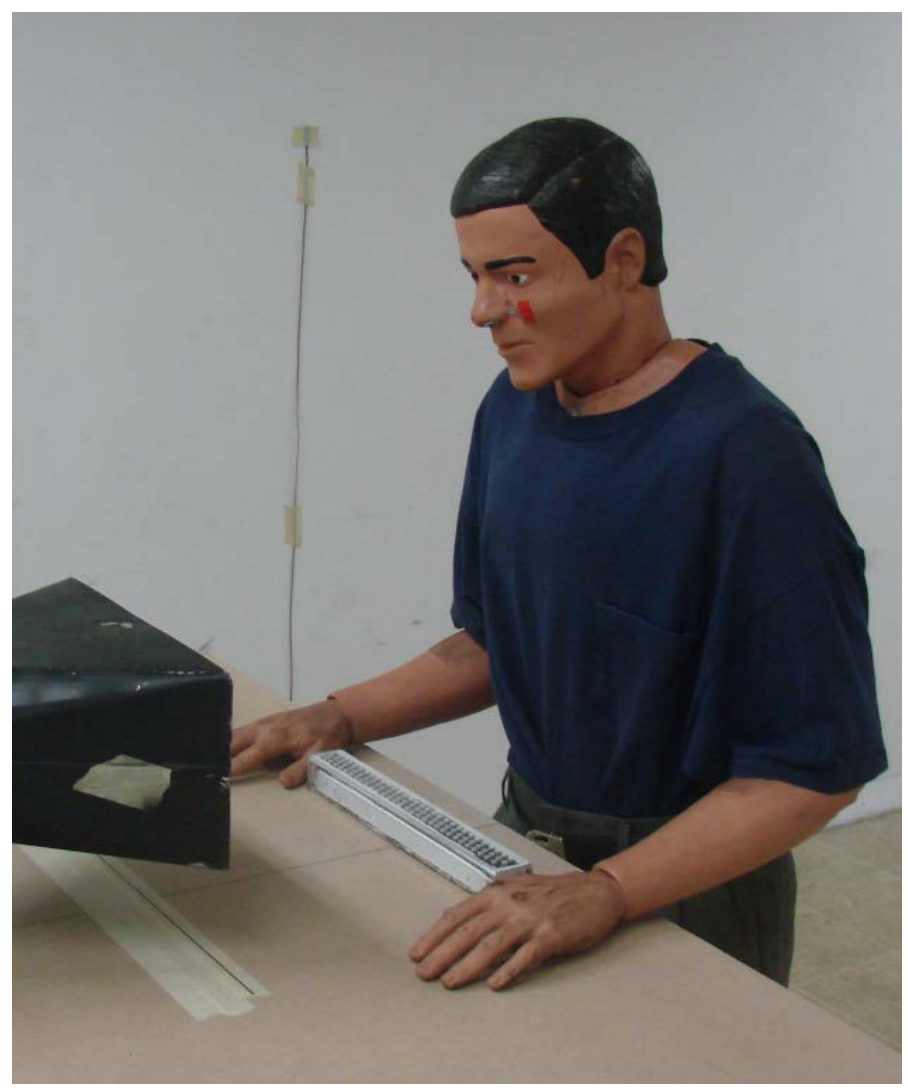

Figure 3-8. Manikin 


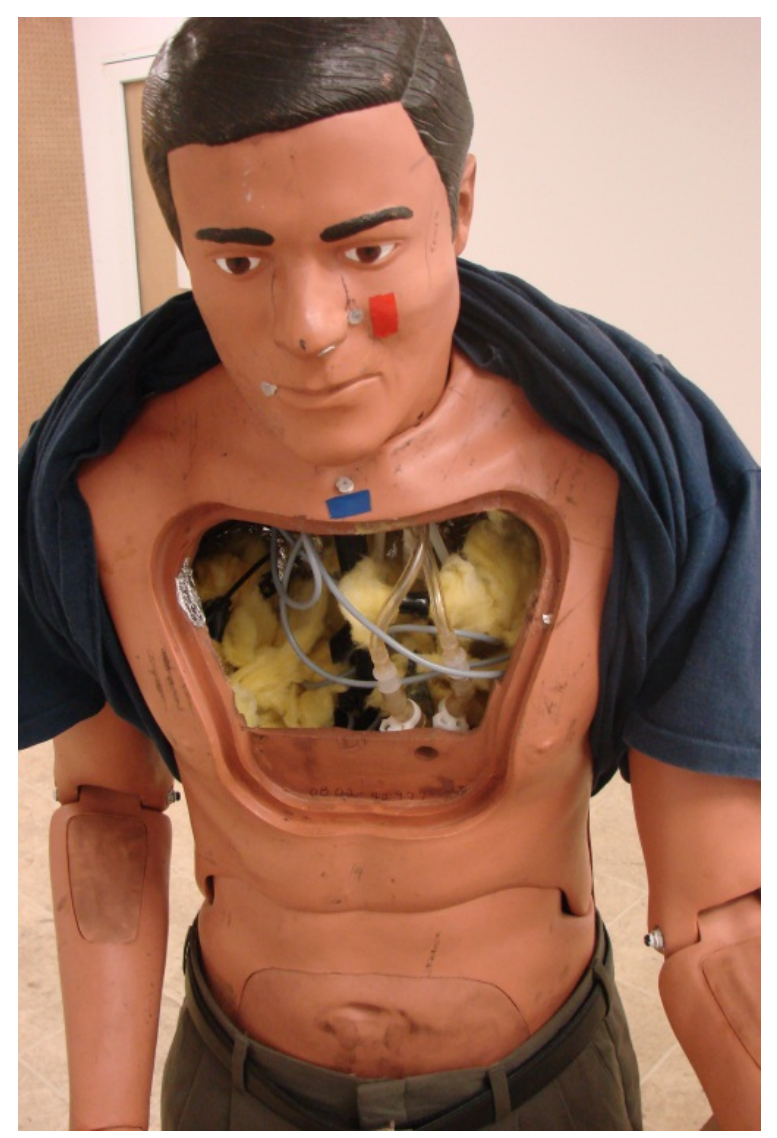

Figure 3-9. Manikin heating system

The experimental manikin was positioned so that its navel was two inches from the leading edge of the table. The medial axis of the manikin was aligned with the center line of the hood and tracer gas source using a laser level. The manikin was fitted with two thermocouples located on the shoulder and mid-back to continuously monitor the manikin's temperature. Thermocouples were calibrated against am American Society of Testing and Materials (ASTM), National Institute Standards and Technology (NIST) traceable laboratory thermometer.

\subsection{Breathing System}

Human breathing was simulated by a bellows system. This system was used in previous studies (Lewis, 2010; He, 2010; El-Sotouhy, 2008). The bellow system operates at 38 cycles per minute, which is considerably higher than the average adult breathing rate of 12-18 breaths per minute (Tortora \& Anagnostakos, 1990). However due to the design of the breathing system a higher breathing rate is required for the system to operate optimally and to produce an at rest minute 
ventilation rate approximate to that of an adult at rest. The breathing system produced a measured minute ventilation volume of $976 \mathrm{in}^{3}$, which is modestly higher than the average at rest minute ventilation rate for an adult of 366-732 $\mathrm{in}^{3}$ but much less than the average found during exercise of 4,271-5,492 $\mathrm{in}^{3}$ (Karwowski \& Marras, 1999).

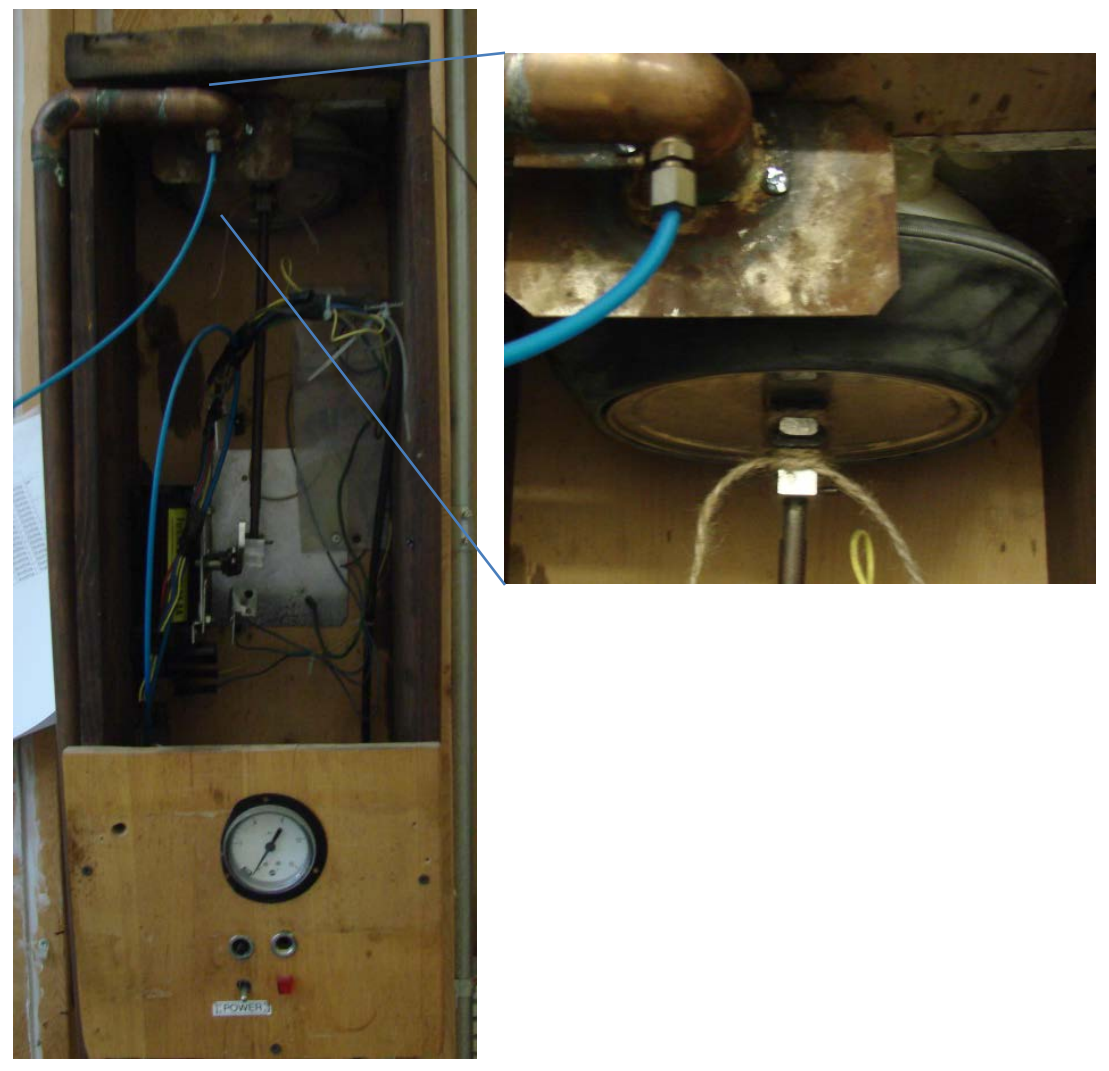

Figure 3-10. Bellows type manikin breathing system

The breathing system draws ambient air in and out of the nostrils of the manikin in a sinusoidal pattern. Air is drawn through plastic tubing ran from the bellows system through the heated chest of the manikin to two 0.25 -inch inside-diameter tubes that terminated at the nostrils of the manikin. The two 0.25 inch tubes connect to a single piece 0.5 inch inside-diameter Tygon ${ }^{\circledR}$ tubing by way of a plastic $Y$ coupler. The Tygon ${ }^{\circledR}$ tubing from the manikin is connected to a 1 inch copper pipe from the bellows system. The copper pipe runs from the exterior of the wind tunnel where the bellows system is located through the wind tunnel wall and connects to the 0.5 inch plastic tubing inside the experimental chamber. 


\subsection{Tracer Gas Sampling System}

Air samples were drawn through 0.125-inch inner diameter hard-plastic tubing and 0.25-inch inside-diameter Tygon ${ }^{\circledR}$ tubing by SKC Inc. model 222 and SKC Inc. pocket pump air sampling pumps at a flow rate of $0.2 \mathrm{lpm}$. Samples taken inside the wind tunnel were routed through the wall of the wind tunnel through compression fittings. Sample lines were color coded on each side of the wind tunnel wall to identify sample locations. Samples were taken simultaneously by drawing air into Tedlar ${ }^{\circledR}$ bags through different trains of tubing, pumps, and bags from the locations listed in Table 3-2.

Table 3-2.Tracer gas sample locations

\begin{tabular}{lcl}
\hline \multicolumn{1}{c}{ Location } & Abbreviation & \multicolumn{1}{c}{ Description } \\
\hline $\begin{array}{l}\text { Manikin's nose } \\
\text { Manikin's mouth }\end{array}$ & $\mathrm{C}_{\text {nose }}$ & $\begin{array}{l}0.5 \mathrm{~cm} \text { laterally from nasal orifice } \\
\text { At the mouth } 3 \mathrm{~cm} \text { from the right of the } \\
\text { lip }\end{array}$ \\
$\begin{array}{l}\text { Inside duct downstream } \\
\text { of hood face }\end{array}$ & $\mathrm{C}_{\text {duct }}$ & $\begin{array}{l}\text { Approximately } 5 \mathrm{~m} \text { downstream of the } \\
\text { hood before the duct passes through the } \\
\text { side of the wind tunnel wall } \\
2 \mathrm{~m} \text { in front of the inlet of the wind } \\
\text { tunnel }\end{array}$
\end{tabular}

Samples were collected in Tedlar ${ }^{\circledR}$ bags using SKC Inc. air sampling pumps to achieve an approximate total sample volume of 4 liters over the test period of approximately 20 minutes. The bag samples were analyzed using a Gasmet model DX 4015 Fourier transform infrared (FTIR) spectrophometer to determine the concentration of Freon 134a in each collection bag. The concentration of Freon 134a in each bag reflected the average concentration of the sampling location over the experimental period for that location.

Samples within the duct were taken approximately 17' (5 meters) downstream and two elbows downstream of the hood (see Figure 3-11). According to Hampl, Niemela, Shulman, \& Bartley (1986) in order to obtain an accurate sample when performing tracer gas testing of industrial exhaust systems, one should sample at a duct location at least 4 duct diameters downstream of the last elbow for systems with two elbows. 


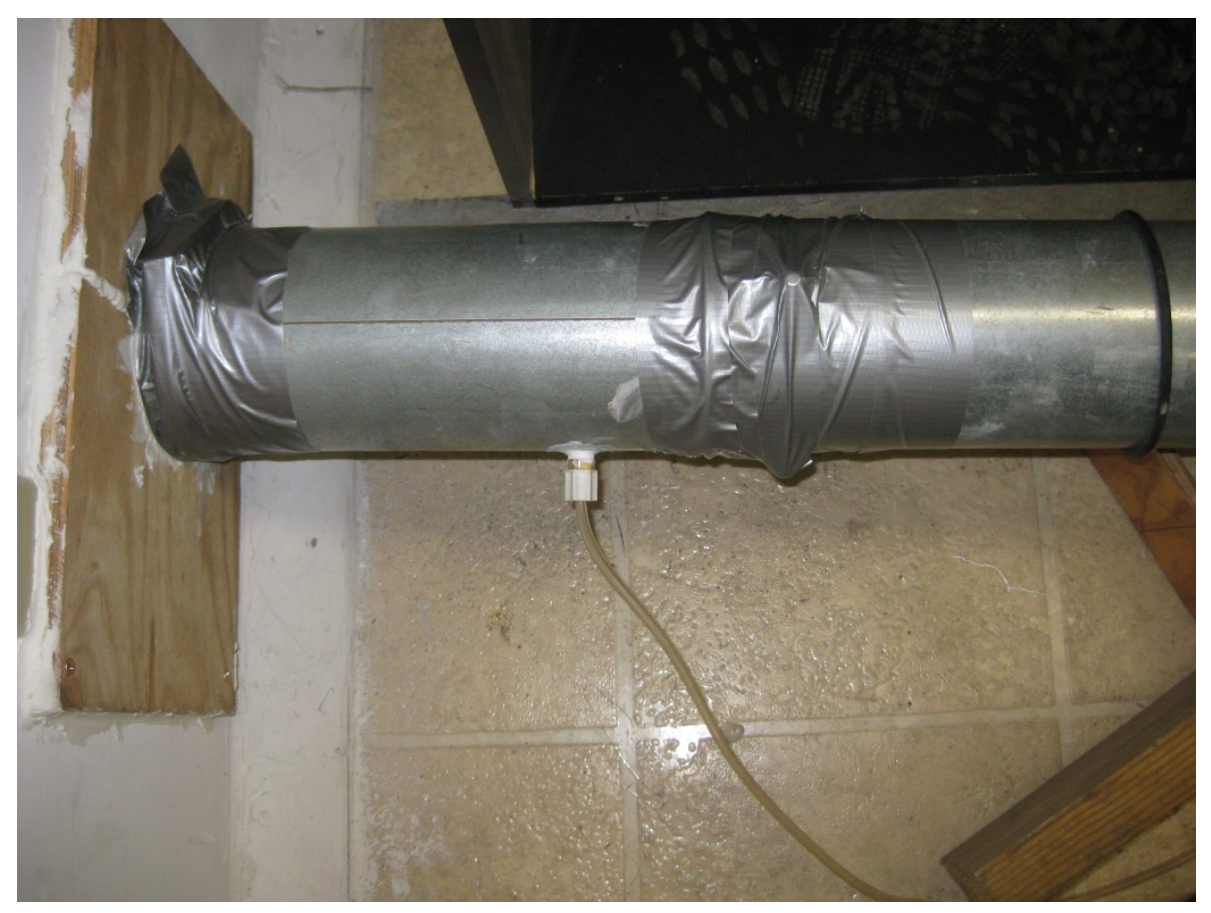

Figure 3-11. $C_{\text {duct }}$ sample location

Samples lines and pumps were tested for leaks and tracer gas adsorption prior to the study. This was done by attaching a 10-liter Tedlar ${ }^{\circledast}$ bag with a known concentration of Freon 134a at the start of the sample train being tested. The Freon 134a mixture passed through the sample train and was collected in a clean 10-liter Tedlar ${ }^{\circledast}$ bag on the exterior to the wind tunnel. The two bags were analyzed by the FTIR and compared to determine the integrity of the sample system. Through this method no leaks in the sampling system were found.

\subsection{Tracer Gas Measurement System}

Samples were analyzed using a Fourier Transform Infrared (FT-IR) analyzer (see Figure 3-12) manufactured by Gasmet (model DX-4015). The FT-IR was calibrated using known Freon 134a concentrations at 0 to 200 PPM. Known concentrations were created by adding 3 liters of ambient air to a 5 liter sample bag using a 3 liter gas-tight syringe manufactured by Pulmonary Data Service Instrumentation. Next, a known amount of Freon 134a was injected into the same sample bag using a gas-tight syringe manufactured by the Hamilton Company. 
Prior to analysis, the FTIR was given at least 30 minutes to reach operating temperature. Following the warm-up period the sample cell of the FTIR was purged with nitrogen for 5 minutes, followed by a 5 minute resting period while the background was established by the instrument's software.

Sample bags are connected to the FTIR using $1 / 4$ " plastic tubing and plastic friction couplers. The FTIR analysis was controlled by the Calcmet software version 10.09 (Gasmet Technologies Oy, Helsinki, Finland). The sample was drawn into the FTIR for 1 minute and analyzed for 1 minute prior to recording the results. Results were recorded by hand as well as automatically logged to a computer file by the Calcmet software. The "residual" for each sample were also recorded, along with any warnings or errors the software associated with the sample. The "residual" given by the Calcmet software is a measure of how similar the sample absorbance spectra is to the reference absorbance spectra for the chemical of interest, a value greater than 0.01 is given a "warning" code and 0.02 is given an "error" code by the software. Samples which return a warning are considered to be acceptable and samples which return an error were discarded and the test was repeated.

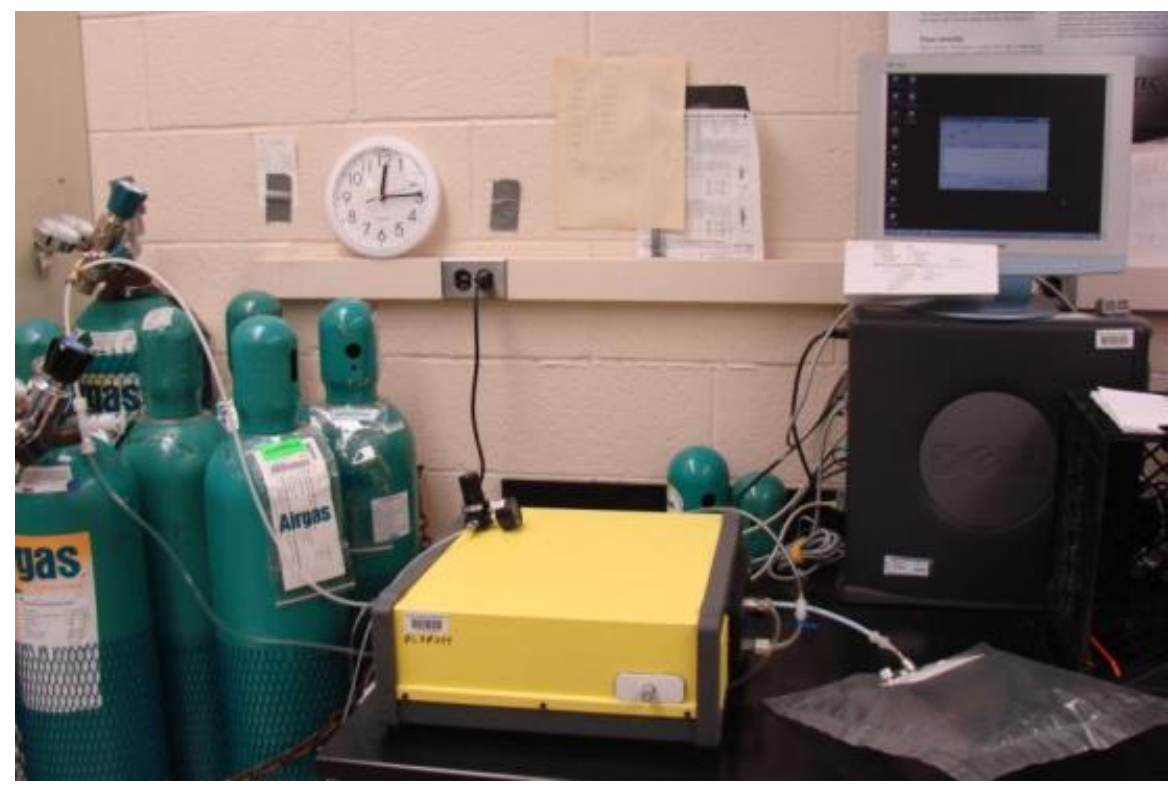

Figure 3-12. Gasmet FT-IR, gas analysis system 
To reduce high residual values and the occurrence of errors or warnings in the analyzed samples, the samples taken at $\mathrm{C}_{\text {duct }}$ were diluted to a lower concentration. The ratio of dilution depended on the hood fan speed since duct concentrations were higher for lower airflows. The samples taken with a hood fan controller frequency of $23 \mathrm{~Hz}$ were diluted 6:1 and the samples taken at a hood fan controller frequency of 40 and $55 \mathrm{~Hz}$ were diluted 3:1. Both the diluted and undiluted samples were analyzed by the FTIR.

Data from the Pitot traverses and from the FTIR were logged in HvMeasurement for analysis.

\subsection{Tracer Gas Release and Metering System}

The tracer gas mixture used in this study was a mixture of ultra-high purity helium and Freon R134a, both manufactured by Airgas, Inc. Both helium and Freon flowed from their respective cylinders to their respective pressure regulators, which reduced the internal pressure to 15 PSI (see Figure 3-13). Each gas was fed to a factory calibrated gas specific mass flow controller (Model GFC-10, Manufactured by Aalborg Instruments and Controls, Inc.) by way of 0.25 inch internal diameter Tygon ${ }^{\circledR}$ tubing. Helium was released at a rate of 4.9 liters per minute (Ipm) and Freon was released at $1.79 \mathrm{lpm}$. 


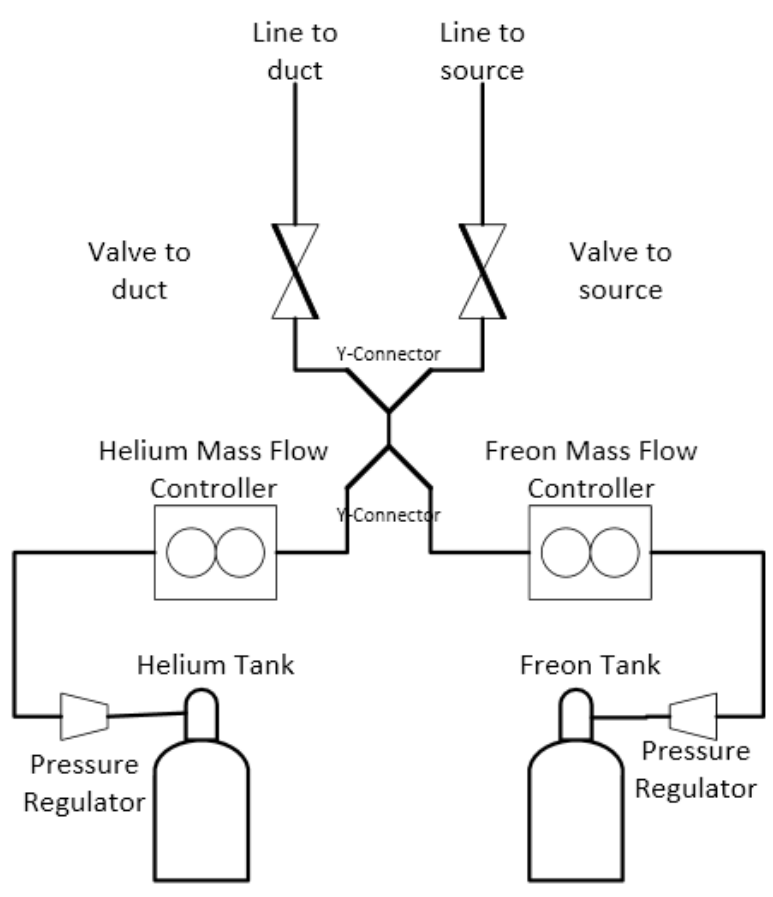

Figure 3-13. Flow diagram of tracer gas mixture

The flow rate of gas from the mass flow controller was calibrated using a Bios Defender 510 primary flow standard (Bios International Corporation of Butler, $\mathrm{NJ}$ ) after allowing the mass flow controller to warm-up for at least 30 minutes and gas to flow for at least 5 minutes prior to calibration. Calibration was performed before and after the experiment. 


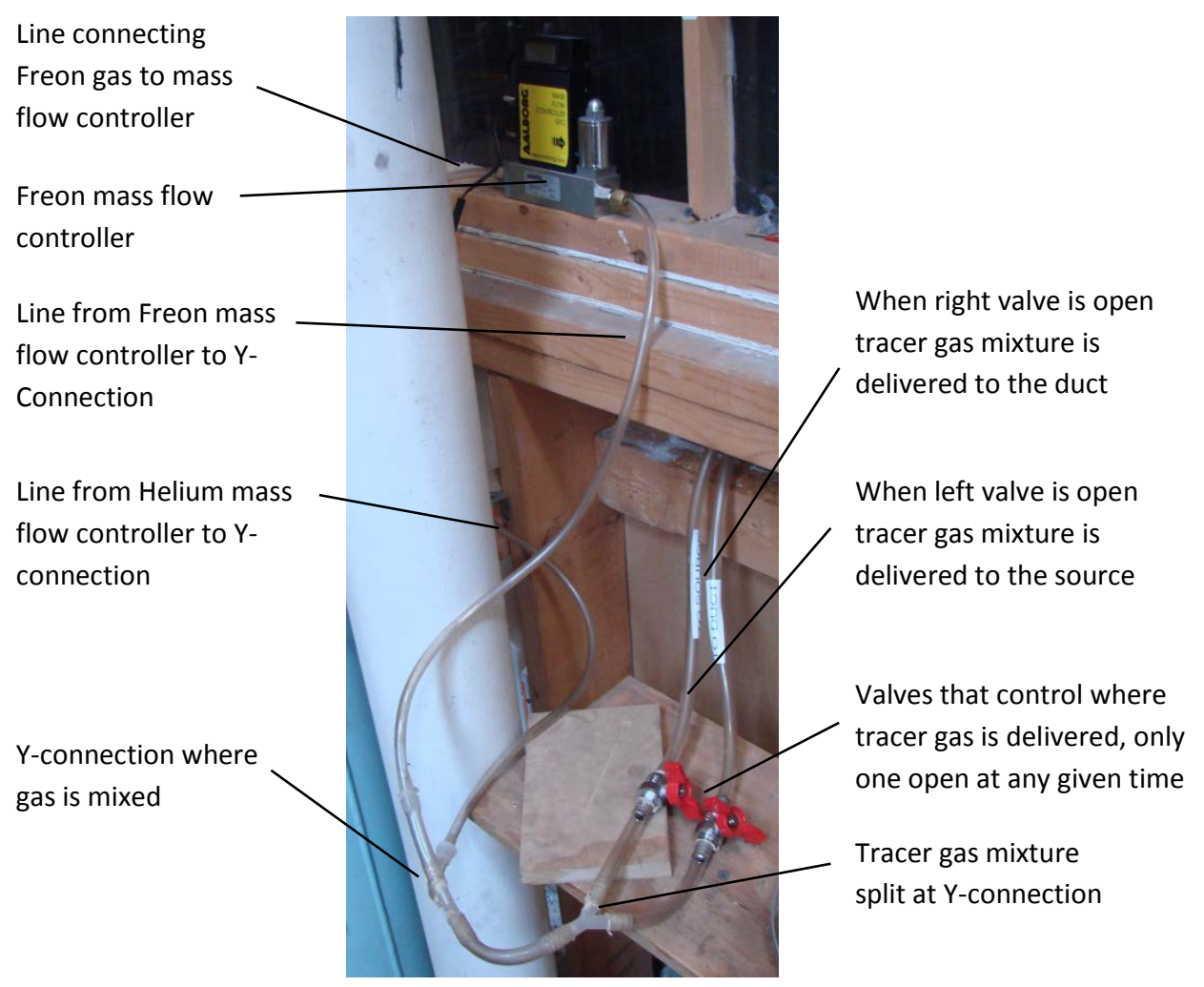

Figure 3-14. Tracer gas mixture delivery controls

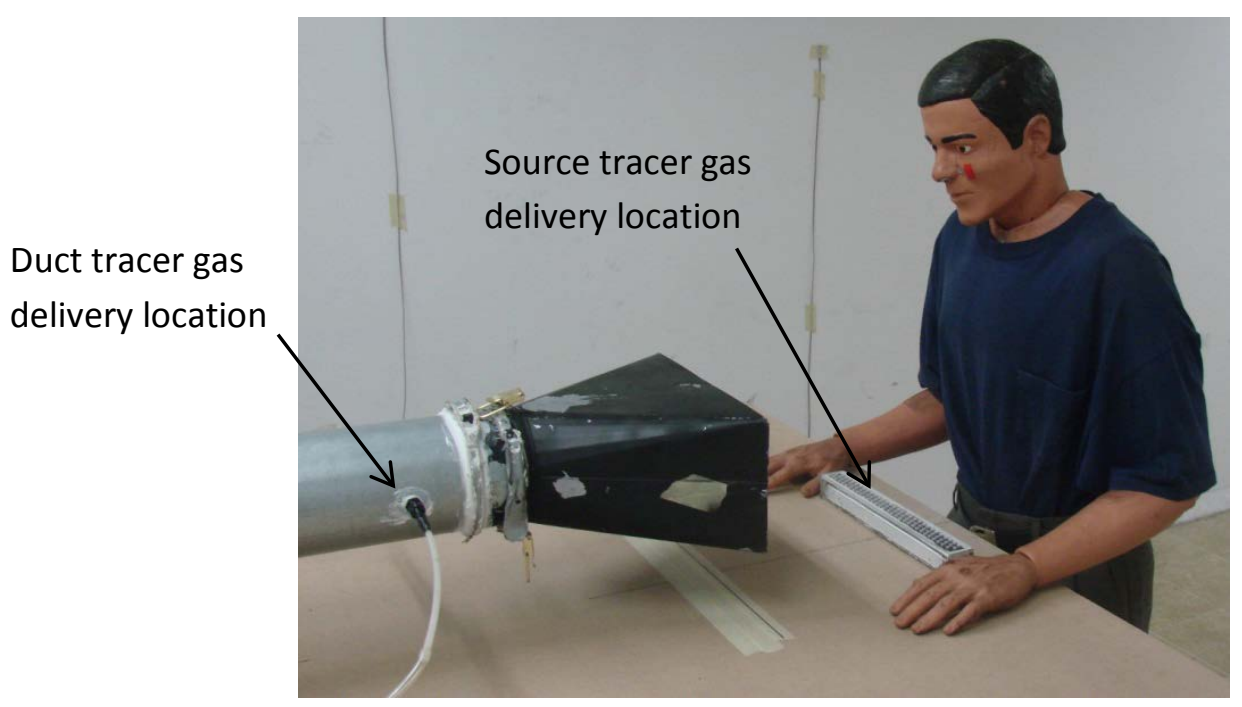

Figure 3-15. Tracer gas mixture release locations

Gas from each mass flow controller is mixed into a single line by a Y-connection. The tracer gas mixture is split again by another Y-connection where two valves control the direction the tracer gas mixture by opening one valve while keeping the other shut (see Figure 3-13 and Figure 
3-14). The tracer gas mixture was directed to either the duct or the source by manipulating the valves (see Figure 3-15). The density of the mixture was modestly less dense than air, at 1.145 g/l.

The source was a rectangular box constructed of 0.1875 inch Plexiglass $^{\circledR}$ (see Figure 3-16) with approximate external dimensions of 1.375 inches in height, 1.375 inches in depth and 12.375 inches in length. The approximate internal dimensions were 1 inch in height, 1 inch in depth, and 12 inches in length. The midpoint of the source was aligned with the center line of the capturing hood using a laser level.

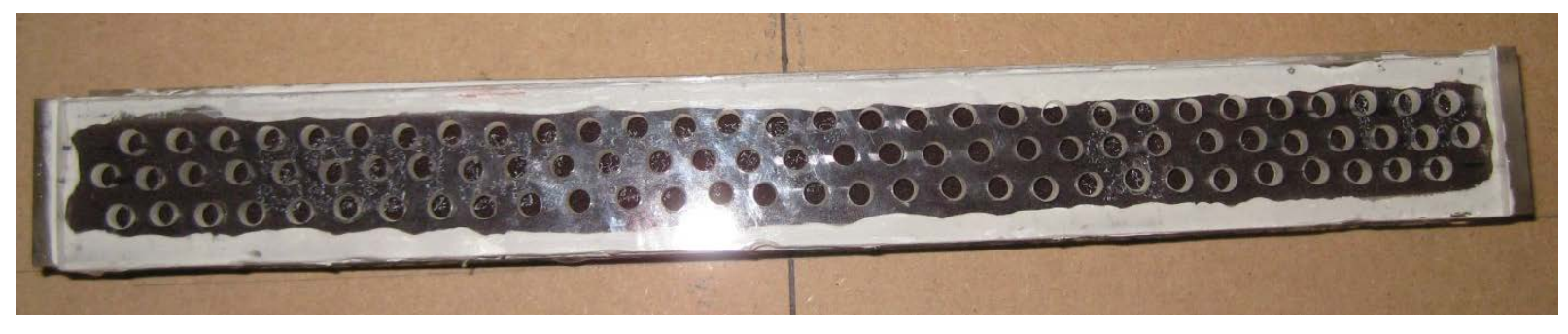

Figure 3-16. Tracer gas source

The tracer gas mixture enters by way of four $1 / 8$ inch plastic tubes routed through the bottom of the table and into four compression fittings mounted in the bottom panel of the rectangular source. The interior of the source was filled with three layers of $3 \mathrm{M}$ Scotch Bright ${ }^{\mathrm{TM}}$ porous material to ensure even dispersion of the tracer gas mixture through the interior of the source. The top of the source contained three rows of 3/16 inch holes. Two rows had 30 holes and one had 31 holes, for a total of 91 holes. Each row was spaced at 0.5 inches from the next row and 0.375 inches between each hole in a row. The tracer gas mixture exited the source with a calculated bulk velocity of $0.02 \mathrm{fpm}$ and an average velocity through the holes of $13 \mathrm{fpm}$.

\subsection{Point Velocity Measurement System}

The velocities induced by the hood $\left(V_{x}\right)$ at the source location (see Figure 3-17) were measured using a constant temperature anemometer (CTA) (Model 54T30,Dantec Dynamics A/S

Skovlunde, Denmark) equipped with a model 55P16 single sensor hot wire miniature probe (see Figure 3-18). 


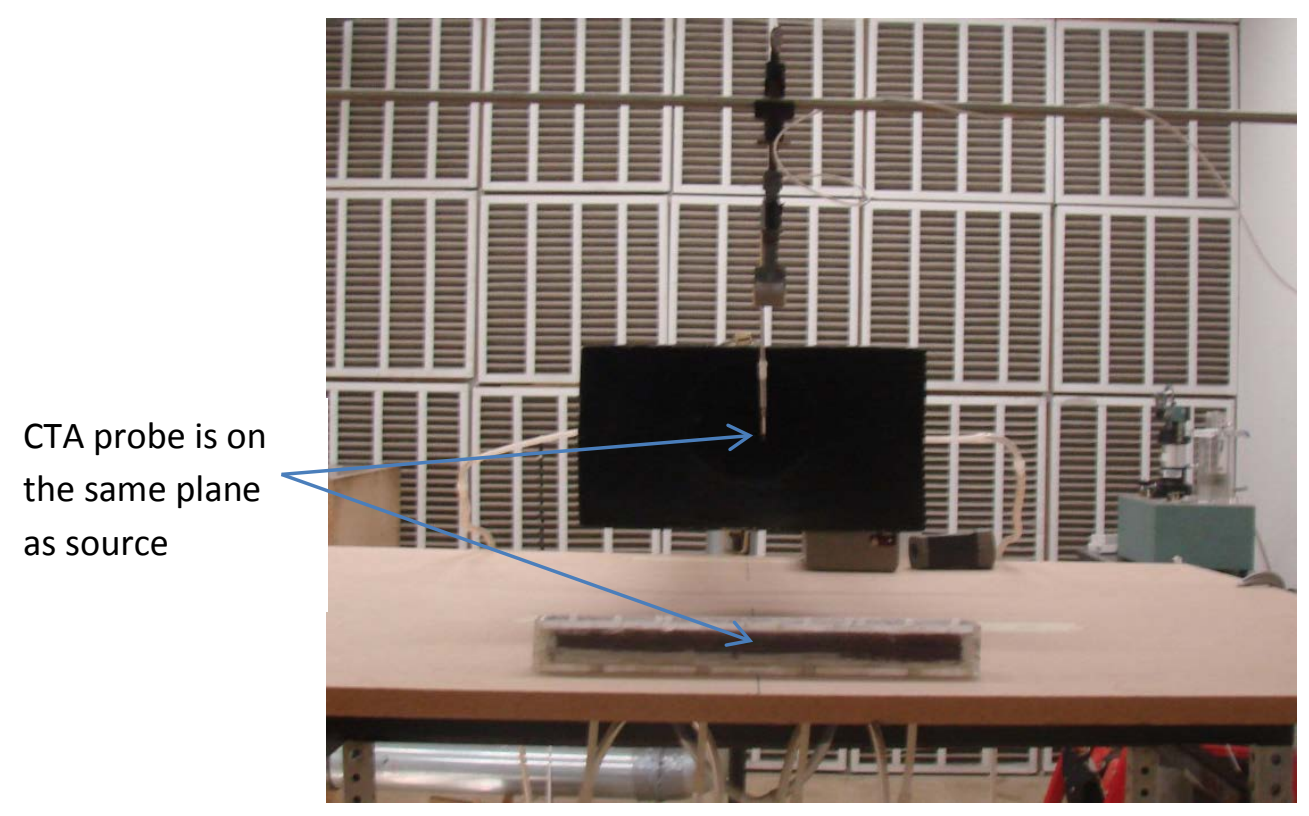

Figure 3-17. $V_{x}$ measurement location with CTA

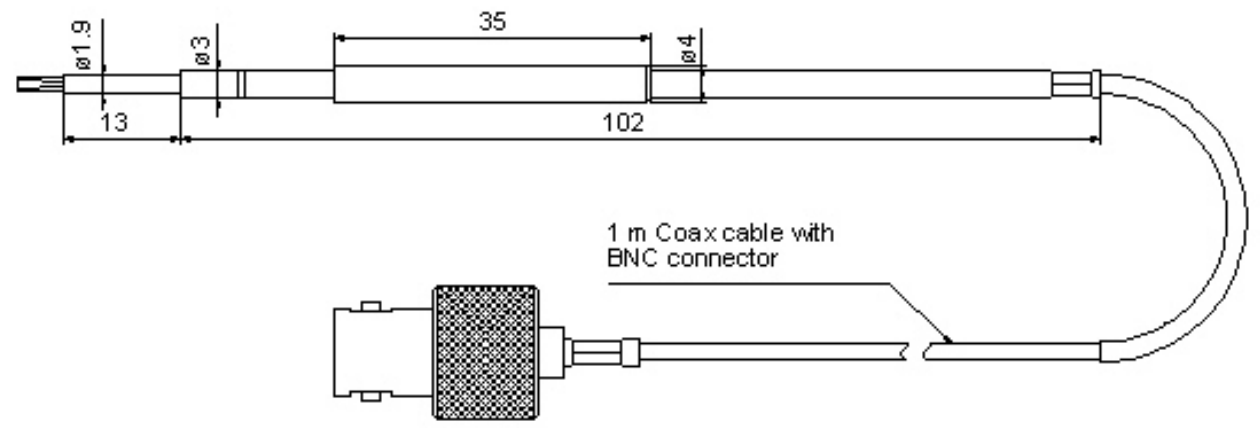

Figure 3-18. Detailed description of CTA probe used with permission by Dantec Dynamics.

Analog voltages from the CTA were acquired by a National Instruments data acquisition system and converted to digital voltage signals. The National Instruments data acquisition system includes a BNC module (Model NI9215), a module carriage (Model NI ${ }_{C} D A Q$ 9172), and National Instrument's Signal express data acquisition software at sample rate set at $1 \mathrm{KHz}$ for during calibration and $100 \mathrm{~Hz}$ during the study. 


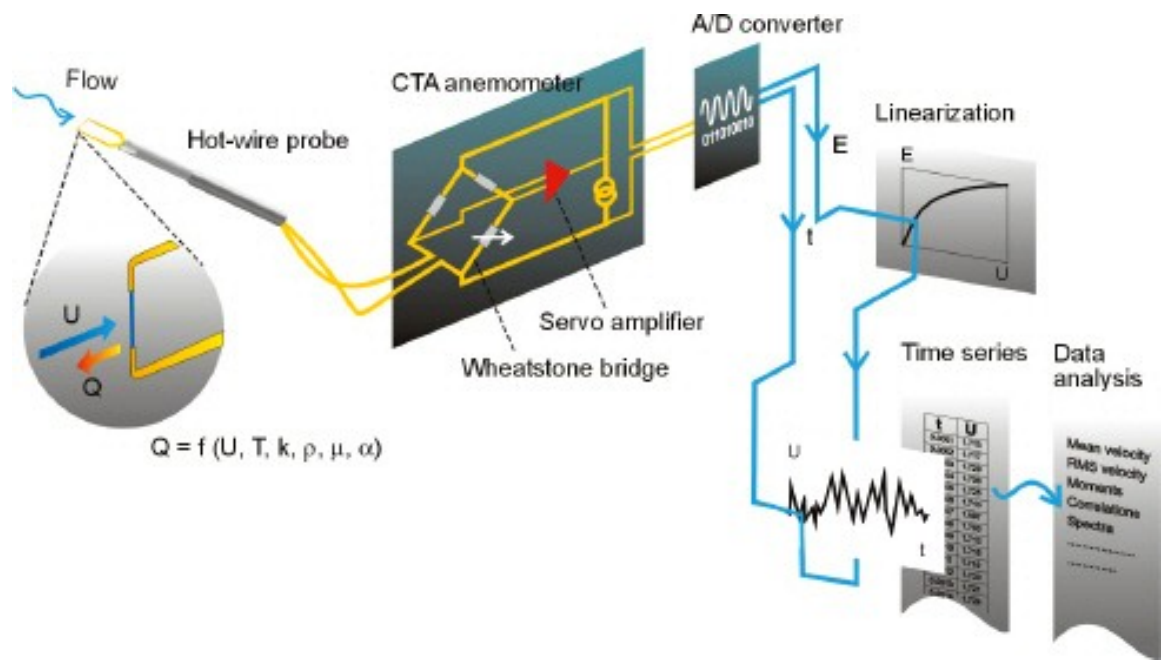

Figure 3-19. CTA principle of operation used with permission by Dantec Dynamics

To measure values of $\mathrm{V}_{\mathrm{x}}$ the CTA probe was positioned at the leading edge of the source, 11 inches from the hood's face, on the midpoint and centerline of the hood face, 6.5 inches above the table. This measurement technique is constant with recommendations for the evaluation of capturing hoods given by the Industrial Ventilation Manual (ACGIH, 2007). Positioning was verified through the use of a laser level. Fan controller frequencies of 23,40 , and $55 \mathrm{~Hz}$ were chosen to produce an approximate $V_{x}$ of 50,100 , and $150 \mathrm{fpm}$, respectively.

The CTA and probe were calibrated using a TSI, Inc. Model 1125 calibrator (see Figure 3-20) designed for calibrating CTAs and other hot wire anemometers. The probe was positioned into the calibration chamber so that the probe's wire was perpendicular to the flow. Laboratory air was connected to the calibrator by $1 / 4$ inch plastic tubing. Flow through the calibrator was controlled by a needle valve. Static pressure measurements from the low velocity calibration chamber were taken using the PVM-100 micromanometer. Velocity through the chamber was calculated from static pressure measurements on the assumption of no losses. The CTA was calibrated to velocities from 0 to $200 \mathrm{fpm}$, the calibration is detailed in Appendix II. 


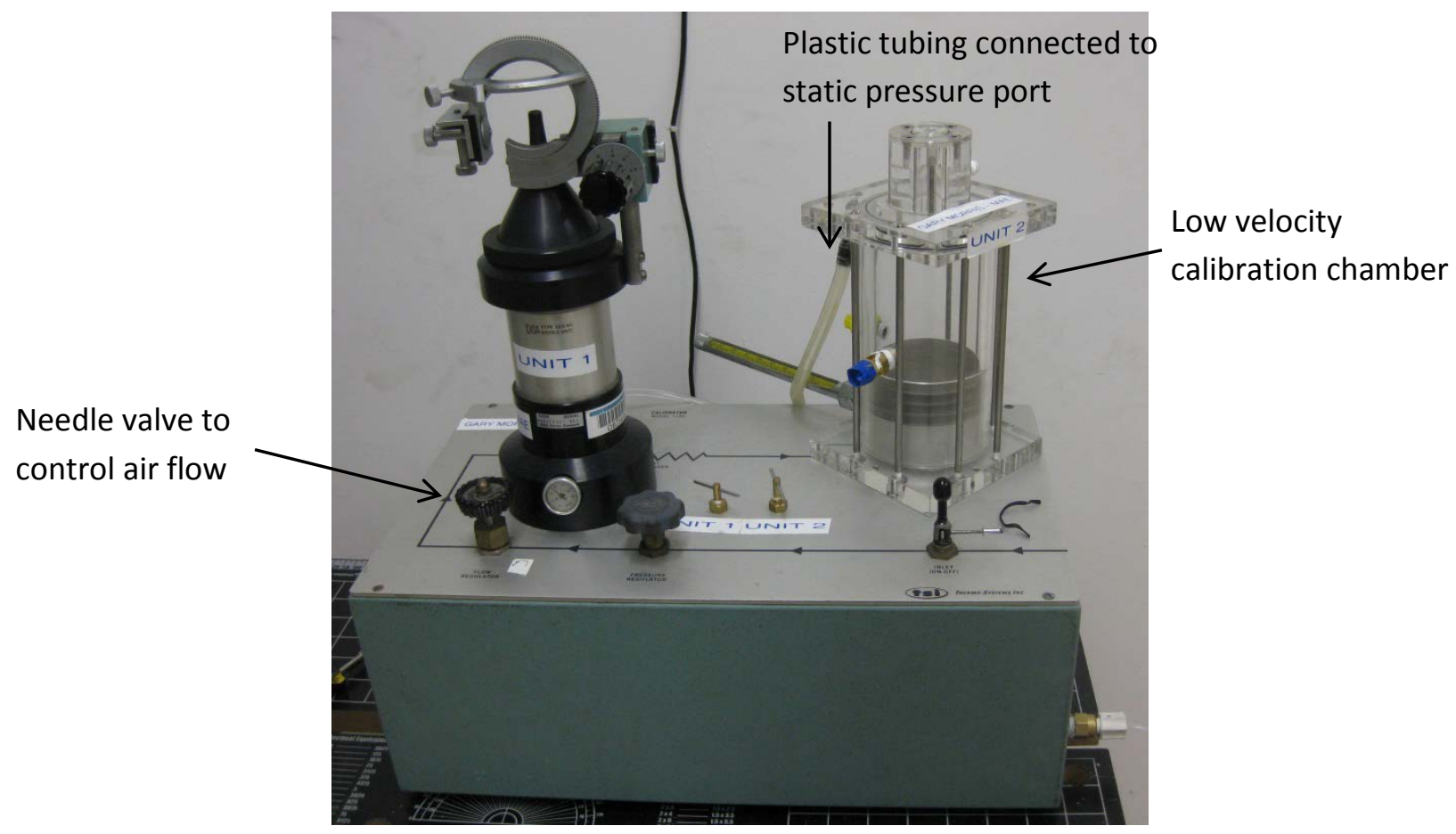

Figure 3-20. TSI, Inc. 1125 calibrator

\subsection{Environmental Measurements}

Temperature, humidity, and barometric pressure were taken prior to each test, recorded, and inputted into the HvMeasurement software, which used them to compute air densities (see Equation 3-4).

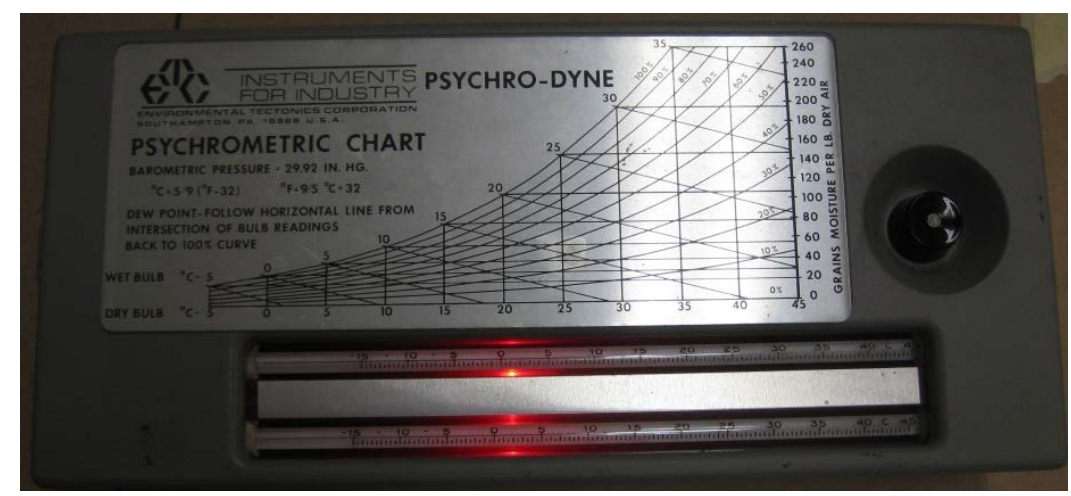

Figure 3-21. Psychrometer

Temperature measurements from the wind tunnel's walls are taken using an Infrared thermometer and thermocouples. Wet and dry bulb thermometer readings were measured 
using a psychrometer (Environmental Tectonics Corporation, South Hampton, PA) taken from inside the wind tunnel prior to each test(see Figure 3-21). All thermometers were checked against an ASTM laboratory thermometer (Ertco, Sn: 8859) by comparing temperature readings simultaneously in the same environment. Barometric pressures were taken at the outer wall of the wind tunnel using a standard laboratory mercury barometer (Environmental Tectonics Corporation, South Hampton, PA). 


\section{CHAPTER 4: METHODS}

\subsection{Study Design}

The dependent variables that were measured in this study are the concentrations of Freon 134a at the nose, mouth, and duct $\left(\mathrm{C}_{\text {nose }}, \mathrm{C}_{\text {mouth }}\right.$, and $\left.\mathrm{C}_{\text {duct }}\right)$.

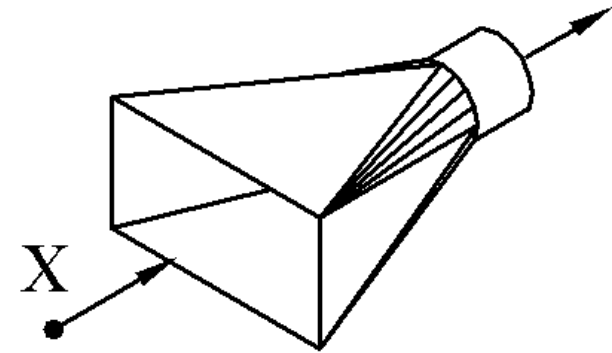

Figure 4-1. Prototypical capturing hood

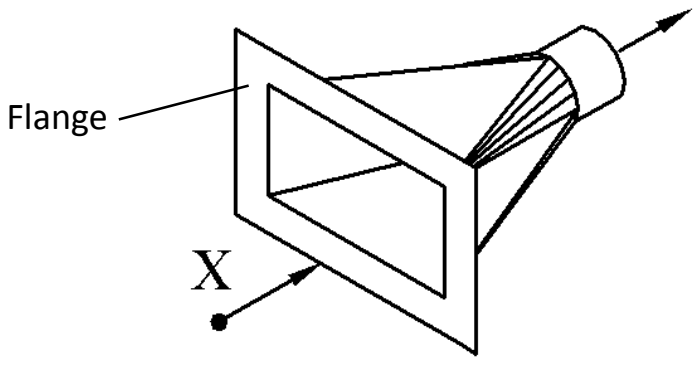

Figure 4-2. Prototypical flanged hood

The independent variables were the presence of a flange (Flange), the average observed air flow $\left(Q_{\text {nom }}\right)$ through the hood at three levels of capturing hood controller speeds (Freq HoodFan $_{\text {), }}$ and the estimated wind tunnel cross draft ( $\left.V_{\text {cross }}\right)$ at two levels of wind tunnel fan rpm

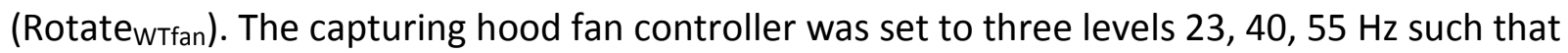
the flow through the hood produced a $V_{x}$ of approximately 50,100 , and 150 feet per minute. The wind tunnel fan was set to an rpm of 150 and 930 such that the calculated $V_{\text {cross }}$ was approximately 10 and 60 feet per minute. Furthermore, there was an expected interactive effect between $V_{\text {cross }}$ and $Q$ due to the innate characteristics of the wind tunnel, and an interactive effect between $Q$ and Flange on the dependent variable.

This study was divided into four parts, three preliminary studies and one main study. The preliminary studies were: velocity measurements at $\mathrm{V}_{\mathrm{x}}$, establishing the $100 \%$ duct concentration when tracer gas is released directly into the duct, and discussion and analysis of interactive effects on $Q$. The main study is where the capture efficiency and protection efficiency for the test hood are determined. Each part of this study used a randomized factorial design. 


\subsubsection{Preliminary Study One}

For the first preliminary study, velocity measurements at $\mathrm{V}_{\mathrm{x}}$, all experimental conditions were tested, Freq $\mathrm{HoodFan}_{\text {, }} \mathrm{V}_{\text {cross, }}$ and Flange (see Table 4-1). Each condition was replicated twice resulting in 24 tests which were conducted in a single randomized order. This preliminary study had the following goals:

1. Determine whether $V x$ is significantly affected by changes in $Q$, the presence of a flange and levels of $\mathrm{V}_{\text {cross }}$

2. Measure $V_{x}$ for each condition

3. Determine how well the "design" equations presented in ACGIH IVM predict $\mathrm{V}_{\mathrm{x}}$

Table 4-1. Experimental Conditions for preliminary study one and the main study

\begin{tabular}{cccc} 
Treatment & Flange & Freq $_{\text {HoodFan }}$ & $\mathbf{V}_{\text {cross }}$ \\
\hline 1 & Yes & 23 & 10 \\
2 & Yes & 23 & 60 \\
3 & Yes & 40 & 10 \\
4 & Yes & 40 & 60 \\
5 & Yes & 55 & 10 \\
6 & Yes & 55 & 60 \\
7 & No & 23 & 10 \\
8 & No & 23 & 60 \\
9 & No & 40 & 10 \\
10 & No & 40 & 60 \\
11 & No & 55 & 10 \\
12 & No & 55 & 60
\end{tabular}

\subsubsection{Preliminary Study Two}

The second preliminary study, establishing the $100 \%$ duct concentration, tested only those conditions which have an effect on the concentration of tracer gas in the duct, Freq HoodFan $_{\text {and }}$ Rotate $_{\text {WTfan }}$ (see Table 4-2). This was done to allow computation of capture efficiency (which

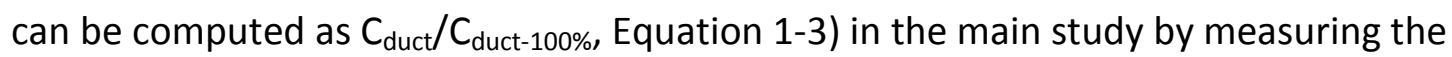
concentration of Freon in the duct when $100 \%$ capture was assured $\left(C_{\text {duct100\% }}\right)$. The 6 conditions were replicated twice resulting in 12 tests which were conducted in a single randomized order. 
In addition to these 12 tests, on each day of the main study two 100\% capture tests were performed. The two $100 \%$ capture tests were selected at random and randomly placed into the block of main study test for that day.

Table 4-2. Conditions for testing $100 \%$ capture

\begin{tabular}{ccc} 
Treatment & Freq $_{\text {HoodFan }}$ & $\mathbf{V}_{\text {cross }}$ \\
\hline 1 & 23 & 10 \\
2 & 23 & 60 \\
3 & 40 & 10 \\
4 & 40 & 60 \\
5 & 55 & 10 \\
6 & 55 & 60
\end{tabular}

\subsubsection{Preliminary Study Three}

The third preliminary study analyzes and discusses the individual and combined effects of the two fan controller settings of Rotate ${ }_{W T f a n}$ and Freq ${ }_{\text {HoodFan }}$ on the observed $Q$ values. This study used data from both preliminary study number two and the main study. It is known that the Rotate $_{W T f a n}$, which controls the cross draft through the wind tunnel, creates a negative pressure inside the wind tunnel; the negative pressure is greater at higher levels. This negative pressure inside the wind tunnel reduces the observed air flow through the capturing hood fan (Q). Since $Q$ is a usefully measure in this study and desired for statistical analysis it is important to understand the degree of dependence or independence of $Q$ on Rotate ${ }_{W T f a n}$ and Freq HoodFan $_{\text {. No }}$ additional data was collected for this preliminary study.

\subsubsection{Main Study}

The main study included a total of 24 tests, including 2 replications for each of the 12 conditions (see Table 4-1). The 24 tests were randomized in one single order and broken into 4 blocks of 6 tests; each block was conducted in one day. Testing occurred over 4 days, including 6 main study tests each day and two preliminary $100 \%$ capture study tests each day. The statistical power of the study was not determined prior to collecting data, but this study was modeled on previous tracer gas studies where two replications provided sufficient power (ElSotouhy, 2008; He, 2010). 
The data was analyzed for statistical significance using multiple regression analysis and a fixedeffect ANOVA model in the Data Desk software (Data Descriptions, Cornell, NY).

\subsection{Procedure}

The following are the procedures used to conduct the preliminary $V_{x}$ study, preliminary $100 \%$ duct study and the main study.

\subsubsection{Calibrations prior to testing}

1. Calibrate the FT-IR with known concentration of Freon ranging from $0-200$ PPM

2. Calibrate Mass Flow Controllers using the DryCal

3. Calibrate the microanemometer using Dwyer hook gauge

4. Calibrate thermocouples and thermometers using ASTM thermometer

\subsubsection{Preliminary study one: Measurement of $V_{x}$}

1. Calibrate the CTA using the TSI model 1125 calibrator

a. Connect CTA to the 12 volt battery

b. Connect BNC cables to the probe and data acquisition system

c. Place probe into the smaller barrel of the "unit 2" on the calibrator

d. Orient the probe such that the probe's wire is perpendicular to the air flow

e. Open National Instrument's Signal Express data acquisition program

f. Attach the PVM-100 micromanometer to the static pressure port on "unit 2" of the calibrator.

g. Attach laboratory air supply to the calibrator and turn on lab air

h. Record temperature and pressure

i. Adjust the flow valve on the calibrator to the achieve the desired velocity pressure in "unit 2" of the calibrator

j. Acquire CTA voltages at $1 \mathrm{k} \mathrm{Hz}$ for 1 second

k. Record the average voltages for the sample period

I. Repeat for the desired range of velocities to be measured

$m$. Graph in excel and record polynomial calibration equation

n. Apply the polynomial calibration equation to the equation in the signal express program

o. Remove the CTA probe from the calibrator

2. Position the CTA probe on the centerline of the hood at the furthest point of the source $\left(V_{x}\right)$ \{distance of 11 inches from hood face and 6.5 inches above the table\}

3. Orient the probe's wire such that it is perpendicular to the flow of air (hood face)

4. Verify positioning with a laser level and reposition if needed

5. Record environmental data and all necessary information of the experiment's data sheet 
6. Shut wind tunnel doors

7. Turn capturing hood on and adjust to desired controller frequency

8. Turn wind tunnel fan and adjust to desired fan rpm

9. Allow room to stabilize for 5 minutes

10. Set the signal express program to data log

11. Acquire CTA voltages at $100 \mathrm{~Hz}$ for 600 seconds (10 minutes)

12. Measure flow through the capturing hood by Pitot traverse

13. Repeat twice for all experimental conditions in random order

\subsubsection{Preliminary study two: Measurement of 100\% duct}

1. Uses same procedures as the main study with following exceptions:

a. The condition flange is not used

b. Only bag samples from the duct and ambient location are taken

\subsubsection{Main study}

\subsubsection{Prior to each day to testing}

1. Manikin heat turned on at least 1.5 hours prior to experiment

2. Plug in mass flow controllers at least one hour prior to experiment

3. Turn on FTIR at least one-half hour prior to experiment.

4. After FTIR has been running for at least one-half hour purge the FTIR with ultra-high purity nitrogen for five minutes

5. Stop purging of FTIR and wait five more minutes

6. Run the background on the FTIR

7. Purge Tedlar ${ }^{\mathrm{TM}}$ sampling bags twice with ambient air

8. Check manikin posture, location of its head in the plane of the hood face, locations of hands to each side of the source, heating and breathing

\subsubsection{Prior to each test}

1. Turn on wind tunnel fan and exhaust hood fan and adjust the fan controllers to desired airflows

2. Turn on the manikin breathing system

3. Turn on sample pumps

4. Connect Tedlar ${ }^{\mathrm{TM}}$ bags to the sampling pumps

5. Record environmental conditions in the wind tunnel (temperature, humidity, barometric pressure)

6. If required attach flange

7. Open or close valves on the tracer gas release system to direct tracer gas mixture to the desired location

8. Turn on tracer gas release system 


\subsubsection{Testing procedure}

1. Ensure wind tunnel doors are closed

2. Wait 10 minutes with tracer gas running and wind tunnel doors shut for the wind tunnel to equalize

3. After 10 minutes open valves on sampling bags

4. While sample bags are filling conduct Pitot traverses at the capturing hood duct

5. Allow experiment to run for 20 minutes

6. After 20 minutes close valves on sampling bags and disconnect the bags from the pumps

\subsubsection{After each test}

1. For tests where the hood fan frequency was 40 or 55 (23) Hz dilute bags $3: 1$ (6:1) by:

a. Connect duct sample bag to 3 liter syringe

b. Open duct sample bag

c. Draw $\sim 0.2$ liters of the duct sample into 3 liter syringe

d. Close duct sample bag

e. Disconnect bag from syringe and exhaust syringe into ambient air

f. Connect sample bag to syringe and draw 1 liter ( 0.5 liters) of sample into 3 liter syringe

g. Close sample bag and disconnect the syringe

h. Connect syringe to a new clean sample bag and open valve

i. $\quad$ Add 1 liter ( 0.5 liters) of duct sample to new sample bag

j. Close new sample bag and disconnect syringe

k. Draw 3 liters of ambient air into syringe

I. Connect syringe to new sample bag and open

m. Add 3 liters of air to the new sample bag

n. Close new sample bag and disconnect syringe

2. Connect a sample bag to the FTIR and open valve on sample bag

3. Draw sample into the analyzer for $1 \mathrm{~min}$

4. Analyze sample for 1 min and note Feron-134a concentration, residuals, and warnings or alarms on screen

5. Repeat for the next sample bag

6. Rinse analyzed sample bag twice with lab air and lab vacuum prior to reusing bags 


\section{CHAPTER 5: PRELIMINARY STUDY ONE}

The main study does not use $\mathrm{V}_{\mathrm{x}}$ as an independent variable because, as is demonstrated here, it is a function of the hood fan output (Q), the presence of the flange, and, to a much lesser degree, the cross draft velocity $\left(\mathrm{V}_{\text {cross }}\right)$. Hence, using $\mathrm{V}_{\mathrm{x}}$ would make it difficult to determine the independent effects of the other variables.

However, since $V_{x}$ is the basis of current practices in evaluating capture hoods, this study was done to allow estimation of $\mathrm{V}_{\mathrm{x}}$ values for the conditions of this study.

This preliminary study measured capture velocities $\left(V_{x}\right)$ at the source for each combination of hood fan setting (Freq HoodFan $)$, wind tunnel cross draft velocity based on Rotate ${ }_{W T f a n}\left(V_{\text {cross }}\right)$, and Flange (present or not). The study determined the velocity at the source $\left(V_{x}\right)$ on the centerline of the hood face without a manikin present. The measurement location and absence of a "worker" are consistent with current recommendations for evaluating capturing hoods in the Industrial Ventilation Manual (ACGIH, 2007).

Specifically, this preliminary study had the following goals:

1. Determine whether $V_{x}$ is significantly affected by changes in $Q$, the presence of a flange and levels of $\mathrm{V}_{\text {cross }}$

2. Measure $V_{x}$ for each condition

3. Determine how well the "design" equations presented in ACGIH IVM predict $\mathrm{V}_{\mathrm{x}}$

\subsection{Study Design}

The study was a randomized factorial design with the same conditions investigated in the main study (see Table 4-1), including air flow through the hood based on 3 levels of Freq HoodFan $_{\text {(Q), } 2}$ levels of $\mathrm{V}_{\text {cross, }} 2$ levels of Flange (on/off), and with two replications for each combination. Tests of all conditions and replications were conducted in one randomized order. 


\subsection{Results}

As expected, values of $V_{x}$ increased with increasing $Q, V_{\text {cross, }}$ and with Flange (see Table 5-1). The observed velocities at $V_{x}$ ranged from 37 to $160 \mathrm{fpm}$ without a flange and 73 to $227 \mathrm{fpm}$ with a flange. The range of measured $V_{x}$ values fell fairly close to the desired range of 50 to 150 $\mathrm{fpm}$. The minimum $V_{\mathrm{x}}$ recommended by the Industrial Ventilation Manual is $100 \mathrm{fpm}$ for the conditions tested. The minimum $V_{x}$ used in the study about $40 \mathrm{fpm}$, however as shown in the main study the hood was still highly effective.

Table 5-1. Velocity measurements by CTA at the source on the centerline of the hood $\left(V_{x}\right)$ for each condition

\begin{tabular}{|c|c|c|c|c|c|c|c|c|c|c|c|}
\hline \multirow[b]{2}{*}{ Freq $_{\text {HoodFan }}$} & \multirow[b]{2}{*}{$\begin{array}{c}\text { Avg } \\
\text { Q, } \\
\text { cfm }\end{array}$} & \multirow[b]{2}{*}{$\begin{array}{l}V_{\text {cross, }} \\
\text { fpm }\end{array}$} & \multirow[b]{2}{*}{ Flange } & \multirow[b]{2}{*}{$\begin{array}{c}\text { Mean } \\
V_{x} \\
\text { fpm }\end{array}$} & \multirow[b]{2}{*}{$\begin{array}{c}V_{x} \\
\text { StdDev } \\
\text { fpm }\end{array}$} & \multicolumn{2}{|c|}{ Flange } & \multicolumn{2}{|c|}{$\begin{array}{l}\text { No Flange, } \\
\text { due to } V_{\text {cross }}\end{array}$} & \multicolumn{2}{|c|}{$\begin{array}{c}\text { Flange, } \\
\text { due to } \mathrm{V}_{\text {cross }}\end{array}$} \\
\hline & & & & & & $\begin{array}{l}\Delta V_{x} \\
\text { fpm }\end{array}$ & $\% \Delta V x$ & $\begin{array}{l}\Delta V x, \\
\text { fpm }\end{array}$ & $\% \Delta V x$ & $\begin{array}{l}\Delta V x, \\
\text { fpm }\end{array}$ & $\% \Delta V x$, \\
\hline 23 & 425 & 10 & No & 36 & 8 & 37 & $102 \%$ & \multirow{4}{*}{27} & \multirow{4}{*}{$75 \%$} & \multirow{4}{*}{5} & \multirow{4}{*}{$7 \%$} \\
\hline 23 & 425 & 10 & Yes & 73 & 10 & 37 & $102 \%$ & & & & \\
\hline 23 & 367 & 60 & No & 63 & 17 & \multirow{2}{*}{15} & \multirow{2}{*}{$23 \%$} & & & & \\
\hline 23 & 362 & 60 & Yes & 78 & 15 & & & & & & \\
\hline 40 & 792 & 10 & No & 93 & 14 & 61 & 650 & \multirow{4}{*}{28} & \multirow{4}{*}{$30 \%$} & \multirow{4}{*}{11} & \multirow{4}{*}{$7 \%$} \\
\hline 40 & 797 & 10 & Yes & 154 & 15 & \multirow{3}{*}{44} & \multirow{3}{*}{$36 \%$} & & & & \\
\hline 40 & 758 & 60 & No & 121 & 21 & & & & & & \\
\hline 40 & 753 & 60 & Yes & 165 & 21 & & & & & & \\
\hline 55 & 1112 & 10 & No & 138 & 15 & & & \multirow{4}{*}{24} & \multirow{4}{*}{$17 \%$} & \multirow{4}{*}{16} & \multirow{4}{*}{$8 \%$} \\
\hline 55 & 1120 & 10 & Yes & 210 & 19 & 13 & ५ट\% & & & & \\
\hline 55 & 1083 & 60 & No & 161 & 20 & \multirow{2}{*}{65} & \multirow{2}{*}{$40 \%$} & & & & \\
\hline 55 & 1087 & 60 & Yes & 227 & 21 & & & & & & \\
\hline
\end{tabular}

On average the Flange added $53 \%$ to the measured value of $\mathrm{V}_{\mathrm{x}}$. As shown in Table $5-1$, at lower levels of $\mathrm{V}_{\text {cross }}$ the velocity added to $\mathrm{V}_{\mathrm{x}}$ by Flange decreased from $102 \%$ to $52 \%$ with increasing levels of $Q$. At higher levels of $V_{\text {cross }}$ the velocity added to $V_{x}$ by Flange increased from $23 \%$ to $40 \%$ with increasing levels of $Q$. This effect may be explained by $V_{\text {cross }}$ at higher levels reducing the air flow through the hood and adding velocity to the measured $V_{x}$. Table 5-3 shows the amount of velocity added to $V_{x}$ due to the change in $V_{\text {cross }}$ when no flange is present, which is 
fairly constant at $26 \pm 2 \mathrm{fpm}$. The increasing effect of the flange at the higher level of $V_{\text {cross }}$ therefore appears to be the velocity added by the flange overcoming the velocity added by $V_{\text {cross }}$ to $V_{\mathrm{x}}$.

\section{Vx Measurements}

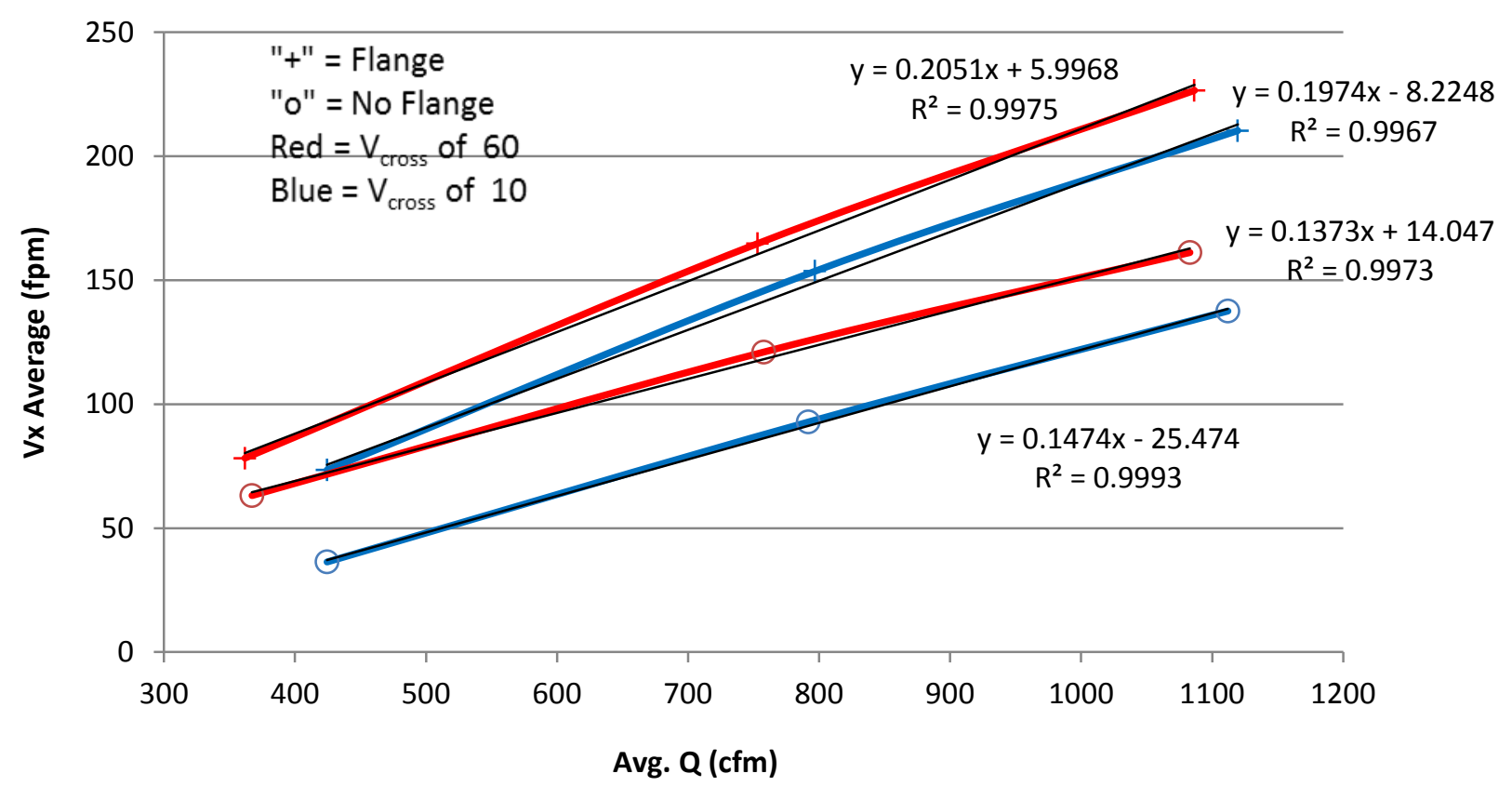

Figure 5-1. $V_{x}$ Measurements by CTA.

The $V_{x}$ measurements are all highly linear $\left(R^{2}>99 \%\right)$ with increasing levels of $Q$. Adding a flange appears to change the relationship between $Q$ and $V_{x}$, by increasing the slope. This suggests that a flange's effect on $V_{x}$ is not simply an additive effect as assumed by the Industrial Ventilation Manual $(A C G I H, 2007)$, but the effect increases as $Q$ increases. $V_{\text {cross }}$ appears to have a small effect on slope and the Y-intercept; however the effect is not consistence across all conditions and the $\mathrm{Y}$-intercept it is not simply the difference in $\mathrm{V}_{\text {cross. }}$.

\subsection{Effect of Variables on $V_{x}$}

Analysis of variance with a fixed-effect model was performed for the effect of $Q_{\text {nom }}, V_{\text {cross, }}$ Flange, $Q_{\text {nom }} V_{\text {cross, }}$ and $Q_{\text {nom }}$ Flange on the measured values of $V_{x}$. Only data collected as part of Preliminary Study One was used in this analysis. In ANOVA analysis the average observed $Q$ for 
each level of Freq $\mathrm{Hoodfan}_{\text {was }}$ used in place of the observed $\mathrm{Q}$ for each treatment. This was done because the observed $\mathrm{Q}$ is shown in Preliminary Study Three to modestly dependent on $\mathrm{V}_{\text {cross. }}$. The average value of $Q$ is noted as the nominal value of $Q$ for each level of Freq Hoodfan $_{(}\left(Q_{\text {nom }}\right)$.

Table 5-2. Analysis of Variance for dependent variable $V_{x}$

\begin{tabular}{lrllll}
\multicolumn{1}{c}{ Source } & df & \multicolumn{1}{c}{$\begin{array}{c}\text { Sums of } \\
\text { Squares }\end{array}$} & \multicolumn{1}{c}{$\begin{array}{c}\text { Mean } \\
\text { Square }\end{array}$} & \multicolumn{1}{c}{ F-ratio } & \multicolumn{1}{c}{ Prob } \\
\hline Const & 1 & 384605 & 384605 & 6313.8 & $\leq 0.0001$ \\
$\mathrm{Q}_{\text {nom }}$ & 2 & 59171.7 & 29585.8 & 485.69 & $\leq 0.0001$ \\
$\mathrm{~V}_{\text {cross }}$ & 1 & 2041.67 & 2041.67 & 33.517 & $\leq 0.0001$ \\
Flange & 1 & 14491.4 & 14491.4 & 237.9 & $\leq 0.0001$ \\
$\mathrm{Q}_{\text {nom }}{ }^{*} \mathrm{~V}_{\text {cross }}$ & 2 & 21.5098 & 10.7549 & 0.17656 & 0.8399 \\
$\mathrm{Q}_{\text {nom }}{ }^{*}$ Flange & 2 & 1875.61 & 937.807 & 15.395 & 0.0002 \\
Error & 15 & 913.726 & 60.9151 & & \\
Total & 23 & 78515.6 & & &
\end{tabular}

$$
\begin{aligned}
& \text { ANOVA Model: } Y=\mu+\alpha_{i}+\beta_{j}+\gamma_{k}+\alpha \beta_{i j}+\alpha \gamma_{i k}+\varepsilon_{i j k l} \\
& \text { Where: } \quad \begin{aligned}
Y & =\text { Dependent variable } \mathrm{V}_{\mathrm{x}} \\
\alpha & =\text { Effect of } \mathrm{Q}_{\text {nom }} \\
\beta & =\text { Effect of } \mathrm{V}_{\text {cross }} \\
\gamma & =\text { Effect of Flange } \\
\alpha \beta & =\text { Effect of Interaction between } \mathrm{Q}_{\text {nom }} \text { and } \mathrm{V}_{\text {cross }} \\
\alpha \gamma & =\text { Effect of Interaction between } \mathrm{Q}_{\text {nom }} \text { and Flange }
\end{aligned}
\end{aligned}
$$

The effect of variables $Q_{\text {nom }}, V_{\text {cross, }}$ Flange, and the interaction term $Q_{\text {nom }}$ *Flange were found to be highly significant $(p<0.001)$ with $V_{x}$. Given the ANOVA model, the variance in $V_{x}$ is mostly explained by $Q_{\text {nom, }}$ which contributes to $75 \%$ of the Sum of Squares, while $V_{\text {cross }}$ and

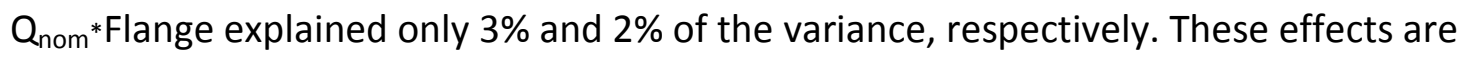
consistent with observations from Figure 5-1. It should be noted that the ANOVA model was a fixed-effect model and may only be applied to the specific levels for each variable tested in this study.

In conclusion, the variables which have an effect on $V_{x}$ for this study are $Q_{n o m}, V_{\text {cross, }}$, Flange, and the interaction between $Q_{\text {nom }}$ and Flange. $V_{x}$ was mostly affected by $Q_{n o m}$. If it is true that $V_{x}$ 
predicts protection efficiency or capture efficiency, then one would expect that protection efficiency or capture efficiency to be determined by the same variables.

\subsection{Comparison of Measure $V_{x}$ to $V_{x}$ Predicted by Equation 2-4}

With the results showing a greater than $33 \%$ increase in capture velocity due to the addition of a flange as assumed with Equation 2-4 presented in the industrial ventilation manual (ACGIH, 2007), the measured values of $V_{x}$ were compared to the predicted values of $V_{x}$ (see Equation 2-

4).

Table 5-3. $V_{x}$ calculated from ACGIH's design formula and measured $V_{x}$ values.

\begin{tabular}{|c|c|c|c|c|c|c|c|c|}
\hline \multirow[b]{2}{*}{$\mathbf{V}_{\text {cross }}$} & \multirow[b]{2}{*}{$\mathrm{Hz}$} & \multirow[b]{2}{*}{$\begin{array}{c}\text { Avg Q } \\
\text { cfm }\end{array}$} & \multicolumn{3}{|c|}{ No Flange } & \multicolumn{3}{|c|}{ Flange } \\
\hline & & & $\begin{array}{c}\text { Predicted } \\
V_{x}, f p m\end{array}$ & $\begin{array}{c}\text { Measured } \\
V_{x}, \mathrm{fpm}\end{array}$ & \%Diff. & $\begin{array}{c}\text { Predicted } \\
V_{x}, f p m\end{array}$ & $\begin{array}{c}\text { Measured } \\
V_{x}, \mathrm{fpm}\end{array}$ & \% Diff \\
\hline \multirow{3}{*}{$\begin{array}{l}\frac{\varepsilon}{2} \\
\stackrel{0}{\circ} \\
\text { 욱 }\end{array}$} & 23 & 425 & 47.7 & 36.4 & $-23.8 \%$ & 63.7 & 73.5 & $15.4 \%$ \\
\hline & 40 & 795 & 89.3 & 92.8 & $4.0 \%$ & 119.1 & 153.6 & $29.0 \%$ \\
\hline & 55 & 1115 & 125.2 & 137.6 & $9.9 \%$ & 167.0 & 210.3 & $26.0 \%$ \\
\hline \multirow{3}{*}{$\begin{array}{l}\frac{\varepsilon}{2} \\
\frac{0}{0}\end{array}$} & 23 & 365 & 41.0 & 63.1 & $54.0 \%$ & 54.7 & 78.2 & $43.1 \%$ \\
\hline & 40 & 755 & 84.8 & 121.0 & $42.7 \%$ & 113.1 & 164.8 & $45.7 \%$ \\
\hline & 55 & 1085 & 121.9 & 161.2 & $32.2 \%$ & 162.5 & 226.5 & $39.4 \%$ \\
\hline
\end{tabular}

The errors from between the measured and predicted $V_{x}$ given by Equation 2-4 were less at $\mathrm{V}_{\text {cross }}$ of $10(-24 \%$ to $10 \%)$ and greater at $\mathrm{V}_{\text {cross }}$ of $60 \mathrm{fpm}$ (32\% to $54 \%$ ). Clearly values predicted by Equation 2-4 fit experimental values much better when $\mathrm{V}_{\text {cross }}$ was lower than at a higher $\mathrm{V}_{\text {cross }}$. Equation 2-4 also performed poorly when predicting the $\mathrm{V}_{\mathrm{x}}$ with the presence of a flange (see Figure 5-2, Figure 5-3, and Figure 5-4). 


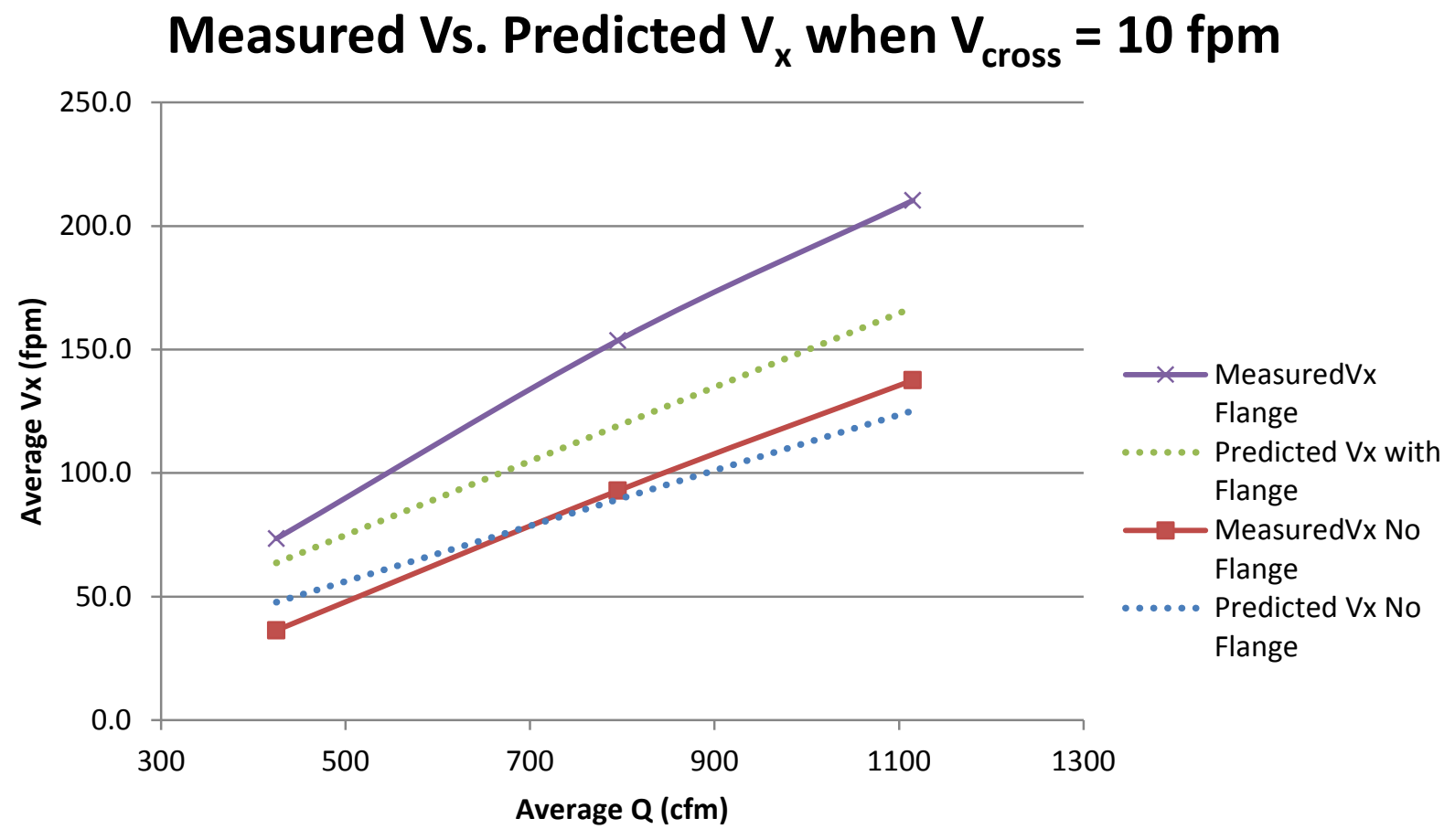

Figure 5-2. Graph of measured $V_{x}$ with a cross draft of $10 \mathrm{fpm}$ and the predicted $V_{x}$ from Equation 2-3 given in ACGIH's IVM.

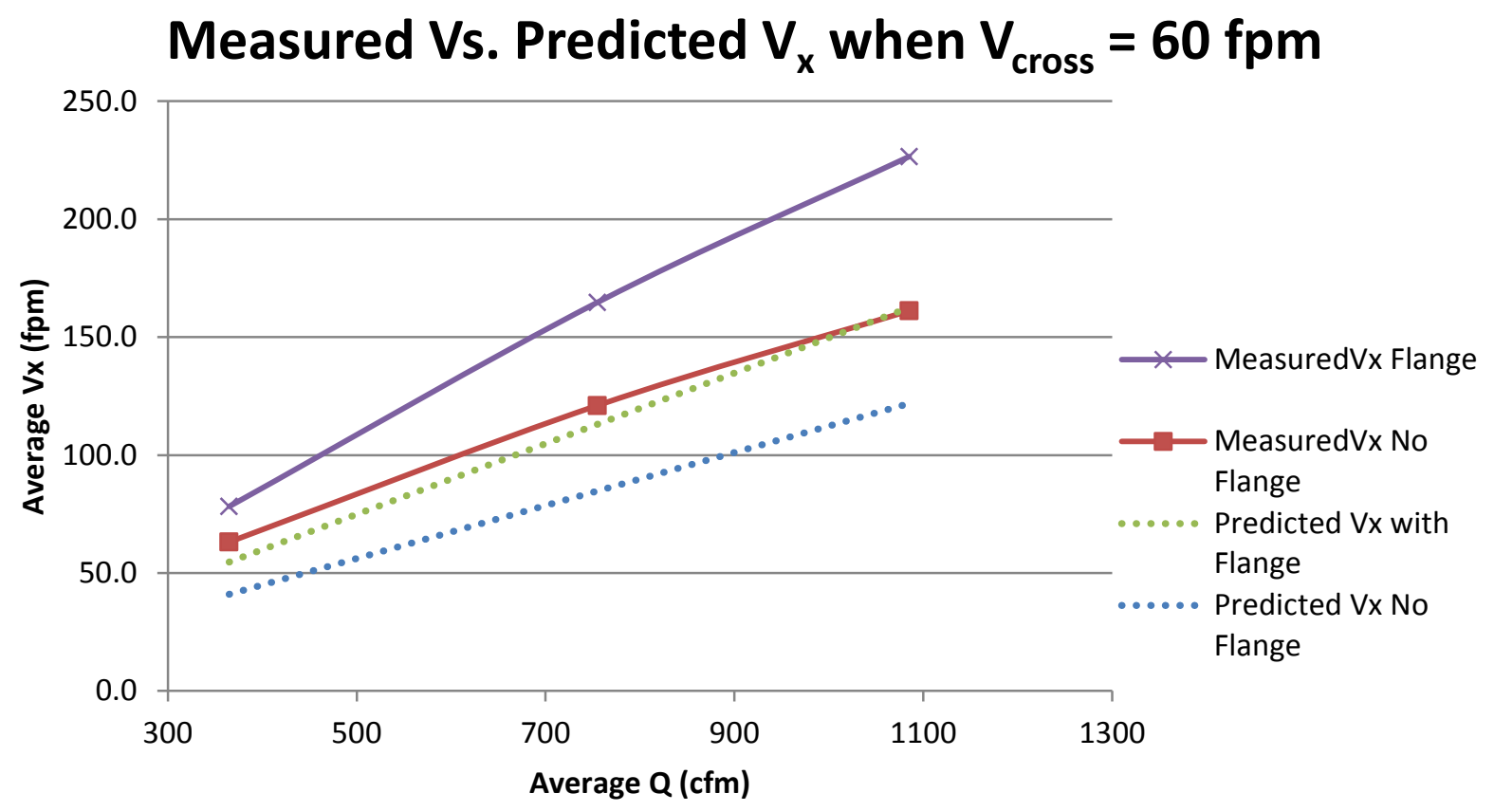

Figure 5-3. Graph of measured $V_{x}$ with a cross draft of $60 \mathrm{fpm}$ and the predicted $V_{x}$ from Equation 2-3 given in ACGIH's IVM. 


\section{Combined Measured Vs. Predicted $\mathrm{V}_{\mathrm{x}}$}

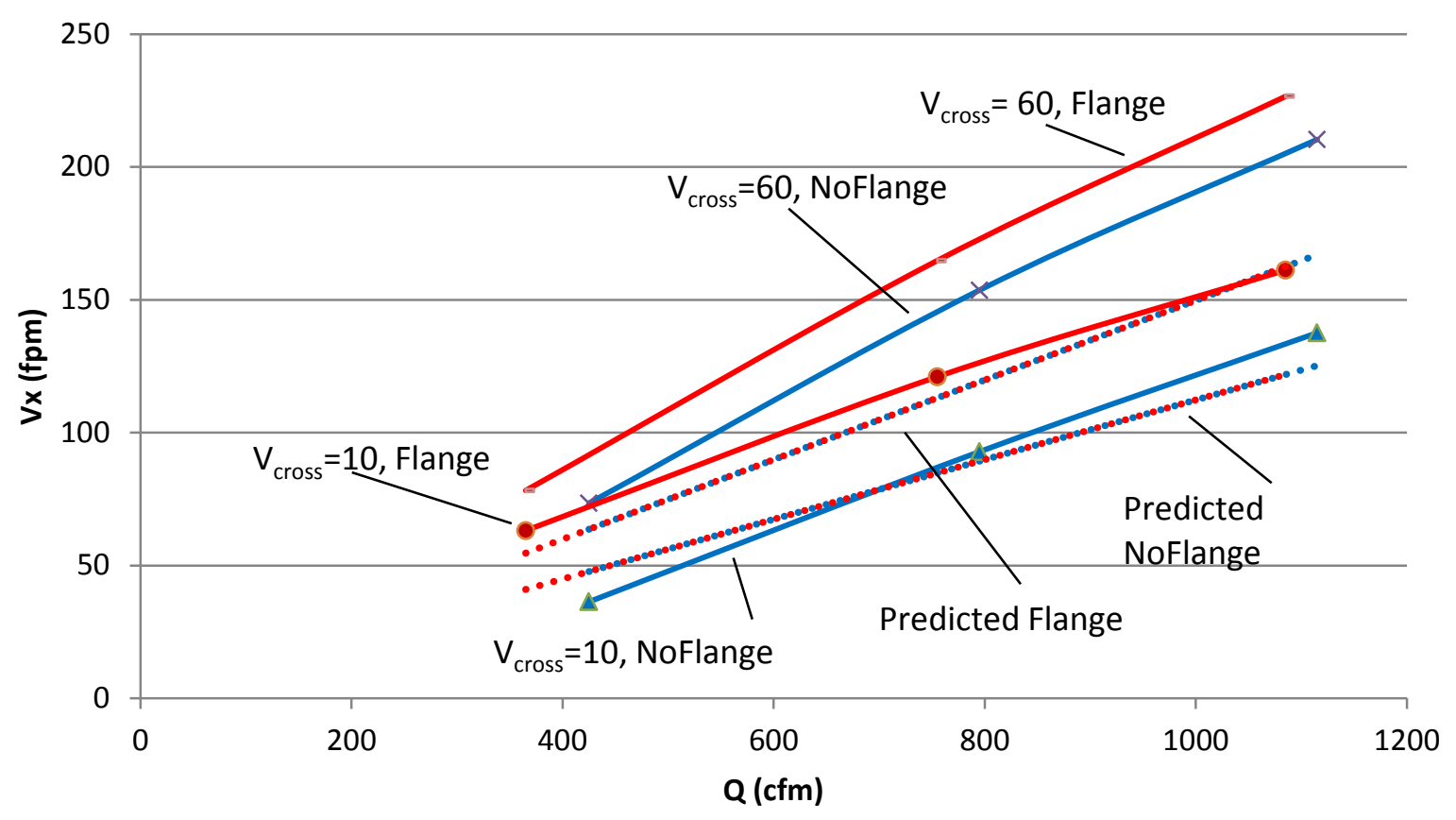

Figure 5-4. Graph of measured $V_{x}$ with a cross draft of 10 and $60 \mathrm{fpm}$ and the predicted $V_{x}$ from Equation 2-3 given in ACGIH's IVM.

Equation 2-3, used to predict $V_{x}$, does not include parameters for the presence of a table or a cross draft, which both were present during testing. Since the modifier used in Equation 2-3 for a flange is based on the observed effect of a flange when no table or cross draft was present, it is easy to understand why the equation did not predict $V_{x}$ accurately. In application the direction and intensity of the cross draft would be highly variable and very difficult to predict. 


\section{CHAPTER 6: PRELIMINARY STUDY TWO}

Previous experience with the apparatus used in the main study showed that capture efficiencies computed using the reported values from the mass flow controllers often exceeded $100 \%$, which of course violates mass balance and cannot be correct. Despite diligent attempts, it has not been possible to remedy this error.

For that reason, the main study computes capture efficiency in two different ways: (1) using Equation 1-2, which uses the generation rate reported by the mass flow controller (G) and (2) Equation 1-3, which does not use G. Equation 1-3 uses the concentration of Freon in the duct measured when $100 \%$ capture was assured. This preliminary study was done to determine the concentrations of Freon in duct that occur when $100 \%$ capture is assured $\left(C_{\text {duct-100\% }}\right)$. The $C_{\text {duct- }}$ $100 \%$ values are then used to compute the capture efficiency measure ( $\left.\eta_{\mathrm{e}-\text { duct }} 100 \%\right)$ in the main study.

Since $100 \%$ capture is assured the capture efficiency based on $\mathrm{G}\left(\eta_{\mathrm{e}-\mathrm{G}}\right)$, Equation1-2, was also calculated to determine the degree to which the equation over estimates the capture efficiency. The measure of $\eta_{\mathrm{e}-\mathrm{G}}$ may then be adjusted reflect a maximum average value of $100 \%$.

\subsection{Study Design}

This preliminary study was a randomized factorial design conducted to establish the Freon concentration in the duct for the situation where $100 \%$ capture was assured $\left(C_{\text {duct-100\% }}\right)$. The independent variables tested were the observed airflow in the duct (Q) for 3 levels of hood fan

controller frequency ( Freq $_{\text {Hoodfan }}$ ) and 2 levels of $\mathrm{V}_{\text {cross. }}$. Each combination of Freq $\mathrm{HoodFan}_{\text {and }} \mathrm{V}_{\text {cross }}$ was replicated twice in a single random order.

\subsection{Apparatus and Methods}

With a few exceptions, the apparatus and methods were the same as those described in Chapter 3 and 4 . One exception was that only $C_{\text {duct-100\% }}$ and $C_{\text {ambient }}$ samples were taken. They were taken while all of the tracer gas mixture was being continuously released directly into the 
duct, with none released into the custom made source. The mixture of Freon and helium was the same as in the main study.

For some tests the $\mathrm{C}_{\text {duct-100\% }}$ bag samples were mixed with clean air to dilute the bag concentration. This was done to avoid excessively high "residuals," which were thought to occur most often with in a specific range of concentrations. For that reason, the sampling bag was mixed with 3:1 with air when Freq ${ }_{\text {HoodFan }}=40 \mathrm{~Hz}$ or $55 \mathrm{~Hz}$ and with 6:1 air when Freq HoodFan $_{\text {n }}$ $=23 \mathrm{~Hz}$.

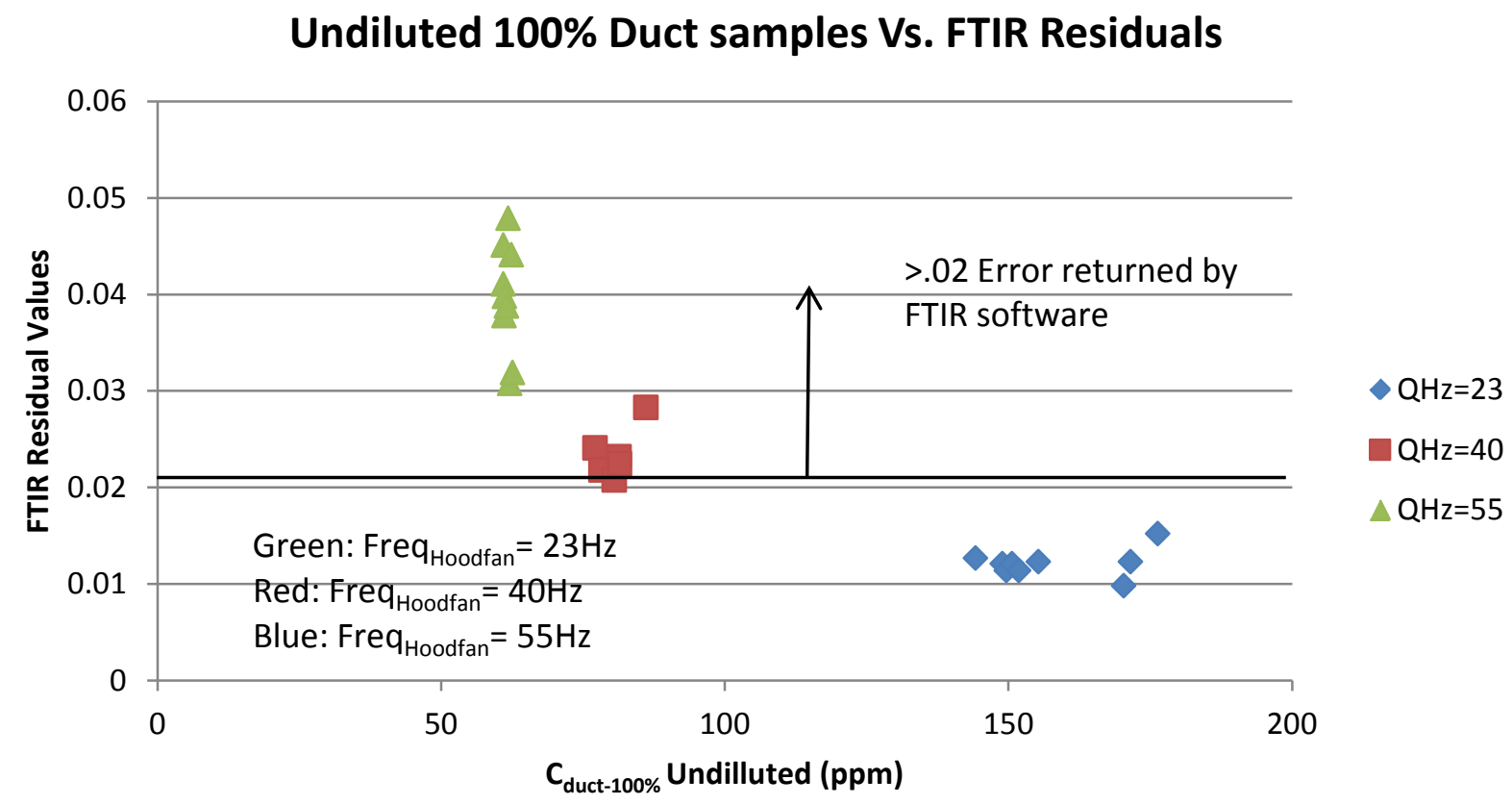

Figure 6-1. Undiluted $100 \%$ duct sample results and the corresponding residual value given by the FTIR, error statements were applied at residual $>0.02$. 


\section{Diluted 100\% Duct samples Vs. FTIR Residuals}

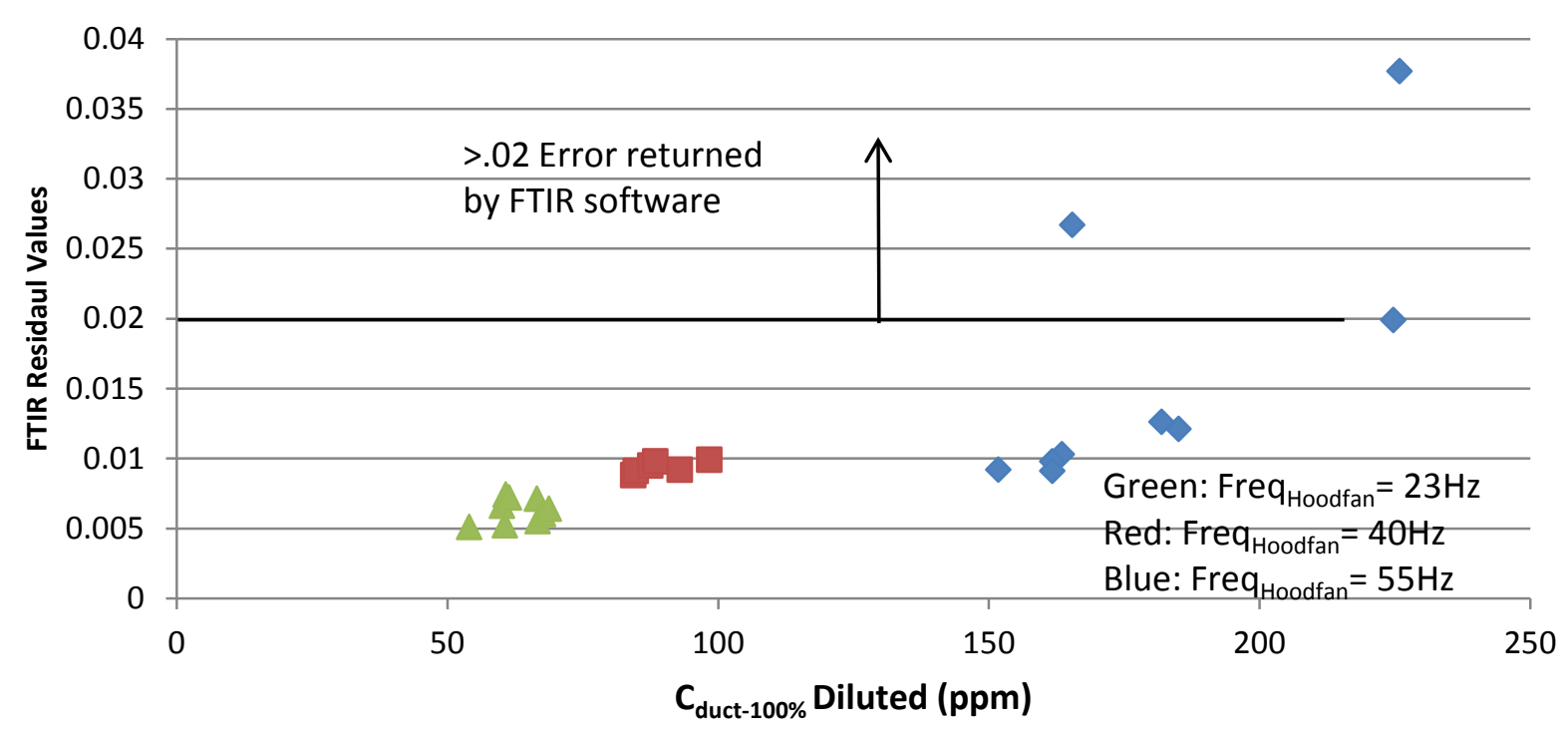

Figure 6-2. Diluted $100 \%$ duct sample results and the corresponding residual values given by the FTIR, not all values show are used in data analysis.

As a check, the sampling bag concentrations were analyzed both before and after dilution. As feared, the Gastec software indicated an error due to excessive residuals (i.e., $>0.02$ ) for all undiluted samples except those measured when Freq HoodFan $=23 \mathrm{~Hz}$, see Figure 6-1. In those cases only the diluted sample results were used in further analyses. Fortunately, no excessive residuals were reported for the diluted samples, see Figure 6-2. Thus for later analyses, undiluted sample results were used for samples where Freq $_{\text {Hoodfan }}=23 \mathrm{~Hz}$ and diluted sample results were used for Freq HoodFan $=40$ and $55 \mathrm{~Hz}$.

\subsection{Results}

The results are shown in Table 6-1. The capture efficiency values ( $\left.\eta_{\mathrm{e}-\mathrm{G}}\right)$ were computed from $C_{\text {duct, }}, G$, and $Q$ using Equation 1-2. 
Table 6-1. 100\% capture study results.

\begin{tabular}{|c|c|c|c|c|}
\hline $\begin{array}{c}\text { Freq }_{\text {HoodFan, }} \\
\mathrm{Hz}\end{array}$ & $\begin{array}{l}V_{\text {cross }} \\
\text { fpm }\end{array}$ & $\begin{array}{c}Q \\
\text { cfm }\end{array}$ & $\begin{array}{c}C_{\text {duct-100\%, }} \\
\text { ppm }\end{array}$ & $\begin{array}{l}\eta_{e-G} \\
(\%)\end{array}$ \\
\hline 23 & 10 & 438.3 & 176.4 & 121.8 \\
\hline 23 & 10 & 432.0 & 150.6 & 102.2 \\
\hline 23 & 10 & 421.4 & 151.9 & 100.8 \\
\hline 23 & 10 & 438.8 & 149.7 & 103.5 \\
\hline 23 & 10 & 436.5 & 144.2 & 99.2 \\
\hline 23 & 60 & 366.8 & 149.0 & 85.9 \\
\hline 23 & 60 & 375.6 & 155.3 & 91.9 \\
\hline 23 & 60 & 382.6 & 171.6 & 103.4 \\
\hline 23 & 60 & 373.5 & 170.4 & 100.3 \\
\hline Average & & & 157.7 & 101.0 \\
\hline 40 & 10 & 794.2 & 88.4 & 109.8 \\
\hline 40 & 10 & 791.1 & 87.4 & 108.9 \\
\hline 40 & 10 & 794.7 & 98.4 & 123.2 \\
\hline 40 & 60 & 763.0 & 84.8 & 101.9 \\
\hline 40 & 60 & 760.3 & 84.4 & 100.9 \\
\hline 40 & 60 & 764.8 & 92.9 & 111.7 \\
\hline Average & & & 89.4 & 109.4 \\
\hline 55 & 10 & 1112.7 & 60.1 & 105.3 \\
\hline 55 & 10 & 1103.6 & 61.4 & 106.6 \\
\hline 55 & 10 & 1119.0 & 68.7 & 121.2 \\
\hline 55 & 10 & 1111.6 & 66.7 & 116.8 \\
\hline 55 & 10 & 1118.9 & 54.1 & 95.2 \\
\hline 55 & 60 & 1094.4 & 60.8 & 104.6 \\
\hline 55 & 60 & 1094.6 & 66.6 & 114.7 \\
\hline 55 & 60 & 1098.0 & 67.7 & 117.0 \\
\hline 55 & 60 & 1091.7 & 60.6 & 104.2 \\
\hline Average & & & 63 & 109.5 \\
\hline
\end{tabular}

The measured concentration of Freon in the duct decreased exponentially with increasing levels of $Q$ (see Figure 6-3), as expected. One would expect $V_{\text {cross }}$ to have no direct effect on $C_{\text {duct-100\%. }}$. However, higher values of $V_{\text {cross }}$ are necessarily associated with higher static pressures inside the wind tunnel, which serves to reduce the airflows produced by the hood fan at any given

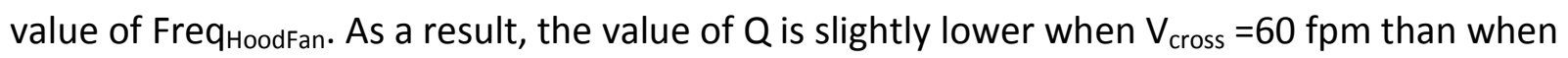
$V_{\text {cross }}=10 \mathrm{fpm}$. With $100 \%$ capture the concentrations should be determined only by the level of $\mathrm{Q}$. Instead, there appears to be small but distinct effect of $\mathrm{V}_{\text {cross }}$ on values of $\mathrm{C}_{\text {duct- }-100 \% \text {. }}$ 


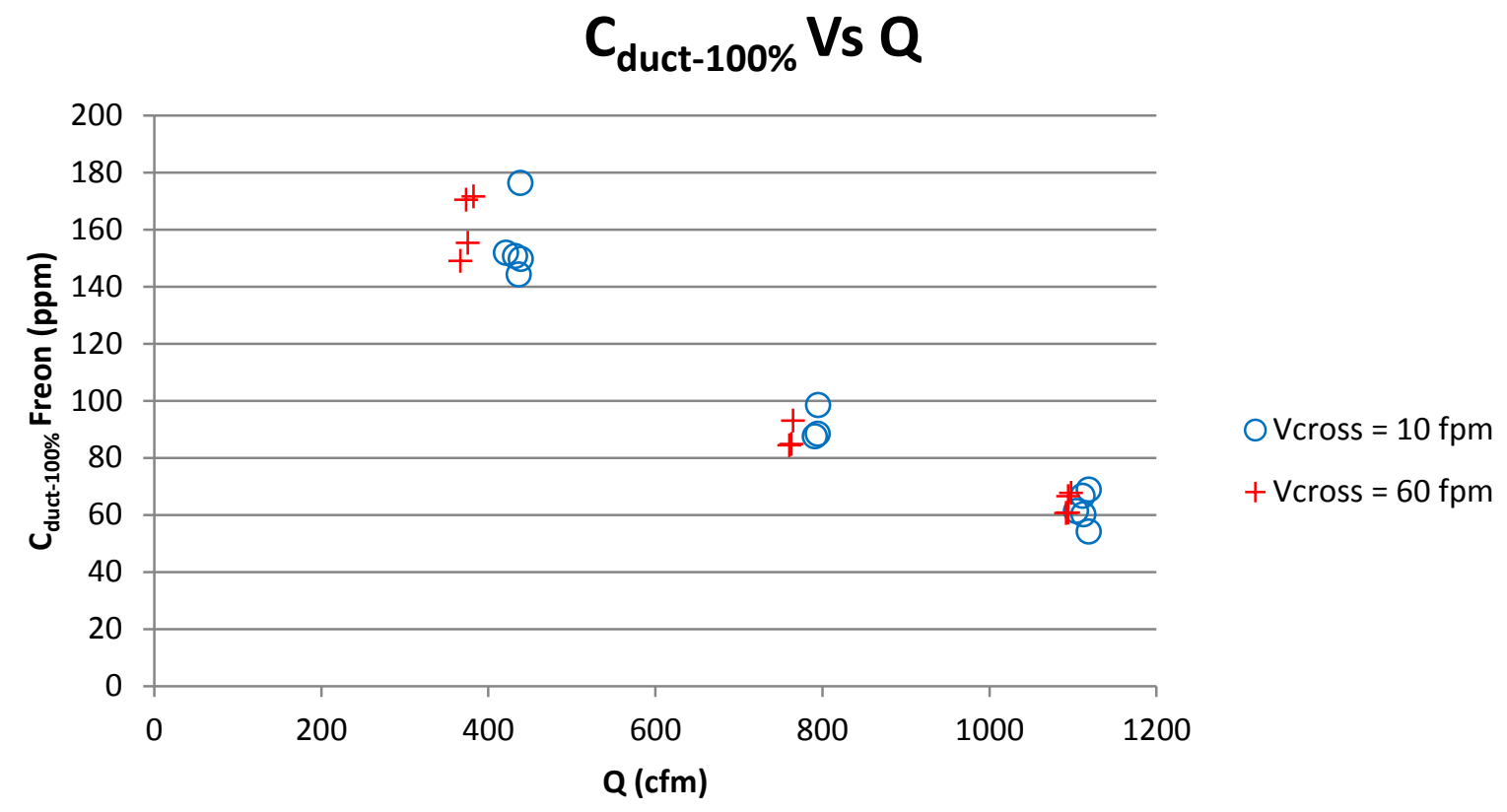

Figure 6-3. Diluted Freon duct samples from the $100 \%$ duct tests

\section{\% Capture Efficiency Calculated from G}

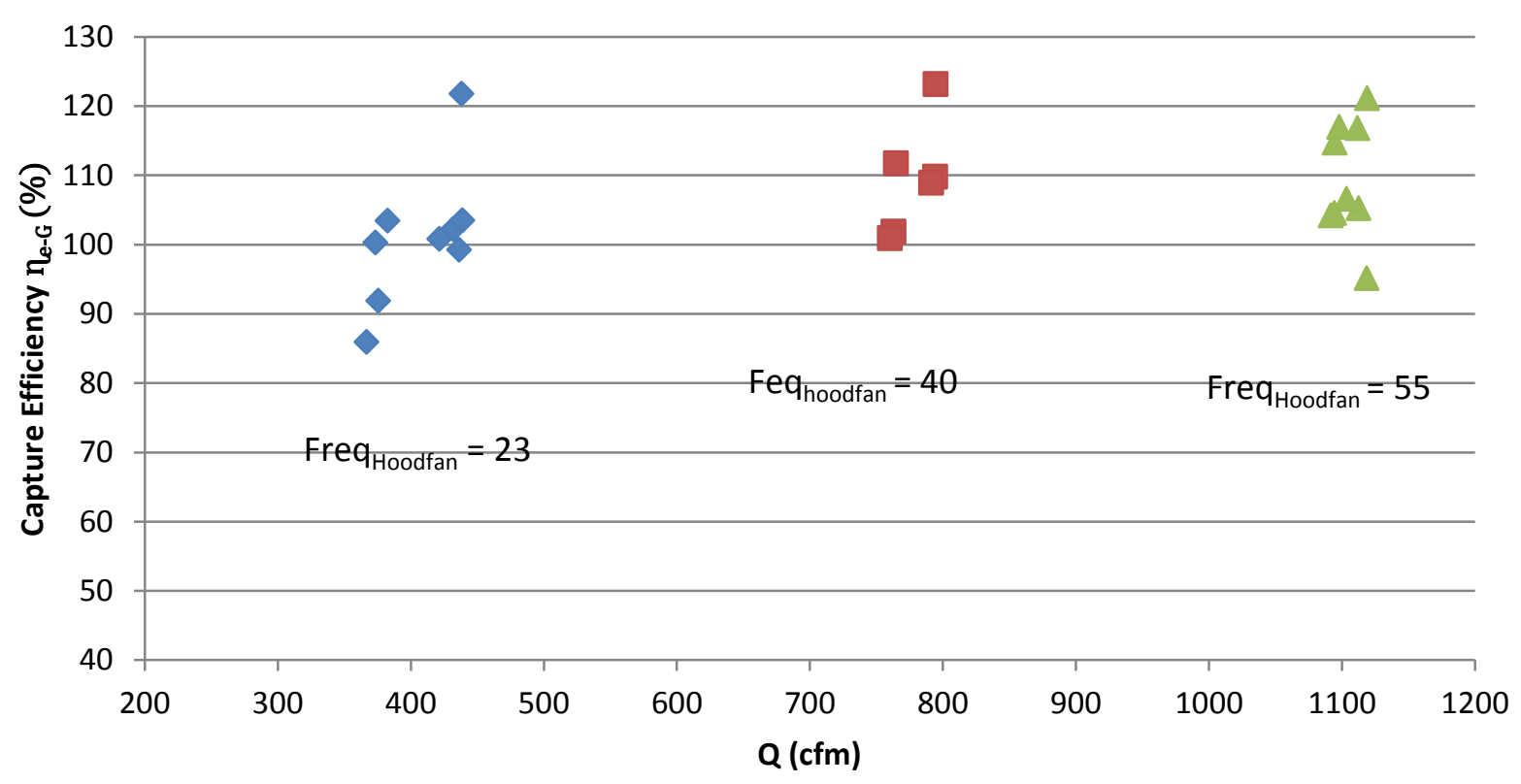

Figure 6-4. Unadjusted capturing efficiency for the $100 \%$ duct study calculated using Equation 1-2 


\subsection{Discussion}

Figure 6-4 graphs the capture efficiencies as computed by Equation 1-2, for which the numerator has values of $C_{\text {duct-100\% }}$ and the denominator has values of the measured release rate (G) of Freon-134a and $Q$. This measure is based on mass balance, the true ratio must be unity. Nevertheless, as shown in Figure 6-4, the ratios were in the range of $83-122 \%$, indicating very high variability (0.094) and a mean value of $106.3 \%$.

The observed mean is greater than unity. However, the $90 \%$ confidence interval of the mean is 90-122\%. Since that range includes unity, one cannot safely dismiss the possibility that the true mean is unity. In short, the coefficient of variation of $9 \%$ is high enough that the efficiency here must be considered to be a very imprecise tool but it is not necessarily an inaccurate one.

Investigations to determine the known errors for the elements of the procedure have not revealed the source of this high variability and impossibly high values of capture efficiency. The FTIR calibration showed a high degree of linearity $\left(R^{2}=99.5 \%, p\right.$ for slope $\left.<0.0001\right)$ and the coefficient of variation for $Q$ for the same conditions was less than $1.6 \%$. The mass flow device that measured and controlled the rate of release of the Freon-134a showed accurate and stable calibrations.

The remaining source of error is error in injecting Freon-134a in the creation of known concentrations for calibrations. However, since the original "calibration" of the unit has not been changed and comparisons to known concentrations of Freon 134a have shown remarkable accuracy and stability.

Table 6-2. Statistics for the Freon concentrations measured during the $100 \%$ capture tests

\begin{tabular}{|c|c|c|c|c|c|c|c|c|}
\hline Freq $_{\text {HoodFan }}$ & $\begin{array}{c}\text { Avg } Q \\
\text { cfm }\end{array}$ & Count & $\begin{array}{c}\text { Mean } \\
\text { ppm }\end{array}$ & $\begin{array}{c}\text { Median } \\
\text { ppm }\end{array}$ & Variance & StdDev & $\begin{array}{c}\text { Range } \\
\text { ppm }\end{array}$ & StdErr \\
\hline 23 & 407 & 9 & 157.66 & 151.9 & 139.0 & 11.79 & 32.11 & 3.93 \\
\hline 40 & 778 & 6 & 89.38 & 87.9 & 28.97 & 5.38 & 14.04 & 2.20 \\
\hline 55 & 1105 & 9 & 62.97 & 61.4 & 22.82 & 4.78 & 14.68 & 1.60 \\
\hline Overall & 762 & 24 & 105 & 87.9 & 1902.42 & 43.62 & 122.28 & 8.9 \\
\hline
\end{tabular}




\subsection{Conclusions}

Under perfect conditions the capturing hood should have mean $\eta_{\mathrm{e}-\mathrm{G}}$ of $100 \%$. However, the actual mean for $\eta_{\text {e-G }}$ during the $100 \%$ capture study was $106.3 \%$. The source of this error is unknown. It is not clear if the results are inaccurate, though they are certainly imprecise. However, since later determinations of efficiency will also show values well in excess of $100 \%$, the analyses in following chapters will assume a constant $6.3 \%$ error and adjust for it. 


\section{CHAPTER 7: PRELIMINARY STUDY THREE}

In regression analyses it is important to know whether independent variables are independent and if not, to what degree they are mutually dependent. In the main study it is useful to consider $\mathrm{Q}$ and $\mathrm{V}_{\text {cross }}$ as independent variables, yet previous results have shown that $\mathrm{Q}$ actually varies slightly with changes in $\mathrm{V}_{\text {cross }}$ due to the higher negative pressures in the wind tunnel associated with higher values of $\mathrm{V}_{\text {cross, }}$, see Figure 7-1.

In the all studies, the investigator set two fan controller settings (1) to achieve the desired air flow through the capturing hood $(\mathrm{Q})$ and $(2)$ to achieve the desired cross draft velocity through the wind tunnel $\left(\mathrm{V}_{\text {cross }}\right)$. $\mathrm{Q}$ was determined by 3 different prescribed frequencies (Freq $\mathrm{Hoodfan}_{\text {) }}$ which were inputted into the capturing hood fan controller. $V_{\text {cross }}$ was controlled by setting the wind tunnel fan controller to 2 different rotation rates (Rotate $\left.{ }_{W T f a n}\right)$. Hence, Rotate WTfan $_{\text {and }}$ Freq $_{\text {Hoodfan }}$ are completely independent. Thus, ANOVA was performed with $Q$ as the dependent variable and with Rotate $\mathrm{WTfan}_{\mathrm{n}}$ and Freq $_{\text {Hoodfan }}$ as the independent variables using a fixed-effect model. The goal is to determine the degree that $Q$ depends on its own controller frequency $\left(\right.$ Freq $\left.{ }_{\text {Hoodfan }}\right)$ and the degree it depends on the $V_{\text {cross }}$ controller value (Rotate $\left.{ }_{W T f a n}\right)$, which causes a higher static pressure in the wind tunnel.

Data from Preliminary Study Two and the Main Study was used for analysis in the study. Q

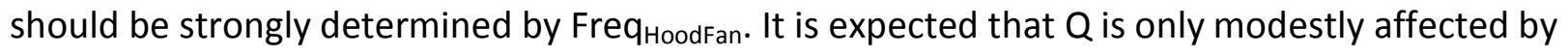
Rotate $_{W T f a n}$. If the latter is proved true, then in the main study $\mathrm{Q}$ and $\mathrm{V}_{\text {cross }}$ can be assumed to be largely independent. 


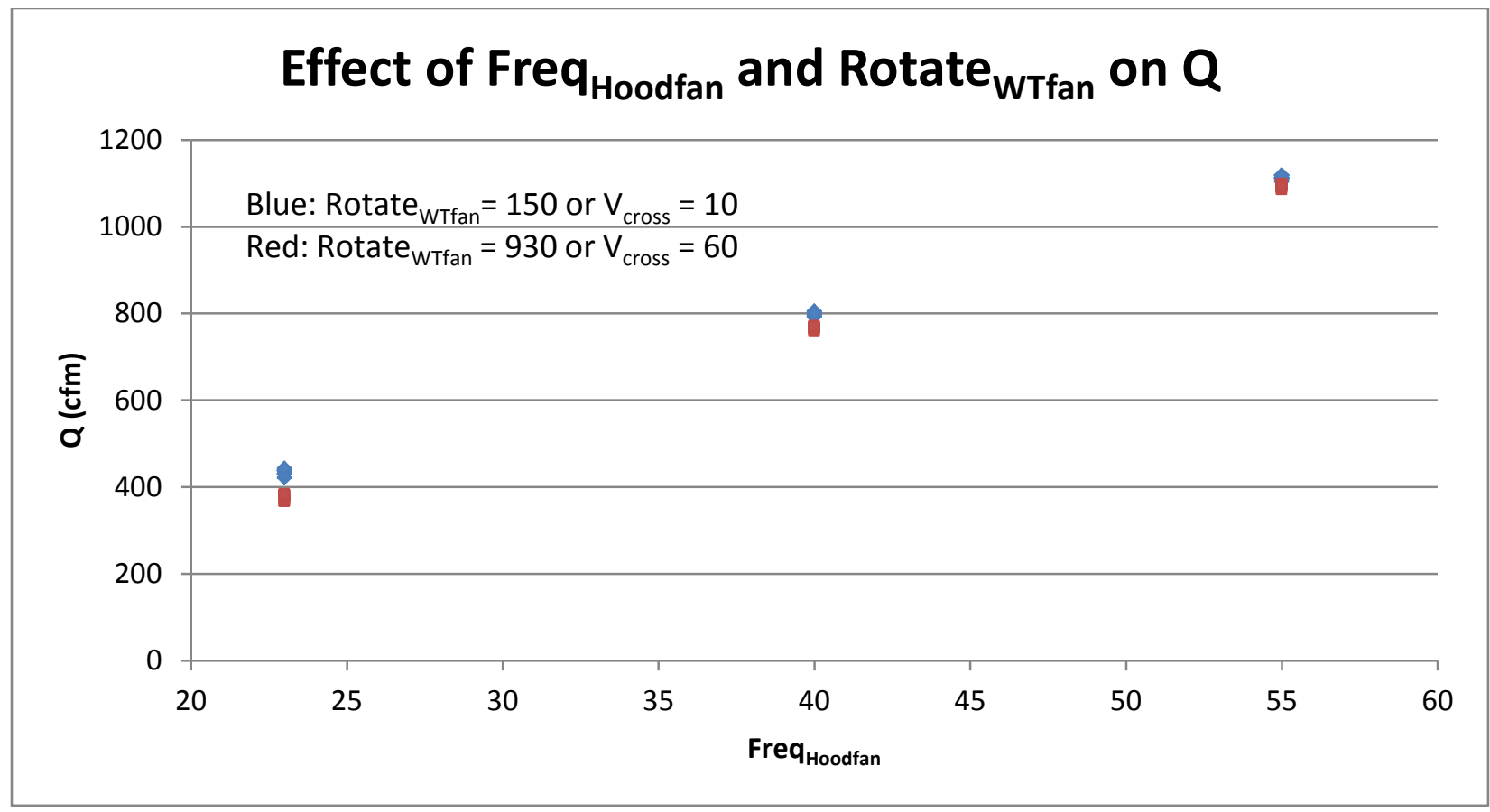

Figure 7-1. Effect of Rotate ${ }_{\mathrm{Wffan}}$ on $\mathrm{Q}$

Table 7-1. Fixed-effect Analysis of Variance for dependent variable $Q$

\begin{tabular}{lccccc} 
Source & df & $\begin{array}{c}\text { Sums of } \\
\text { Squares }\end{array}$ & $\begin{array}{c}\text { Mean } \\
\text { Square }\end{array}$ & F-ratio & Prob \\
\hline Constant & 1 & $2.80 \mathrm{E}+07$ & $2.80 \mathrm{E}+07$ & $2.73 \mathrm{E}+05$ & $\leq 0.0001$ \\
Freq $_{\text {HoodFan }}$ & 2 & $4.14 \mathrm{E}+06$ & $2.07 \mathrm{E}+06$ & 72789 & $\leq 0.0001$ \\
Rotate $_{\text {WTfan }}$ & 1 & 15710 & 15710 & 553 & $\leq 0.0001$ \\
Freq $_{\text {HoodFan }}{ }^{*}$ Rotate $_{\mathrm{WTfan}}$ & 2 & 3317.8 & 1659 & 58.383 & $\leq 0.0001$ \\
Error & 42 & 1193 & 28 & & \\
Total & 47 & $4.16 \mathrm{E}+06$ & & &
\end{tabular}

$$
\text { ANOVA Model: } Y=\mu+\alpha_{i}+\beta_{j}+\alpha \beta_{i j}+\varepsilon_{i j}
$$

$$
\begin{aligned}
& \text { Where: } \quad \alpha=\text { Effect of Freq }{ }_{\text {Hoodfan }} \\
& \beta=\text { Effect of Rotate }{ }_{W T f a n} \\
& \alpha \beta=\text { Effect of interaction between } \text { Freq }_{\text {Hoodfan }} \text { and Rotate }{ }_{W T f a n}
\end{aligned}
$$

\subsection{Results}

As shown in Figure 7-1, $Q$ was changed by a discernible but small amount by $V_{\text {cross. }}$. Fixed-effect ANOVA results (see Table 7-1) show statistical significance $(p<0.0001)$ for Freq Hoodfan, $_{\text {, }}$ Rotate $_{\text {WTfan }}$ and their interaction, the model is highly linear $\left(R^{2}=99.97\right)$. A large proportion of the 
variation is explained by Freq $_{\text {Hoodfan }}(99.5 \%)$ while Rotate ${ }_{W T f a n}$ and the interaction term only explain a small proportion of the variation (0.4\%), given the model used. These results support the contention that values of $Q$ are only modestly affected by Rotate ${ }_{W T f a n}$ and subsequently $\mathrm{V}_{\text {cross. }}$

In conclusion, as expected the observed $Q$ is only modestly, but significantly, dependent of Rotate $\mathrm{WTfan}_{\mathrm{T}}$ and therefore $\mathrm{V}_{\text {cross. }}$. Thus, all analysis performed in this study uses a nominal value for $Q\left(Q_{\text {nom }}\right)$ based on the average observed $Q$ for each level of Freq Hoodfan $_{\text {to avoid }}$ interdependence of independent variables. 


\section{CHAPTER 8: MAIN STUDY RESULTS}

The purpose of the main study was to determine the effects of the independent variables $Q$, $\mathrm{V}_{\text {cross, }}$ and Flange on $\mathrm{C}_{\text {mouth }}, \mathrm{C}_{\text {nose }}$, and $\mathrm{C}_{\text {duct }}$.

Freon 134a concentrations were measured at the mouth $\left(C_{\text {mouth }}\right)$ and nose $\left(C_{\text {nose }}\right)$ of the manikin as well as inside the duct $\left(\mathrm{C}_{\text {duct }}\right)$ while the tracer gas mixture was released at the source in front of the capturing hood. The study was a complete randomized factorial design, including $Q$ observed at 3 levels of Freq $\mathrm{HoodFan}_{1} \mathrm{~V}_{\text {cross }}$ based on two levels of wind tunnel fan rotation rate (Rotate $\left.{ }_{W T f a n}\right)$, and 2 levels of Flange (present and not present). All conditions were tested twice in a single random order.

As demonstrated in Preliminary Study Two, the airflow exhausted through the hood (Q) was affected by Freq ${ }_{\text {HoodFan }}$ and, to a lesser degree, Rotate ${ }_{W T f a n}$. Hence, $\mathrm{Q}$ and $\mathrm{V}_{\text {cross }}$ are mutually dependent, however, the effect of $V_{\text {cross }}$ on $Q$ is small.

Table 8-1. Main study Freon concentrations for each level of independent variable.

\begin{tabular}{|c|c|c|c|c|c|c|c|c|}
\hline $\begin{array}{c}\text { Freq }_{\text {HoodFan, }} \\
\mathrm{Hz}\end{array}$ & $\underset{\mathrm{cfm}}{Q}$ & $\begin{array}{l}V_{\text {cross }} \\
\text { fpm }\end{array}$ & Flange & $\begin{array}{l}C_{\text {duct }} \\
\text { ppm }\end{array}$ & $\begin{array}{c}C_{\text {mouth }} \\
\text { ppm }\end{array}$ & $\begin{array}{l}C_{\text {nose }} \\
\text { ppm }\end{array}$ & $\begin{array}{c}\text { Calculated } \\
\eta_{\mathrm{e}-\mathrm{G}}\end{array}$ & $\begin{array}{l}\text { Calculated } \\
\eta_{\mathrm{e}-100 \% \text { duct }}\end{array}$ \\
\hline 23 & 438.9 & 10 & No & 148.89 & 0.106 & 0.115 & $96.70 \%$ & $94.44 \%$ \\
\hline 23 & 429.3 & 10 & No & 151.18 & 0.122 & 0.120 & $96.00 \%$ & $95.89 \%$ \\
\hline 23 & 430.1 & 10 & Yes & 151.83 & 0.132 & 0.133 & $96.61 \%$ & $96.31 \%$ \\
\hline 23 & 443.1 & 10 & Yes & 150.10 & 0.131 & 0.143 & $98.52 \%$ & $95.21 \%$ \\
\hline 23 & 379.3 & 60 & No & 172.75 & 0.134 & 0.161 & $96.99 \%$ & $109.57 \%$ \\
\hline 23 & 383.0 & 60 & No & 168.60 & 0.838 & 1.001 & $95.46 \%$ & $106.94 \%$ \\
\hline 23 & 368.5 & 60 & Yes & 173.26 & 0.141 & 0.140 & $94.34 \%$ & $109.90 \%$ \\
\hline 23 & 379.9 & 60 & Yes & 171.98 & 0.138 & 0.177 & $96.68 \%$ & $109.09 \%$ \\
\hline Average & 406.5 & & & 161.07 & 0.218 & 0.249 & $96.41 \%$ & $102.17 \%$ \\
\hline 40 & 796.9 & 10 & No & 84.44 & 0.120 & 0.280 & $99.70 \%$ & $94.47 \%$ \\
\hline 40 & 800.4 & 10 & No & 85.68 & 0.105 & 0.114 & $101.75 \%$ & $95.86 \%$ \\
\hline 40 & 803.9 & 10 & Yes & 86.73 & 0.101 & 0.121 & $103.55 \%$ & $97.02 \%$ \\
\hline 40 & 804.9 & 10 & Yes & 92.37 & 0.104 & 0.112 & $110.85 \%$ & $103.34 \%$ \\
\hline 40 & 767.8 & 60 & No & 96.44 & 0.125 & 0.144 & $110.34 \%$ & $107.88 \%$ \\
\hline 40 & 771.5 & 60 & No & 83.01 & 0.115 & 0.102 & $94.59 \%$ & $92.87 \%$ \\
\hline 40 & 768.0 & 60 & Yes & 90.26 & 0.118 & 0.117 & $102.90 \%$ & $100.98 \%$ \\
\hline 40 & 769.0 & 60 & Yes & 91.88 & 0.104 & 0.134 & $105.02 \%$ & $102.79 \%$ \\
\hline Average & 785.3 & & & 88.85 & 0.112 & 0.141 & $103.59 \%$ & $99.40 \%$ \\
\hline
\end{tabular}




\begin{tabular}{ccccccccc}
55 & 1108.4 & 10 & No & 61.78 & 0.123 & 0.117 & $101.49 \%$ & $98.11 \%$ \\
55 & 1111.5 & 10 & No & 64.25 & 0.091 & 0.098 & $106.17 \%$ & $102.03 \%$ \\
55 & 1117.7 & 10 & Yes & 67.58 & 0.122 & 0.123 & $112.66 \%$ & $107.33 \%$ \\
55 & 1113.8 & 10 & Yes & 64.54 & 0.119 & 0.120 & $106.92 \%$ & $102.50 \%$ \\
55 & 1086.1 & 60 & No & 67.80 & 0.125 & 0.129 & $109.64 \%$ & $107.67 \%$ \\
55 & 1090.9 & 60 & No & 63.50 & 0.129 & 0.141 & $102.75 \%$ & $100.84 \%$ \\
55 & 1095.5 & 60 & Yes & 65.34 & 0.119 & 0.125 & $106.39 \%$ & $103.77 \%$ \\
55 & 1098.6 & 60 & Yes & 67.14 & 0.104 & 0.112 & $109.86 \%$ & $106.63 \%$ \\
Average & 1102.8 & & & 65.24 & 0.117 & 0.121 & $106.99 \%$ & $103.61 \%$ \\
\multicolumn{2}{l}{ Overall Average } & & & & 0.153 & 0.170 & $102.33 \%$ & $101.73 \%$
\end{tabular}

\subsection{Protection Efficiency Results}

Freon concentrations at the manikin's mouth $\left(C_{\text {mouth }}\right)$ and nose $\left(C_{\text {nose }}\right)$ were not corrected by subtracting the measured value of $C_{\text {ambient }}$ from each test for a few reasons. One is that the Freon concentrations are very low, most values would be adjusted to zero or negative values (see Figure 8-1 and Figure 8-2). Second is that even without correction, it is clear that the concentrations are very low. Third is that measured values of $C_{a m b i e n t}$ were all between 0.034 ppm and $0.132 \mathrm{ppm}$ with a mean of $0.115 \mathrm{ppm}$, meaning that there was little build-up of Freon in the laboratory. Since Freon is not a common air contaminant, the Freon in the lab's ambient air is due to contaminants that have escaped from the capturing hood and have been mixed with the ambient air in the lab. One would reasonably expect $C_{a m b i e n t}$ to be much lower than $\mathrm{C}_{\text {mouth }}$ and $\mathrm{C}_{\text {nose }}$. The effect of Freon in the laboratory air may have been considered important if $\mathrm{C}_{\text {ambient }}$ was higher or more variable.

As shown in Table 8-1, Figure 8-1 and Figure 8-2, the Freon concentrations in the breathing zone of the manikin $\left(C_{\text {mouth }}\right.$ and $C_{\text {nose }}$ ) for each test were all below $1 \mathrm{ppm}$. All but one value for $\mathrm{C}_{\text {mouth }}$ and $\mathrm{C}_{\text {nose }}$ were above $0.2 \mathrm{ppm}$, a trivially low value only marginally higher than the room air concentration in the lab. Considering the very high Freon generation rate $(1.79 \mathrm{lpm})$ and the extremely high concentration of Freon at the source (roughly 370,000 ppm), the capturing hood's protection was very nearly perfect (see Figure 8-3). 


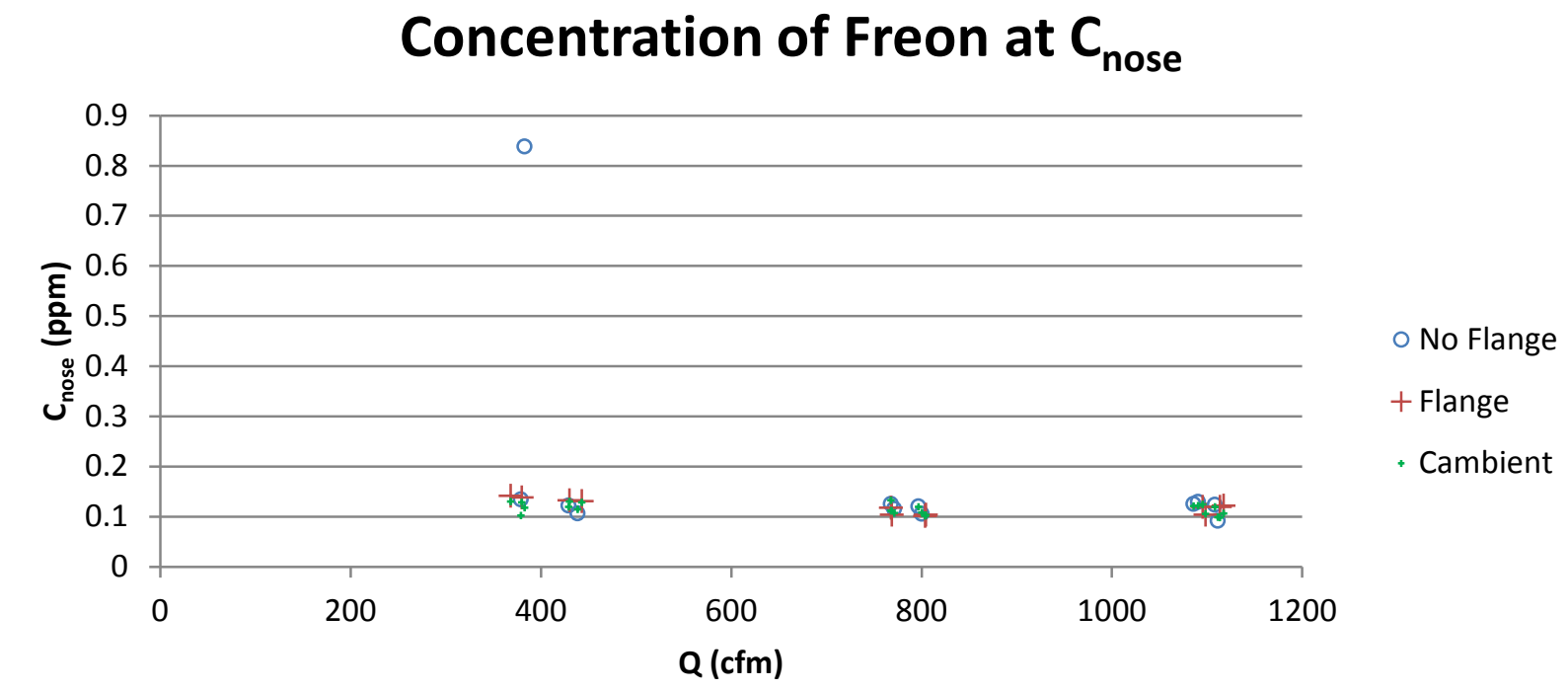

Figure 8-1. Measured Freon concentrations at the nose of the manikin and ambient locations for $Q$ and Flange

\section{Concentration of Freon at $\mathrm{C}_{\text {mouth }}$}

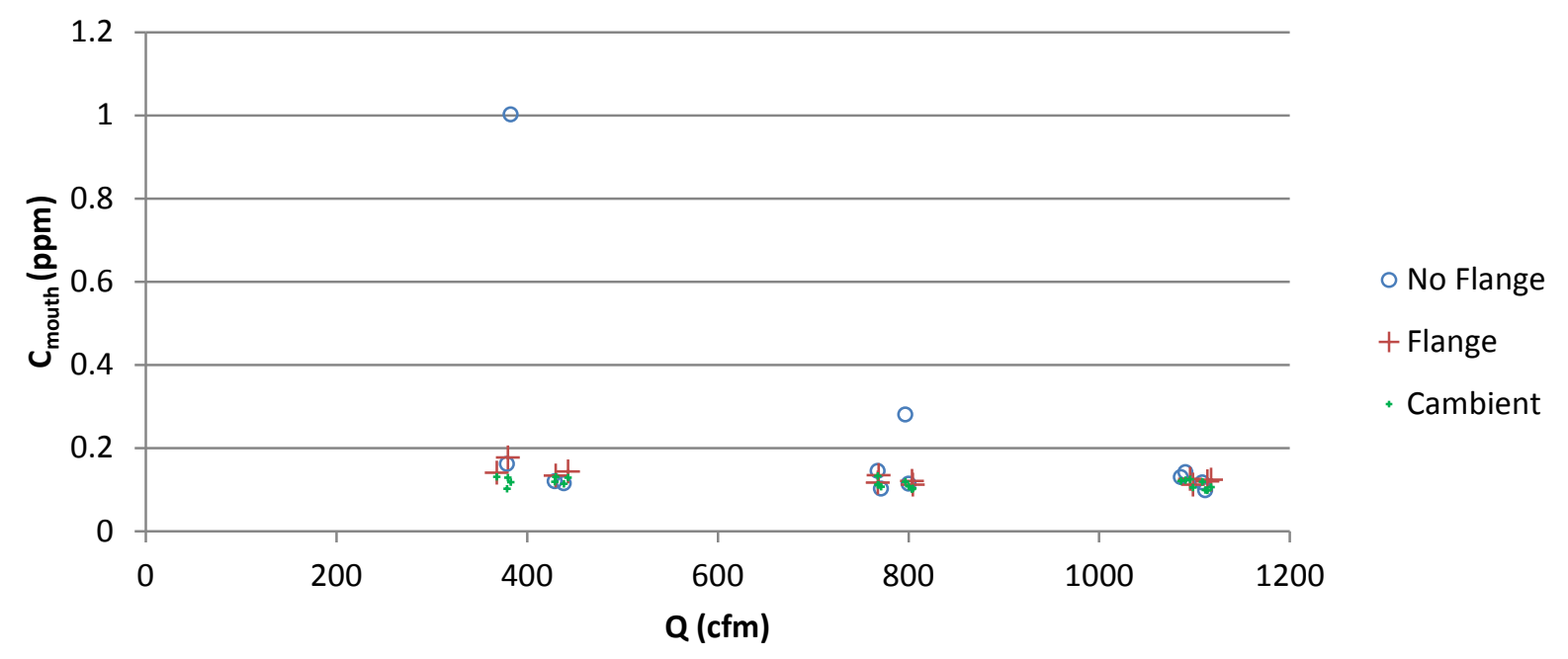

Figure 8-2. Measured Freon concentrations at the mouth of the manikin and ambient locations for $Q$ and Flange

As discussed in Chapter 1, there are several ways to calculate the protection efficiency (PE), none of which is ideal. Considering the concentration of Freon measured at $C_{\text {nose }}$ and $C_{\text {mouth }}$ the 
$P E$ is expected to be extremely high. The calculations for $P E_{G}$ (Equation 1-5) and $P E_{\text {duct }}$ (Equation 1-4) are presented here and are as expected, very high.

Table 8-2. Descriptive statistics for two measure of PE

\begin{tabular}{lrr} 
& \multicolumn{1}{c}{$\mathbf{P E}_{\mathbf{G}}$} & \multicolumn{1}{c}{$\mathbf{P E}_{\text {duct }}$} \\
\cline { 2 - 3 } Mean & $100 \%$ & $99.85 \%$ \\
Median & $100 \%$ & $99.86 \%$ \\
Std Dev & $4.77 \mathrm{E}-07$ & 0.000857 \\
Range & $2.4 \mathrm{E}-04 \%$ & $4.26 \%$ \\
Minimum & $99.997 \%$ & $99.5 \%$ \\
Maximum & $100 \%$ & $99.93 \%$
\end{tabular}

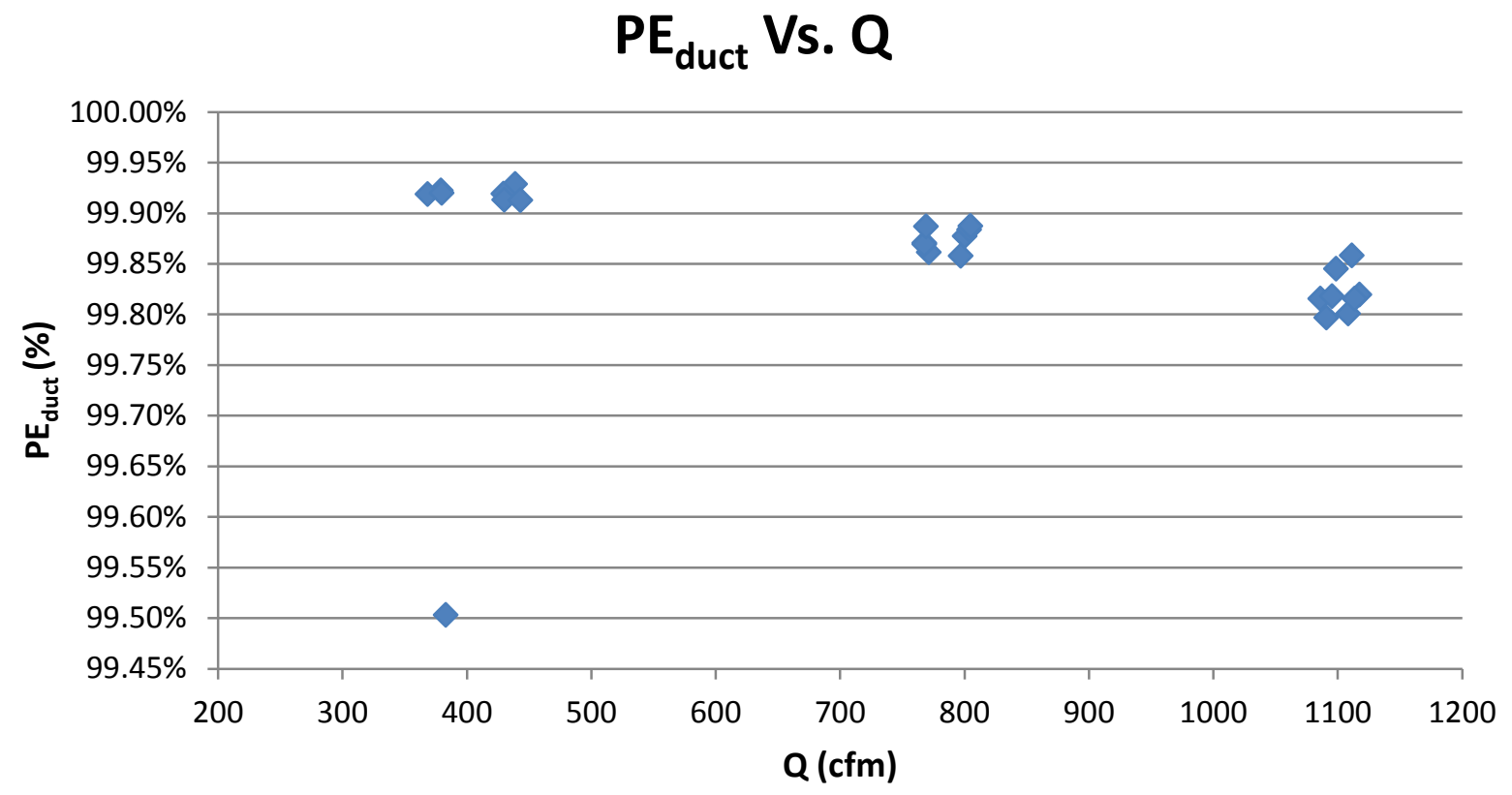

Figure 8-3. Protection efficiency based on $\mathrm{C}_{\text {duct }}$ 


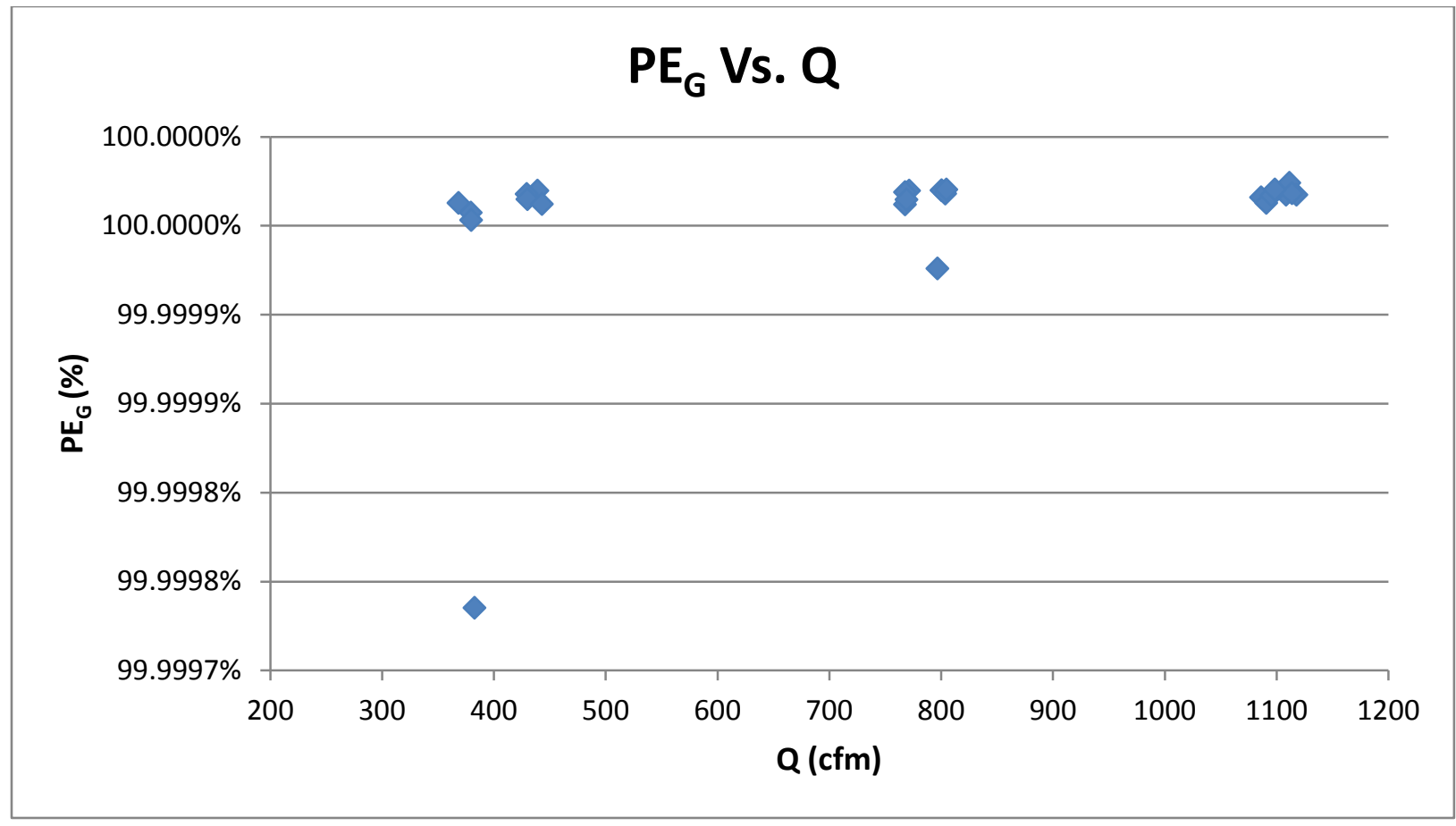

Figure 8-4. Protection efficiency based on G

\subsection{Capture Efficiency Results}

The capture efficiency is an important measure of hood performance because it evaluates the amount of contaminant that the hood will allow to escape into the work environment. It is not necessarily true that the extremely high protection efficiencies require extremely high capture efficiency. After all, the contaminant could simply be blown by $V_{\text {cross }}$ downstream of the manikin and the hood, thus providing low $C_{\text {mouth }}$ and $C_{\text {nose }}$ but poor capture efficiency.

Note that the measured $\mathrm{C}_{\text {duct }}$ values were not adjusted for ambient concentrations because ambient concentrations were all less than $1 \%$ of measured duct concentrations.

Capture efficiency, $\eta_{e}$, was calculated in two different ways for the Main Study. One was based on the generation rate of the tracer gas $\left(\eta_{\mathrm{e}-\mathrm{G}}\right)$ and Equation 1-2. The other was based on $\mathrm{C}_{\text {duct- }}$ 100\% $\left(\eta_{\mathrm{e}-\mathrm{duct} 100 \%}\right.$ ) and Equation 1-3. In Preliminary Study Two, $\eta_{\mathrm{e}-\mathrm{G}}$ was found to overestimate the true capture efficiency by $6.3 \%$. Thus, for the main study, values of $\eta_{\text {e-G }}$ were reduced by $6.3 \%$. 
In both cases the capture efficiency is partially based on observed values of $C_{\text {duct }}$. As shown in Figure 8-5, $C_{\text {duct }}$ fell exponentially with increasing levels of airflow. Note that $C_{\text {duct }}$ values for flanged and unflanged cases fell on the same curve, suggesting no improvement due to the flange. Hence, even though it was shown in Preliminary Study One that the flange increased $V_{x}$ by $23 \%$ to $102 \%$, it did not appear to improve $\eta_{\mathrm{e}}$.

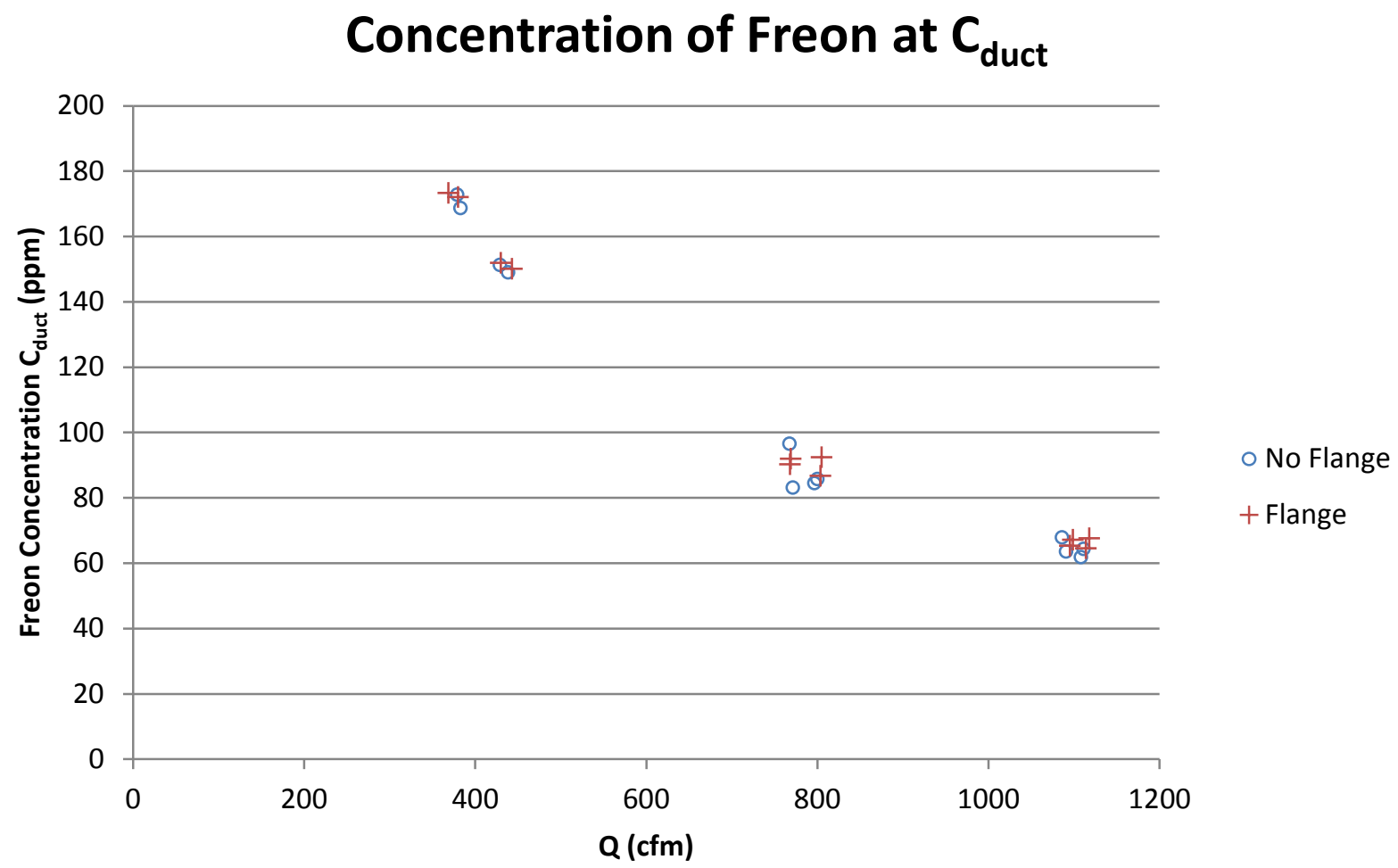

Figure 8-5. Measured Freon concentration in the duct when the tracer gas mixture was being released at the source for $Q$ and Flange. 


\section{Calculated Capture Efficiency ( $\left.\eta_{\mathrm{e}-\mathrm{duct} 100 \%}\right)$}

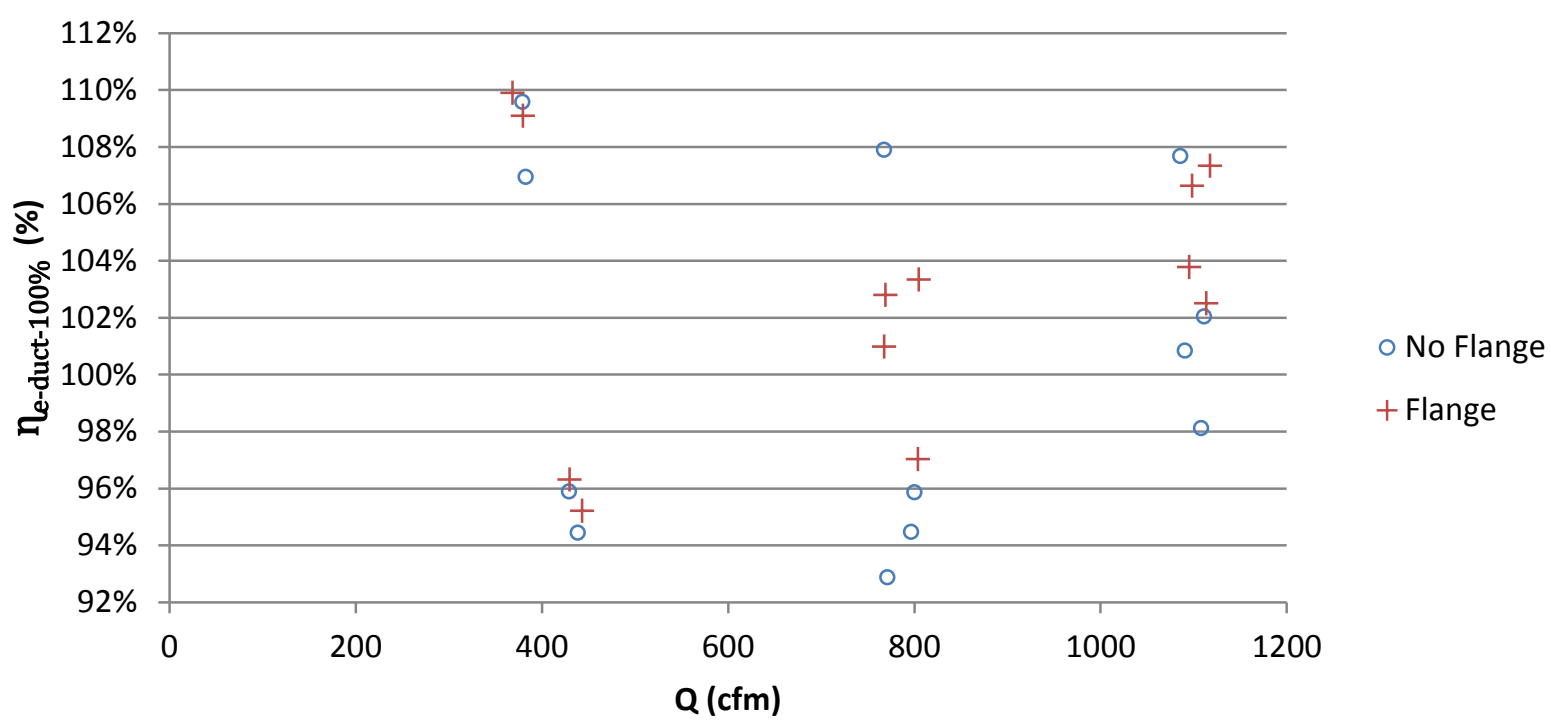

Figure 8-6. Calculated capture efficiency for $Q$ and Flange based on $C_{\text {duct-100\% }}$

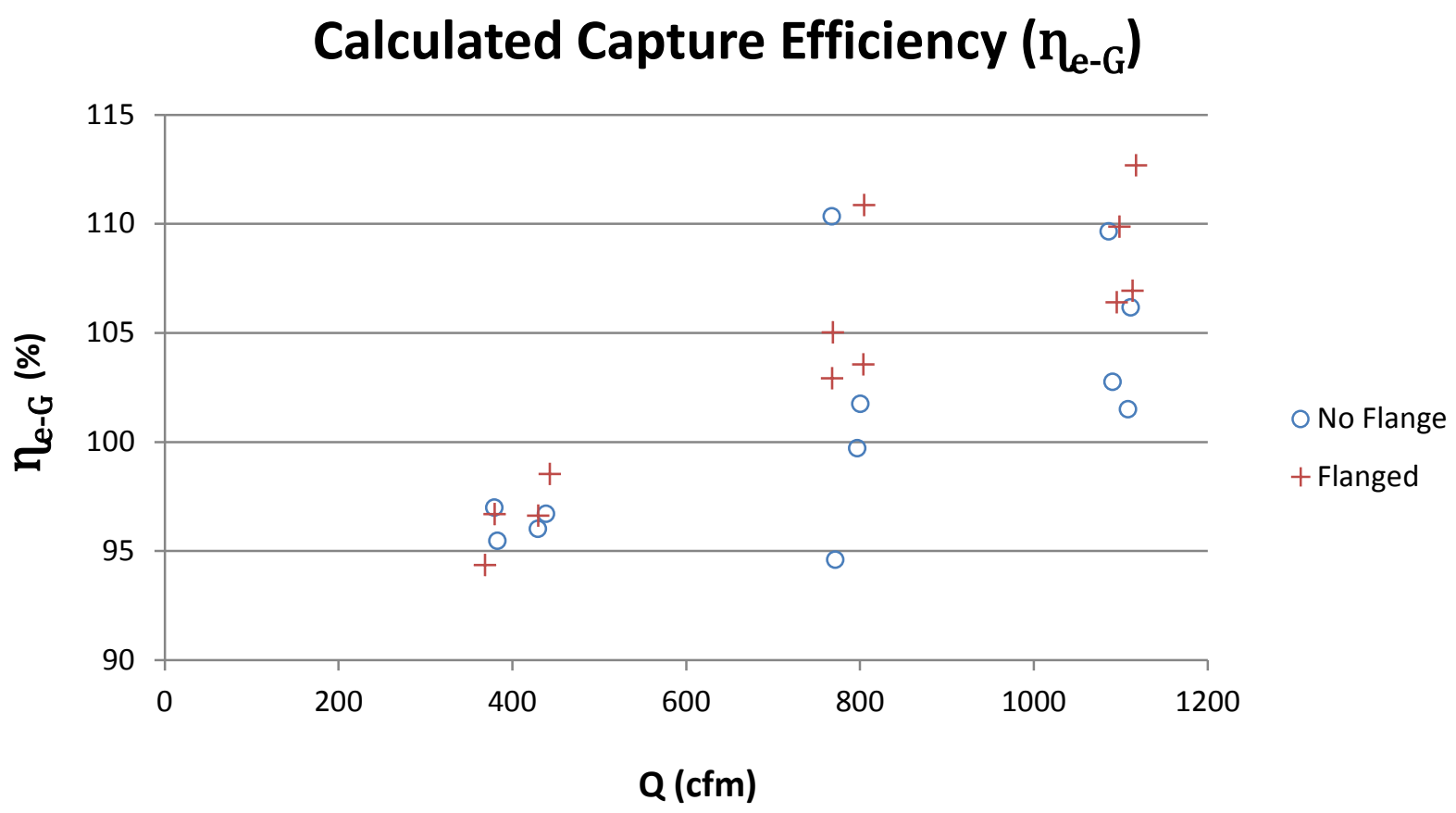

Figure 8-7. Calculated capture efficiency for $Q$ and Flange based on $G$. 


\section{CHAPTER 9: DISCUSSION OF THE MAIN STUDY RESULTS}

The results suggest that the capturing hood was highly effective at controlling contaminant concentrations at the breathing zone of the manikin for all levels of the independent variables and in preventing escape into the room ambient air. However, there was a noticeable difference between the results for the two calculations of $\eta_{\mathrm{e}}$.

As stated in previous chapters, when performing ANOVA analysis the average $Q$ for each level

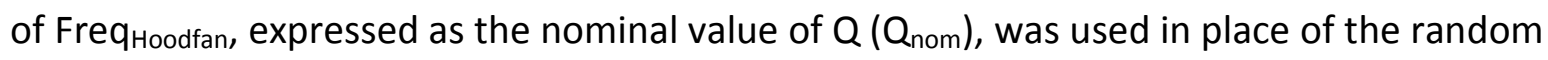
variable $\mathrm{Q}$ which is modestly dependent on $\mathrm{V}_{\text {cross. }}$.

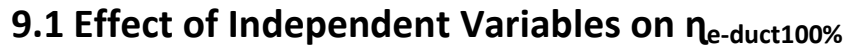

The capture efficiency was computed in two different ways. Using Equation 1-3, $\eta_{\text {e-duct100\% was }}$ computed as the ratio of $C_{\text {duct }}$ to the corresponding concentrations average $C_{\text {duct- }-100 \%}$ concentration shown in Table 6-2. The latter were measured in Preliminary Study Two when $100 \%$ capture was assured $\left(C_{\text {duct-100\% }}\right)$.

As shown in Table 8-1, $\eta_{\text {e-duct } 100 \%}$ values were greater than $92 \%$ for all conditions and $63 \%$ of the values exceeded $100 \%$. The average value was $101.7 \%$, despite being effectively normalized for the average $C_{\text {duct-100\% }}$ value found in preliminary study two (see Figure 6-1). 
Table 9-1. Fixed-effect Analysis of Variance for dependent variable $\eta_{\mathrm{e}-\text { duct } 100 \%}$

\begin{tabular}{ccrrrc} 
& Sf & $\begin{array}{c}\text { Sums of } \\
\text { Squares }\end{array}$ & $\begin{array}{c}\text { Mean } \\
\text { Square }\end{array}$ & \multicolumn{1}{c}{ F-ratio } & Prob \\
\hline Const & 1 & 248361.0 & 248361.0 & 18488.0 & $\leq 0.0001$ \\
$\mathrm{Q}_{\text {nom }}$ & 2 & 72.7 & 36.3 & 2.7 & 0.0992 \\
$\mathrm{~V}_{\text {cross }}$ & 1 & 243.3 & 243.3 & 18.1 & 0.0007 \\
Flange & 1 & 33.3 & 33.3 & 2.5 & 0.1363 \\
$\mathrm{Q}_{\text {nom }}{ }^{*} \mathrm{~V}_{\text {cross }}$ & 2 & 150.4 & 75.2 & 5.6 & 0.0153 \\
$\mathrm{Q}_{\text {nom }}$ Flange & 2 & 6.4 & 3.2 & 0.2 & 0.7911 \\
Error & 15 & 201.5 & 13.4 & & \\
Total & 23 & 707.6 & & &
\end{tabular}

$$
\begin{aligned}
& \text { ANOVA Model: } Y=\mu+\alpha_{i}+\beta_{j}+\gamma_{k}+\alpha \beta_{i j}+\alpha \gamma_{i k}+\varepsilon_{i j k l} \\
& \text { Where: } \quad \begin{aligned}
\alpha & =\text { Effect of } \mathrm{Q}_{\text {nom }} \\
\beta & =\text { Effect of Rotate }{ }_{W T f a n} \text { or } \mathrm{V}_{\text {cross }} \\
\gamma & =\text { Effect of Flange } \\
\alpha \beta & =\text { Effect of Interaction between } \mathrm{Q}_{\text {nom }} \text { and Rotate } \\
\alpha Y & =\text { Effect of Interaction between } \mathrm{Q}_{\text {nom }} \text { and Flange }
\end{aligned}
\end{aligned}
$$

Using ANOVA with a fix-effect model and $\eta_{\mathrm{e}-\mathrm{duct} 100 \%}$ as the dependent variable, the effect of $V_{\text {cross }}$ was the only variable found to be significant $(p=0.0007)$ based on the model used.

Surprisingly the effect of $\mathrm{V}_{\text {cross }}$ on $\eta_{\mathrm{e}-\mathrm{duct} 100 \%}$ was in the opposite direction than expected, with

$V_{\text {cross }}=10 \mathrm{fpm}$ causing a lower $\eta_{\text {e-duct100\% }}$ and $V_{\text {cross }}=60 \mathrm{fpm}$ causing a higher $\eta_{\text {e-duct100\% }}$ (see Table 8-1). It is reasonable to speculate that the cross draft carried the contaminant towards the hood face causing an increase in capture efficiency. If this explanation is correct, it is likely that if $V_{\text {cross }}$ was not oriented towards the hood face that the capturing efficiency would be much lower.

\subsection{Effect of Independent Variables on $\eta_{e-G}$}

Using Equation 1-2, $\eta_{e-G}$ was calculated using the observed air flow through the hood (Q), the generation rate $(G)$, and concentration of Freon measured in the duct $\left(C_{\text {duct }}\right)$. The results were then adjusted by subtracting $6.3 \%$ from each value. The latter was based on the Preliminary Study One results, which showed an average efficiency of $106.3 \%$ instead of the expected value 
of $100 \%$. As show in Table $8-1$, the resulting minimum efficiency was greater than $94 \%$. The average was $107 \%$ and the maximum was $112 \%$. Even with a downward adjustment the efficiencies were still impossibly high.

Table 9-2. Fixed-effect Analysis of Variance for $\eta_{\mathrm{e}-\mathrm{G}}$

\begin{tabular}{lrrrrr} 
Source & df & Sums of Squares & Mean Square & F-ratio & Prob \\
\hline Const & 1 & 251306.0 & 251306.0 & 15675.0 & $\leq 0.0001$ \\
$Q_{\text {nom }}$ & 2 & 466.1 & 233.0 & 14.5 & 0.0003 \\
$\mathrm{~V}_{\text {cross }}$ & 1 & 1.5 & 1.5 & 0.1 & 0.766 \\
Flange & 1 & 44.6 & 44.6 & 2.8 & 0.116 \\
$\mathrm{Q}_{\text {nom }} * V_{\text {cross }}$ & 2 & 2.3 & 1.1 & 0.1 & 0.9321 \\
$\mathrm{Q}_{\text {nom }} *$ Flange & 2 & 18.4 & 9.2 & 0.6 & 0.5748 \\
Error & 15 & 240.5 & 16.0 & & \\
Total & 23 & 773.329 & & &
\end{tabular}

ANOVA Model: $Y=\mu+\alpha_{i}+\beta_{j}+\gamma_{k}+\alpha \beta_{i j}+\alpha \gamma_{i k}+\varepsilon_{i j k}$
Where: $\quad \alpha=$ Effect of $Q_{\text {nom }}$
$\beta=$ Effect of Rotate Wffan $_{\text {or }} \mathrm{V}_{\text {cross }}$
$\nu \quad=$ Effect of Flange
$\alpha \beta=$ Effect of Interaction between $Q_{\text {nom }}$ and Rotate WTfan
$\alpha \gamma=$ Effect of Interaction between $Q_{\text {nom }}$ and Flange

When the capture efficiency is calculated using the generation rate and analyzed using a fixeffect ANOVA model only the effect of $Q_{\text {nom }}$ is found to be significant at $p<0.0003$. This result was expected because of the strong effect of $Q_{\text {nom }}$ observed on $V_{x}$.

\subsection{Comparison of Two Measures of Capture Efficiency: $\eta_{\mathrm{e}-\mathrm{g}}$ and $\eta_{\mathrm{e}-\mathrm{duct} 100 \%}$}

The two measures of capture efficiency used should have a linear relationship with a slope of unity and an intercept of zero because they are essentially the same measures. 


\section{Comparison of Capture Efficiency Measures}

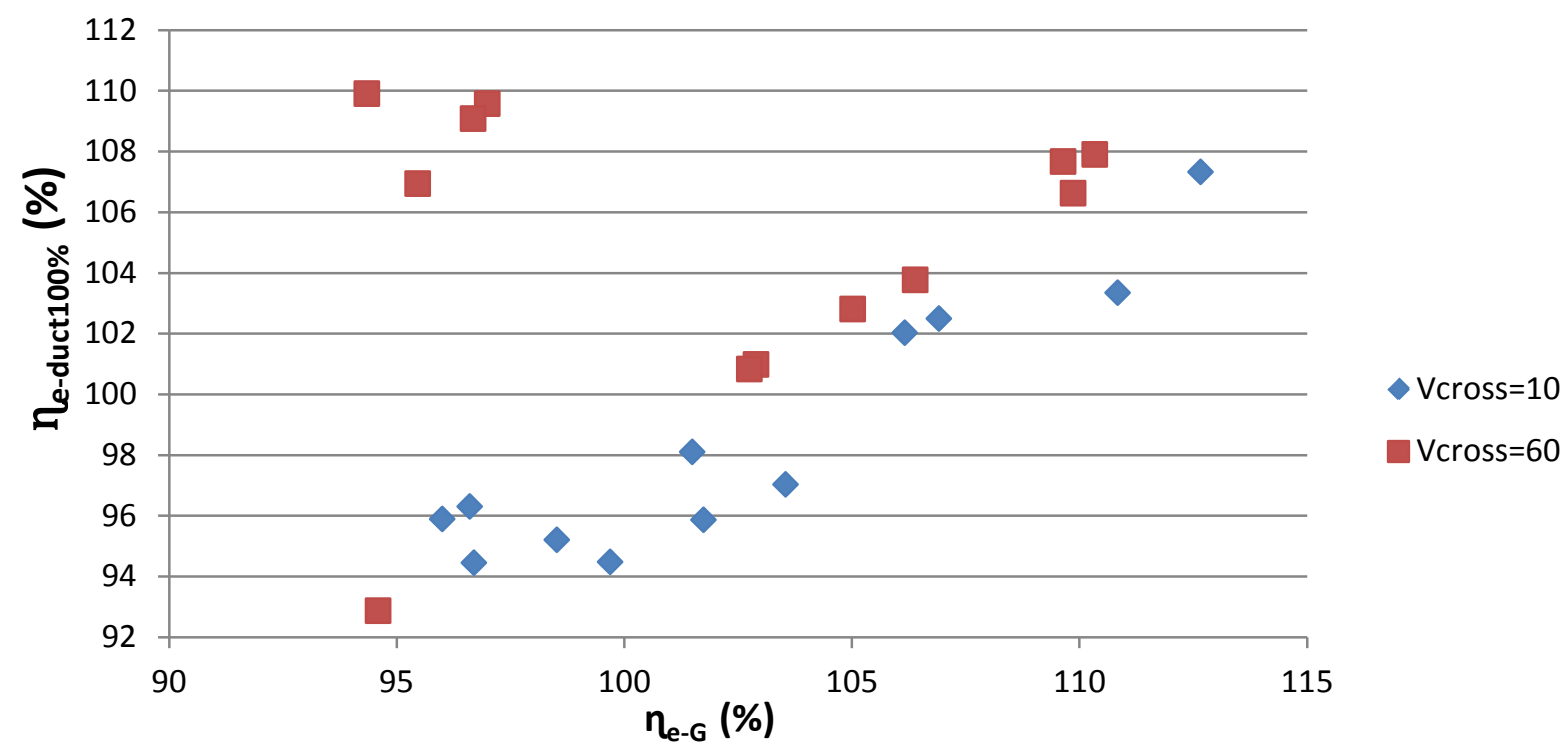

Figure 9-1. Comparison of the two capture efficiency measures used identified by level of $V_{\text {cross }}$

In fact, the two measures do appear to have a linear relationship, with exception of four cases where $V_{\text {cross }}=60 \mathrm{fpm}$ at lower capture efficiencies. These measures happen to occur at Freq $_{\text {HoodFan }}=23 \mathrm{~Hz}$. These are the same conditions where the $\mathrm{V}_{\text {cross }}$ was observed as having a larger effect on the measure of $\eta_{e-d u c t 100 \%}$. 


\section{Comparison of Capture Efficiency Measures}

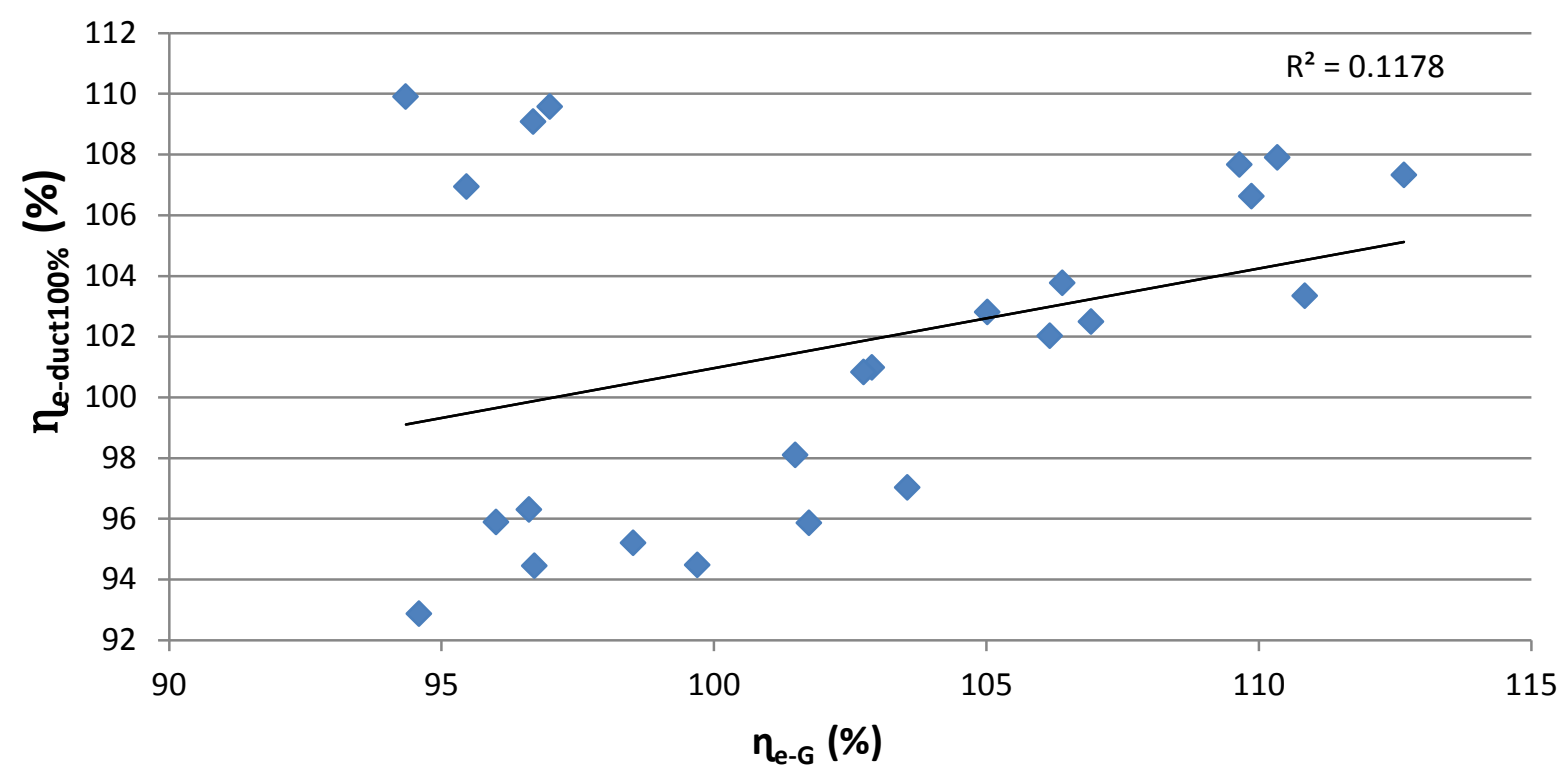

Figure 9-2. Comparison of two measures of capture efficiency

\section{Comparison of Capture Efficiency Measures}

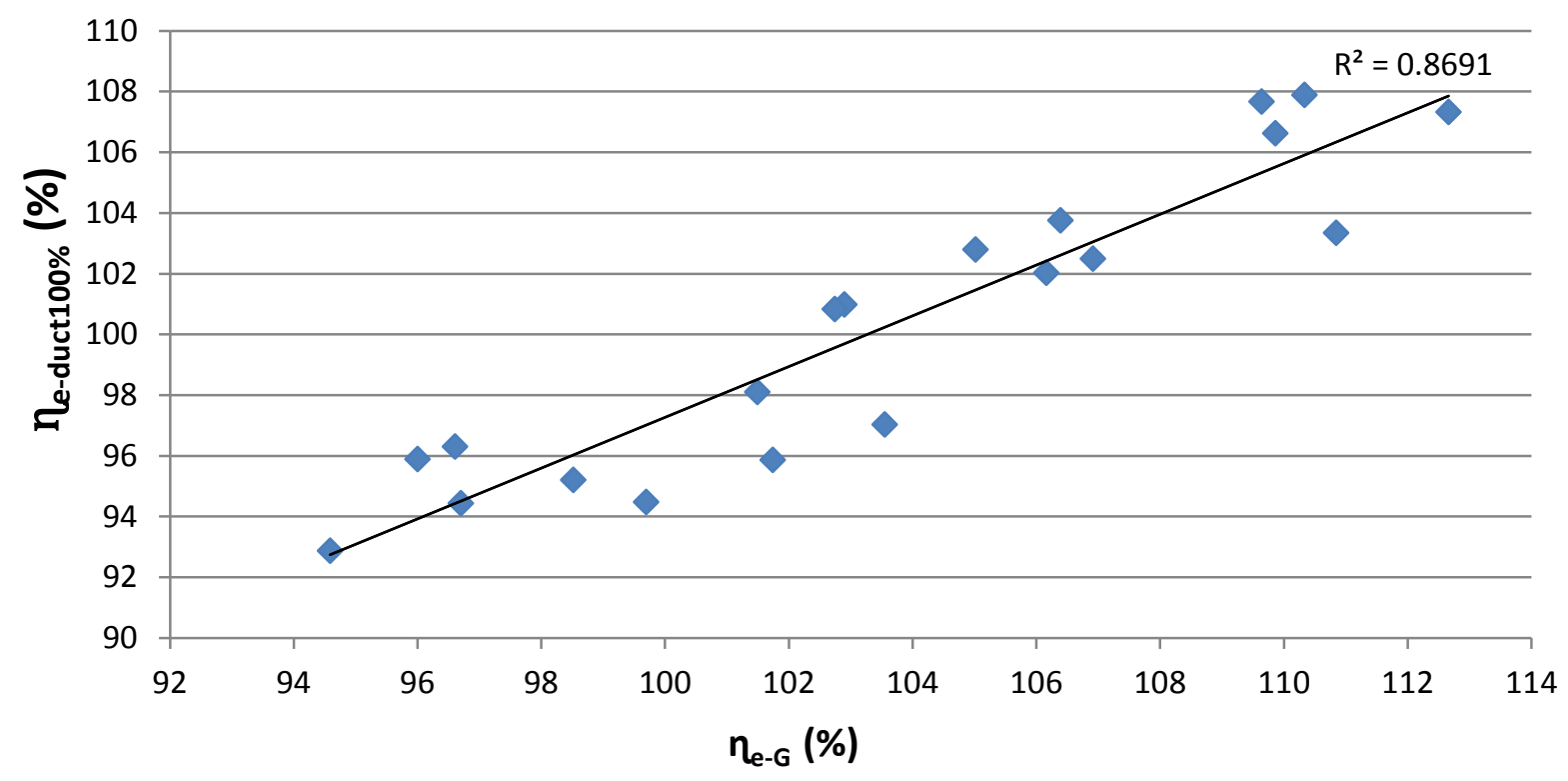

Figure 9-3. Comparison of two measure of capture efficiency with four values removed 
With the four measures from Freq ${ }_{\text {HoodFan }}=23 \mathrm{~Hz}$ removed, the correlation between the two capture efficiencies improves dramatically from an $R^{2}$ of 0.118 to 0.869 . This suggests that $\eta_{e-G}$ may be a better measure of capture efficiency than $\eta_{\text {e-duct } 100 \%}$ because it is less subject to the influence of the cross draft.

\subsection{Effect of Independent Variables on PE}

The measured concentrations for tracer gas in the breathing zone of the manikin, $\mathrm{C}_{\text {nose }}$ and $\mathrm{C}_{\text {mouth, }}$ were extremely low for all conditions tested $(<1 \mathrm{ppm})$ with nearly all below $0.15 \mathrm{ppm}$. The resulting protection efficiencies were extremely high (>99.5\%). Since these concentrations were trivially low, the effect of independent variables on the protection efficiency are of little interest for these data. Unsurprisingly given the lack of diversity in the values of $\mathrm{C}_{\text {nose }}$ and $\mathrm{C}_{\text {mouth }}$, ANOVA was performed using a fixed-effect model, both measures showed no significant effects for the independent variables (see Table 9-3 and Table 9-4).

Table 9-3. Fixed-effect analysis of variance for the dependent variable $C_{\text {mouth }}$

\begin{tabular}{|c|c|c|c|c|c|}
\hline Source & $d f$ & $\begin{array}{l}\text { Sums of } \\
\text { Squares }\end{array}$ & $\begin{array}{l}\text { Mean } \\
\text { Square }\end{array}$ & F-ratio & Prob \\
\hline Const & 1 & 0.69326 & 0.69326 & 22.089 & 0.0003 \\
\hline$Q_{\text {nom }}$ & 2 & 0.076078 & 0.038039 & 1.212 & 0.3251 \\
\hline $\mathrm{V}_{\text {cross }}$ & 1 & 0.032782 & 0.032782 & 1.0445 & 0.323 \\
\hline Flange & 1 & 0.038801 & 0.038801 & 1.2363 & 0.2837 \\
\hline $\mathrm{Q}_{\text {nom }} * \mathrm{~V}_{\text {cross }}$ & 2 & 0.086759 & 0.043379 & 1.3822 & 0.2812 \\
\hline $\mathrm{Q}_{\text {nom }}{ }^{*}$ Flange & 2 & 0.045046 & 0.022523 & 0.71765 & 0.5039 \\
\hline Error & 15 & 0.470768 & 0.031385 & & \\
\hline Total & 23 & 0.750233 & & & \\
\hline
\end{tabular}

Table 9-4 Fixed-effect analysis of variance for the dependent variable $C_{\text {nose }}$

\begin{tabular}{|c|c|c|c|c|c|}
\hline Source & $d f$ & $\begin{array}{l}\text { Sums of } \\
\text { Squares }\end{array}$ & $\begin{array}{l}\text { Mean } \\
\text { Square }\end{array}$ & F-ratio & Prob \\
\hline Const & 1 & 0.529848 & 0.529848 & 25.19 & 0.0002 \\
\hline$Q_{\text {nom }}$ & 2 & 0.057508 & 0.028754 & 1.367 & 0.2849 \\
\hline $\mathrm{V}_{\text {cross }}$ & 1 & 0.027608 & 0.027608 & 1.3125 & 0.2699 \\
\hline Flange & 1 & 0.020417 & 0.020417 & 0.97064 & 0.3401 \\
\hline $\mathrm{Q}_{\text {nom }} * \mathrm{~V}_{\text {cross }}$ & 2 & 0.04478 & 0.02239 & 1.0645 & 0.3696 \\
\hline $\mathrm{Q}_{\text {nom*Flange }}$ & 2 & 0.033886 & 0.016943 & 0.80551 & 0.4653 \\
\hline Error & 15 & 0.315512 & 0.021034 & & \\
\hline Total & 1 & 0.529848 & 0.529848 & 25.19 & 0.0002 \\
\hline
\end{tabular}




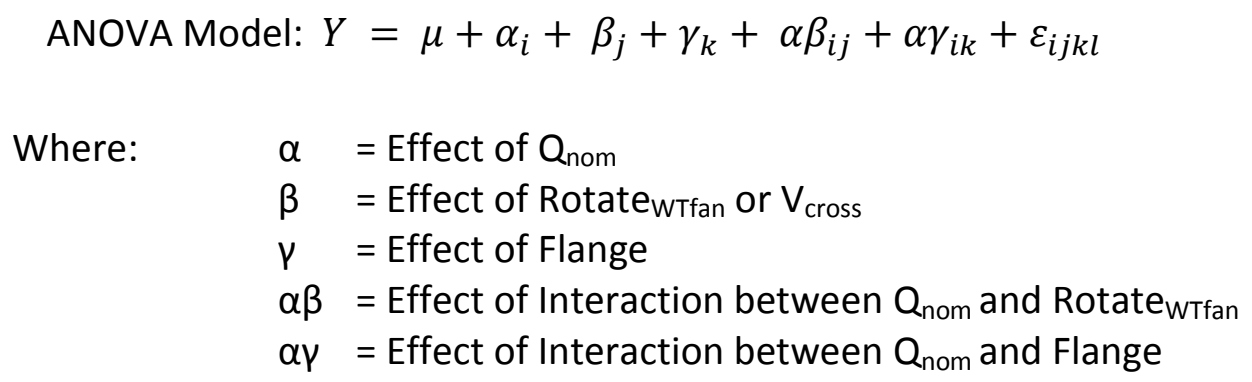

With $V_{\text {cross }}$ oriented towards the back of the manikin was expected to cause a wake zone effect in front of the manikin which would convey the contaminant back into the breathing zone of the manikin. This effect was not seen in these results. It is plausible the $V_{\text {cross }}$ simply pushed the contaminant further downstream, way from the manikin's breathing zone, causing the extremely high protection efficiencies. However, the extremely high capture efficiencies argue that the PE values were low simply because the hood was extremely effective at capturing the contaminant.

\subsection{Smoke Visualization}

Smoke was released to visualize the apparent effectiveness of the hood. A Model 1741 Fog Machine manufactured by Multi Media Electronics, Inc. was used to generate smoke. Smoke was conveyed to the tracer gas source in front of the hood using the tubing employed for the tracer gas delivery system. A helium stage light was utilized to illuminate the smoke released at the source. Each test from the main study was done once. 
Table 9-5. Result of Smoke Visualization

\begin{tabular}{ccccc}
$\begin{array}{c}\text { Freq } \\
\text { fan } \mathbf{H z}\end{array}$ & $\begin{array}{c}\mathbf{V}_{\text {cross }} \\
\mathbf{f p m}\end{array}$ & Flange & $\begin{array}{c}\text { Flow } \\
\text { Disturbed }\end{array}$ & \multicolumn{1}{c}{ Smoke behavior } \\
\hline 23 & 10 & No & Yes & $\begin{array}{l}\text { Followed table surface to hood, low lying. No movement } \\
\text { back towards manikin. Slow moving. Easily disturbed. }\end{array}$ \\
\hline 23 & 10 & Yes & No & $\begin{array}{l}\text { Moved more directly towards hood, some followed table } \\
\text { surface most rose and entered middle of hood. }\end{array}$ \\
\hline 23 & 60 & No & Yes & $\begin{array}{l}\text { Moved towards manikin's body, rose to about mid chest } \\
\text { before entering the hood }\end{array}$ \\
\hline 23 & 60 & Yes & Yes & $\begin{array}{l}\text { Slight movement towards manikin. Part followed table } \\
\text { surface most rose and entered middle of hood }\end{array}$ \\
\hline 40 & 10 & No & No & $\begin{array}{l}\text { Entrainment of at the trailing edge of source. Entered } \\
\text { lower half of hood. Fast moving. }\end{array}$ \\
\hline 40 & 10 & Yes & No & \begin{tabular}{l} 
Entrainment of at the trailing edge of source. Fast moving. \\
\hline 40
\end{tabular} \\
60 & No & Yes & $\begin{array}{l}\text { Little turbulence at source, no movement towards } \\
\text { manikin. Fast moving. }\end{array}$ \\
\hline 40 & 60 & Yes & No & Entrainment of at the trailing edge of source. Fast moving. \\
\hline 55 & 10 & No & No & Pulled directly into the hood. Very fast moving. \\
\hline 55 & 10 & Yes & No & Pulled directly into the hood. Very fast moving. \\
\hline 55 & 60 & No & No & Pulled directly into the hood. Very fast moving. \\
\hline 55 & 60 & Yes & No & Pulled directly into the hood. Very fast moving. \\
\hline & & & &
\end{tabular}

For tests where $\mathrm{V}_{\text {cross }}=10 \mathrm{fpm}$ and $\mathrm{Freq}_{\text {Hoodfan }}=23,40$ and 55, the smoke released from the source was captured with little to no observed disturbance to the smoke and with no visible escape from the hood. The difference in behavior of the smoke released from the source can be observed at different levels of Freq ${ }_{\text {Hoodfan }}$ and with the addition of a flange (see Figure 9-6 and Figure 9-7). However when Freq ${ }_{\text {HoodFan }}$ was $23 \mathrm{~Hz}$, the manikin's wake zone appeared to have an influence on the smoke being released at the source (see Figure 9-4). At a $V_{\text {cross }}=60 \mathrm{fpm}$ the smoke would periodically travel towards the mid-section of the manikin and rise to the mid chest of manikin before being pulled into the hood. Smoke was not observed to rise above the neck of the manikin. 


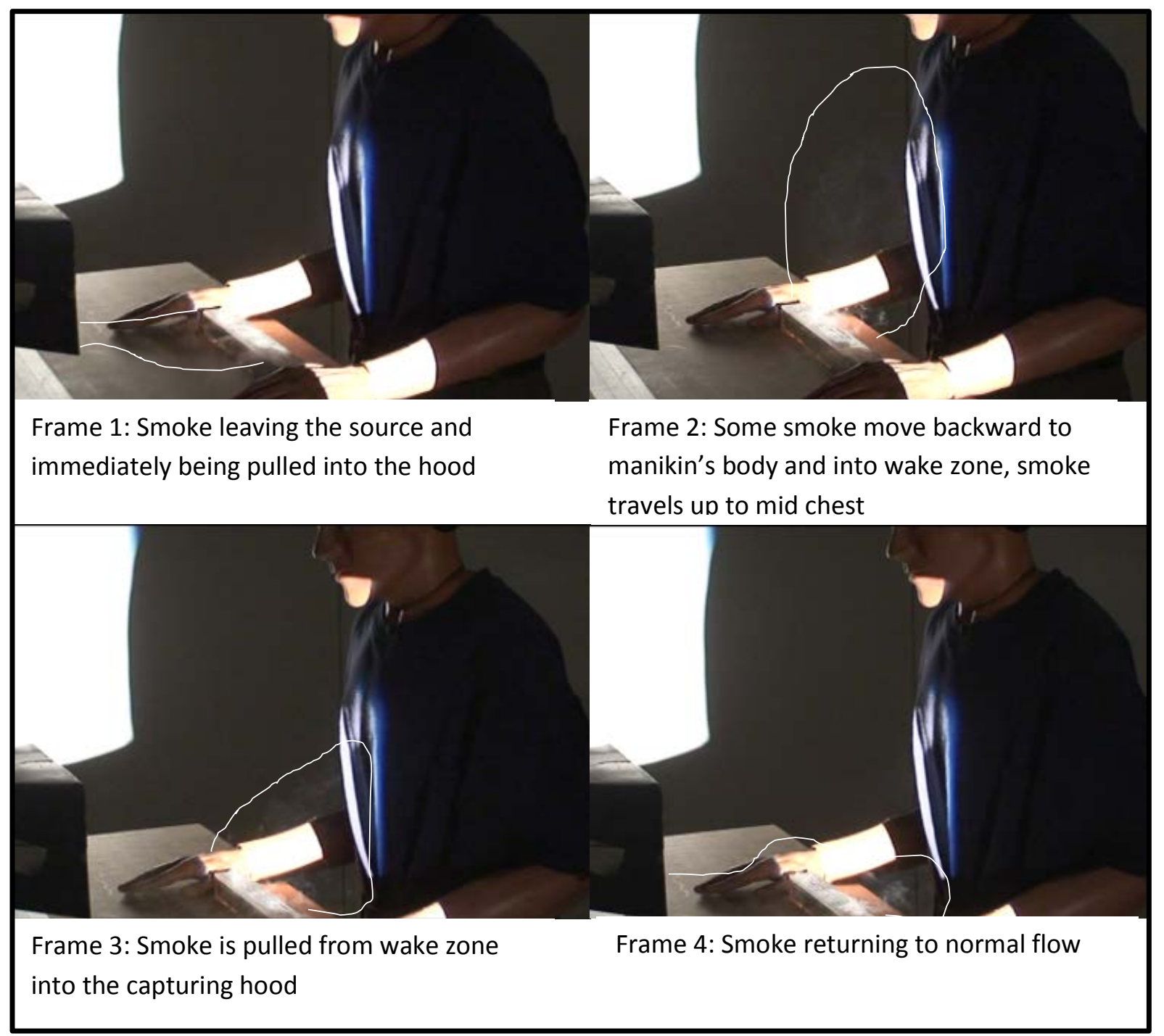

Figure 9-4. Smoke visualization tests at Freq ${ }_{\text {Hoodfan }}=23$ and Rotate $_{\text {WTfan }}=930$ with no flange. 


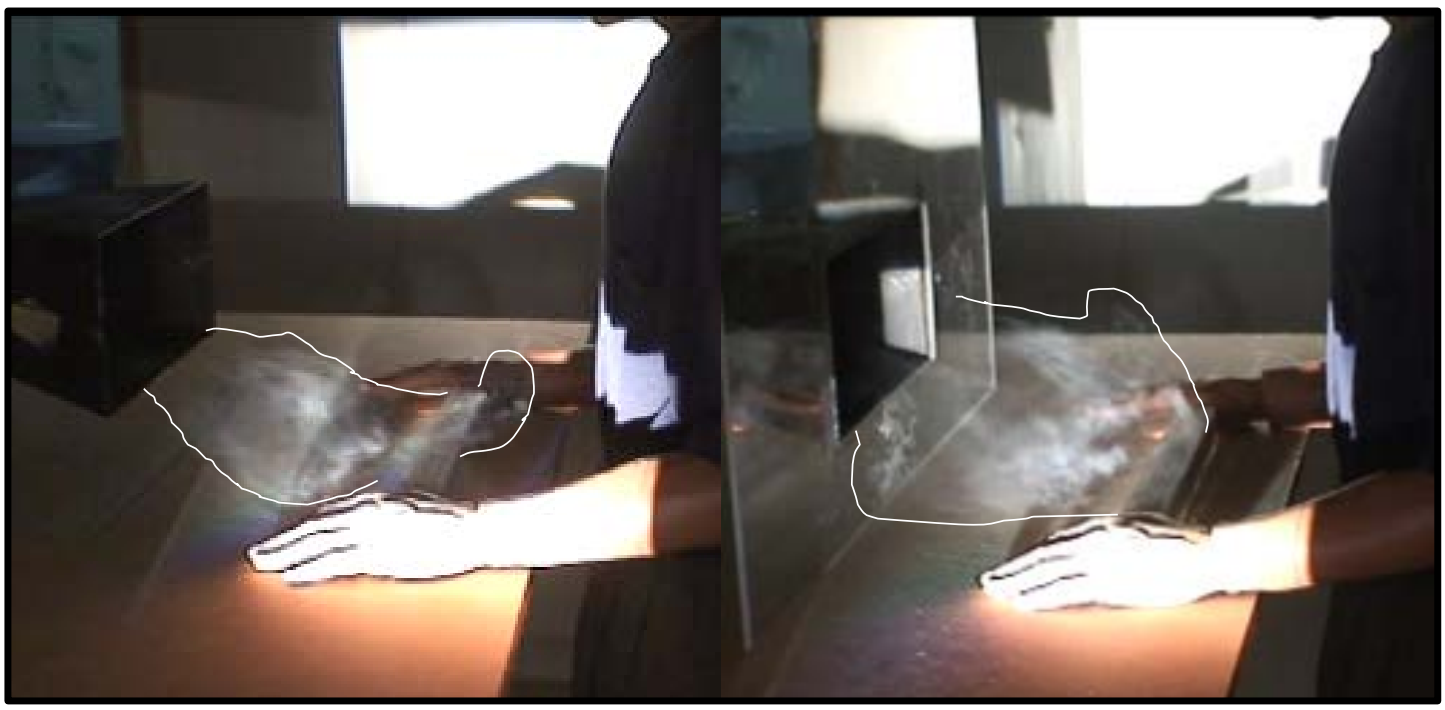

Figure 9-5. Smoke Visualization at Freq ${ }_{\text {Hoodfan }}=23$ Rotate $_{\text {WTfan }}=930$ with and without a flange.

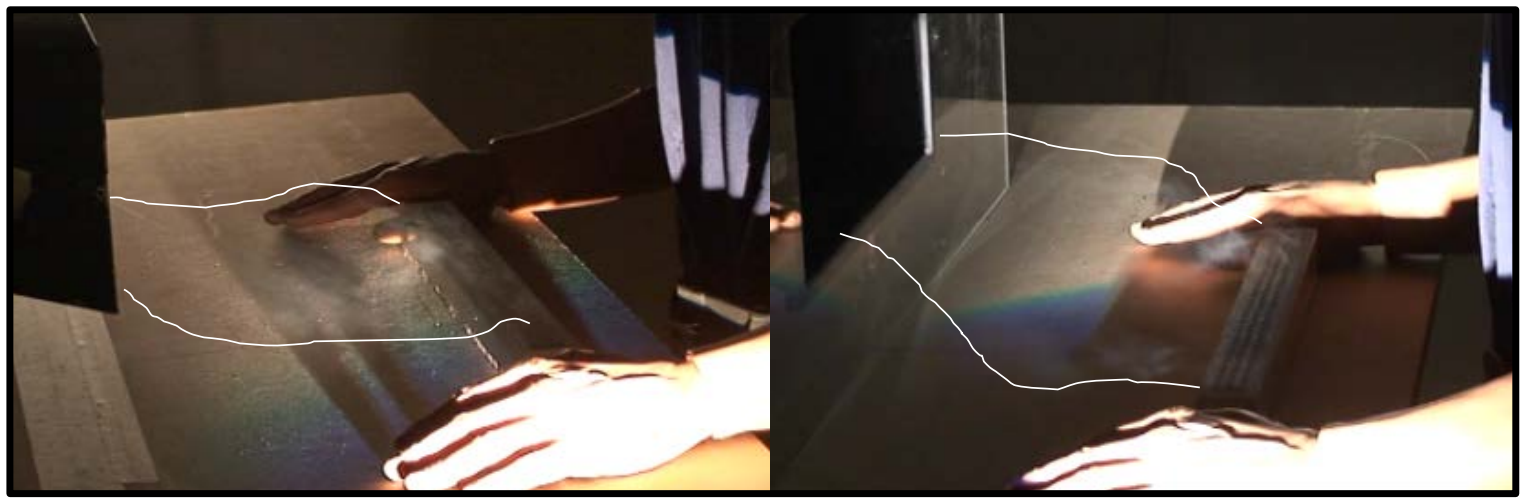

Figure 9-6. Smoke visualization at Freq $\mathrm{HoodFan}=40$ Rotate $_{\mathrm{WTfan}}=930$ with and without a flange.

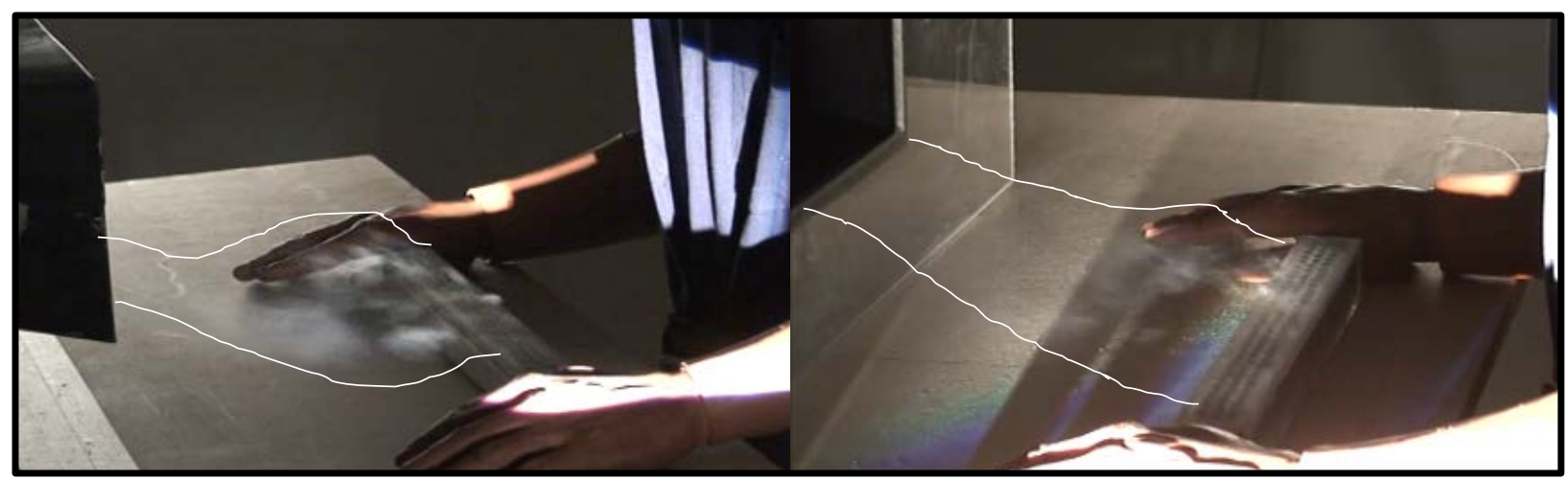

Figure 9-7. Smoke visualization at Freq ${ }_{\mathrm{HoodFan}}=55$ and Rotate $_{W T f a n}=930$ with and without a flange. 


\section{CHAPTER 10: CONCLUSIONS}

The small capturing hood tested controlled $\mathrm{C}_{\text {nose }}$ and $\mathrm{C}_{\text {mouth }}$ to very nearly zero ppm, which was much better than expected. The protection efficiency was nearly $100 \%$ in every case, providing too little diversity for statistical evaluations of the effects of independent variables. Observation of smoke released at the tracer gas source showed no escape from the hood, suggesting that any escape was too minor to see under the conditions.

The capture efficiency ranged from $92 \%$ to $110 \%$ when calculated with $\mathrm{C}_{\text {duct100\% }}$ and $94 \%$ to $112 \%$ when calculated with the generation rate and observed Q. Because of the difficulty in measuring at these concentrations with acceptable precision and accuracy, little confidence should be placed in the capture efficiency results.

The results of this study seem to support Industrial Ventilation's suggestion that capture hoods can be effective if kept close enough to the source to induce a substantial velocity. The reason they may sometimes be highly ineffective is that workers often move the hood or the contaminant source to a distance where the capture velocity approaches the values of convection currents and cross drafts. Since the capture velocity falls with the distance squared from the hood face, even small movements can lead to inadequate capture velocities.

\subsection{Caveats}

It's important to note that study tested only one hood in a highly artificial environment of a wind tunnel for one direction of cross draft with a fixed distance between the source and the hood face. Changing any of the studied parameters may yield dramatically different results.

Likewise, the manikin was placed in a non-moving, fixed posture and had no body or hand movements. If the manikin or its hands moved, the results may have been very different.

\subsection{Recommendations}

Further study with different cross-draft orientations, source distance, and manikin movements should be done before attempting to apply these results in practical applications. For measures 
of capture efficiency, more accurate and precise measurements at the levels found in the duct are needed. 


\section{CHAPTER 11: REFERENCES}

ACGIH. (2007). Industrial Ventilation: A Manual of Recommended Practice for Design (26th ed.). Cincinnati, Ohio: American Conference of Governmental Industrial Hygienists.

Ahn, K., Woskie, S., DiBerardinis, \& Ellenbecker, M. (2008). A Review of Published Quantitative Experimental Studies on Factors Affecting Laboratory Fume Hood Performance. Journal of Occupational and Environmental Hygiene(5), 735-753.

Alden, J. L., \& Kane, J. M. (1982). Design of Industrial Ventilation Systems (5th ed.). New York, NY: Industrial Press Inc.

ANSI/AIHA. (2003). Z9.5. Laboratory Ventilation. American National Standards Association / American Industrial Hygiene Association.

Burgess, W. A., \& Murrow, J. (1976). Evaluation of Hoods for Low Volume-High Velocity Exhaust Systems. American Industrial Hygiene Association Journal, 37(9), 546-549.

Cascetta, F., \& Bellia, L. (1996). Velocity Fields in Proximity of Local Exhaust Hood Openings: an Intercomparison between Current Recommended Formulas and Experimental Studies. Building and Environment, 31(5), 451-459.

Conroy, L. M., Ellenbecker, M. J., \& Flynn, M. R. (1988). Prediction and Measurement of Velocity into flanged Slot Hoods. American Industrial Hygiene Association Journal, 49(5), 226-234.

Dalla Valle, J. M., \& Hatch, T. (1932). Studies in the Design of Local exhaust hoods. Transactions of the American Society of Mechanical Engineers, 54, 31-37.

DallaValle, J. M. (1930). Studies in the Design of Local Exhaust Hoods. Thesis for Sc.D. Harvard Engineering School.

Ellenbecker, M. J., Gampel, R. F., \& Burgess, W. A. (1983). Capture Efficiency of Local Exhaust Ventilation Systems. American Industrial Hygiene Associatio nJournal, 44(10), 752-755.

Elnahass, W. (2005). Effects of heating, breathing, hair style, posture, and air velocity on breathign zone concentrations for an anthropometrically-correct manikin in a wind tunnel. Dissertation, West Virginia University.

El-Sotouhy, A. R. (2008). Dissertation. Effect of Breathing, Posture, and air velocity on Breathing Zone Gas Concentrations for Human Subjects in a Wind Tunnel. Morgantown, WV: West Virginia University.

Fletcher, B. (1977). Centreline Velocity Characteristics of Rectangular Unflanged Hoods and Slots Under Suction. Annals of Occupational Hygiene, 20, 141-146. 
Fletcher, B. (1978). Effect of flanges on the Velocity in front of Exhaust Ventilation Hoods. Annals of Occupational Hygiene, 21, 265-269.

Fletcher, B., \& Johson, A. E. (1982). Velocity Profiles Around Hoods and Slots and the Effects of an Adjacent Plane. Annals of Occupational Hygiene, 25(4), 365-372.

Flynn, M. R. (2003). On the Inertial Range of Particles under the Influence of Local exhaust Hoods. Annals of Occupational Hygiene, 47(2), 151-156.

Flynn, M. R., \& Ellenbecker. (1986). Captur Efficiency of Flanged Circular Local Exhaust Hoods. Annals of Occupational Hygiene, 30(4), 497-513.

Flynn, M. R., \& Ellenbecker, M. J. (1987). Emperical Validation of Theoretical Velocity Fields into Flanged Circular Hoods. American Industrial Hygiene Association Journal, 48(4), 380-389.

Flynn, M. R., \& Miller, C. T. (1988). Comparison of Models for Flow Through Flanged and Plain Circular Hoods. Annals of Occupational Hygiene, 32(3), 373-384.

Flynn, M. R., \& Miller, C. T. (1991). Discrete Vortex Method for the Simulation of Boundary Layer Separation Effects on Worker Exposure. Annals of Occupational Hygiene, 35(1), 35-50.

Garrison, R. P. (1981). Centerline Velocity Gradients for Plain and Flanged local Exhaust Inlets. American Industrial Hygiene Associatio Journal, 42(10), 739-746.

Guffey, S. E. (1993). Air-Flow Redistribution in Exhaust Ventilation Systems Using Dampers and Static Pressure Ratios. Applied Occupational and Environmental Hygiene, 8(3), 168-177.

Guffey, S. E., \& Barnea, N. (1994). Effects of Face Velocity, Flanges, and Mannikin Position on the Effectiveness of a Benchtop Enclosing Hood in the Absence of Cross-Drafts. American Industrial Hygiene Association Journal, 55(2), 132-139.

Hampl, V., Niemela, R., Shulman, S., \& Bartley, D. (1986). Use of Tracer Gas Technique for Industrial Exhaust Hood Efficiency Evaluation - Where to Sample? American Industrial Hygiene Association Journal, 47(5), 281-287.

He, X. (2010). Master's Thesis. Effects of Face Velocity, Cross-Draft Velocity and Interventions on the Performance of a Benchtop Enclosing Hood. West Virginia University.

Huang, R. F., Liu, G. S., Chen, Y.-K., Yeh, W.-Y., Chen, C.-W., \& Chen, C.-C. (2004). Effects of Flange Size on Dividing Streamlines of Exterior Hoods in Cross drafts. Journal of Occupational and Environmental hygiene, 1, 283-288.

Huang, R. F., Sir, S. Y., Chen, Y.-K., Yeh, W.-Y., Chen, C.-W., \& Chen, C.-C. (2001). Capture Envelopes of Rectangular Hoods in Cross Drafts. Ammerican Industrial Hygiene Association Journal, 62(5), 563-572. 
Huang, R. F., Sir, S. Y., Chen, Y.-K., Yeh, W.-Y., Chen, C.-W., \& Chen, C.-C. (2001). The Capture Envelope of a Flanged Circular Hood in Cross Drafts. American Industrial Hygiene Association, 62(2), 199-207.

Jackson, R. S. (1976). Monitoring Local Exhaust Ventilation Systems. Annals of Occupational Hygiene, 19, 309-312.

Karwowski, W., \& Marras, W. S. (1999). The Occupatinal Ergonoimics Handbook. Boca Raton, FI: CRC Press.

Lewis, B. V. (2010). Master's Thesis. Effects of 0 Cross Draft velocity and the Presence of a Table and Manikin on Midlin velocities in Front of a Rectangula Capture Hood. West Virginia University.

National Safety Council. (2002). Fundamentals of Industrial Hygiene (5th ed.). (B. A. Plog, Ed.) United States of America: National Safety Council.

Silverman, L. (1942). Centerline Velocity Characteristics of Round Openings Under Suction. Journal of Industrial Hygiene and Toxicology, 24(9), 259-266.

Tortora, G. J., \& Anagnostakos, N. P. (1990). Principles of Anatomy and Physiology (6th ed.). HarperCollins, New York: John Wiley and Sons.

Tseng, L.-C., Huang, R. F., chen, C.-C., \& Cheng, C.-P. (2006). Correlation Between Airflow Patterns and Performance of a Laboratory Fume Hood. Journal of Occupational and Environmental Hygiene, 3, 694-706.

TSI Incorporated. (2008). Fit Factors vs Protection Factors - Application Note ITI-023. Retrieved July 2012, from TSI Incorporated Web Site:

http://www.tsi.com/uploadedFiles/_Site_Root/Products/Literature/Application_Notes/ITI023.pdf

Volin, C. E., Joao, R. V., Reiman, J. S., Party, E., \& Gershey, E. C. (1998). Fumehood Performance: Face Velocity Variability Inconsistent Air Volume Systems. Applied Occupational and Environmental Hygiene, 13(9), 656-662. 


\section{Appendix I. FTIR Calibration}

The FTRI was calibrated twice, once before and once after testing, by adding ultra-high purity Freon in varying amounts to 9 liters of air laboratory air in a 10 liter Tedlar $^{\circledR}$ bag using gas tight syringes. Varying amounts of the Freon mixture was drawn from the 10 liter bag and injected to in to 5 liter Tedlar bag using a 3 liter syringe. The bag was diluted with laboratory air, if needed, to achieve the desired concentration of Freon. The bags were then analyzed by the FTIR. The residual values for the calibration were also recorded to determine if some measured concentrations resulted in higher residual values. The investigator found that for measured concentrations between approximately 50 to 100 ppm the FTIR returned an error associated with the sample (residual >0.02).

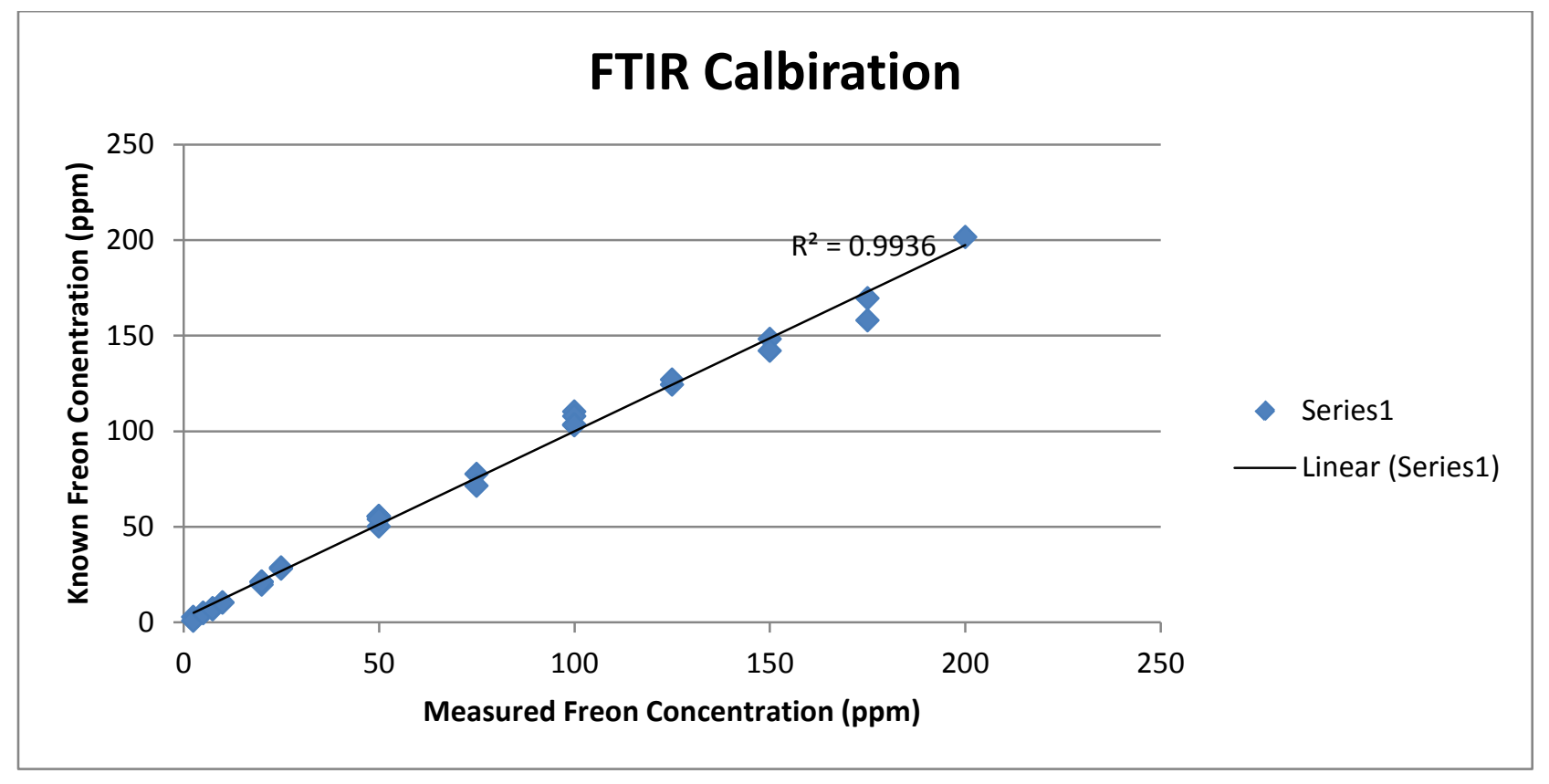

Figure 11-1. Calibration curve for the FTIR, combined pre and post calibrations. 


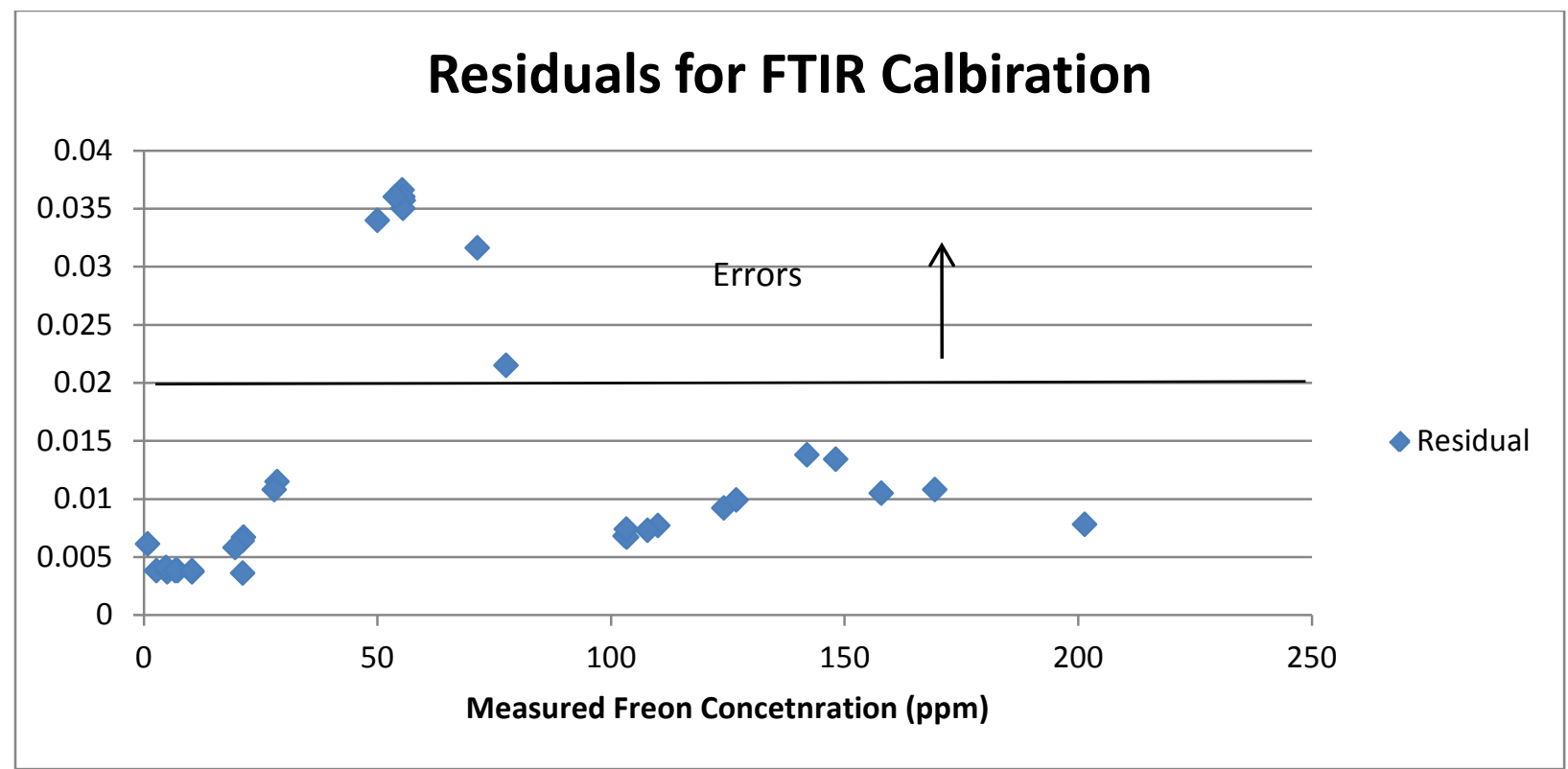

Figure 11-2. Residual values associated with the measured Freon concentrations during calibration.

Dilutions techniques were developed and implemented to avoid range of concentrations which returned high residuals (errors) during the study. Even though the FTIR calibration curve shows that the measured concentrations with errors fit on a line with the measured concentrations which did not receive errors, which suggests that the values with errors may not be in fact erroneous, the FTIR manual clearly states that samples with error statements should never be used. 


\section{Appendix II. CTA Calibration and Directional Sensitivity}

The CTA was calibrated using the TSI, Inc. Model 1125 calibrator, hooked to laboratory air supply, with the probe in the upper chamber of the unit 2 chamber, and the PVM-100 for velocity pressure measurement from the camber. Temperature and pressure in the laboratory were recorded and used for calculations of velocity from velocity pressure during calibration. The pressure inside the chamber was increased from 0 to 0.8 inch of water to achieve a velocity range of approximately 0 to $200 \mathrm{fpm}$.

$$
V=4005 \sqrt{\frac{V P}{d f}}
$$

Where: $\quad$ VP $=$ Velocity pressure

$\mathrm{df}=$ Corrective factor for temperature and pressure

$\mathrm{V} \quad=$ Velocity in the chamber

Table 11-1. CTA Calibration

\begin{tabular}{|c|c|c|c|c|}
\hline Seq No & meas VP & meas Voltage & $\begin{array}{c}\text { calibrator } \\
\text { Position }\end{array}$ & $\begin{array}{l}\text { Chamber } \\
\text { Vel from } \\
\underline{\text { VP }}\end{array}$ \\
\hline 1 & 0.000 & 1.42727 & 1 & 0.00 \\
\hline 2 & 0.049 & 1.50118 & 1 & 47.97 \\
\hline 3 & 0.1 & 1.52881 & 1 & 68.52 \\
\hline 4 & 0.15 & 1.54703 & 1 & 83.92 \\
\hline 5 & 0.199 & 1.56055 & 1 & 96.67 \\
\hline 6 & 0.302 & 1.58206 & 1 & 119.08 \\
\hline 7 & 0.399 & 1.59728 & 1 & 136.88 \\
\hline 8 & 0.500 & 1.61026 & 1 & 153.22 \\
\hline 9 & 0.600 & 1.62152 & 1 & 167.85 \\
\hline 10 & 0.700 & 1.63099 & 1 & 181.30 \\
\hline 11 & 0.800 & 1.63975 & 2 & 193.82 \\
\hline
\end{tabular}




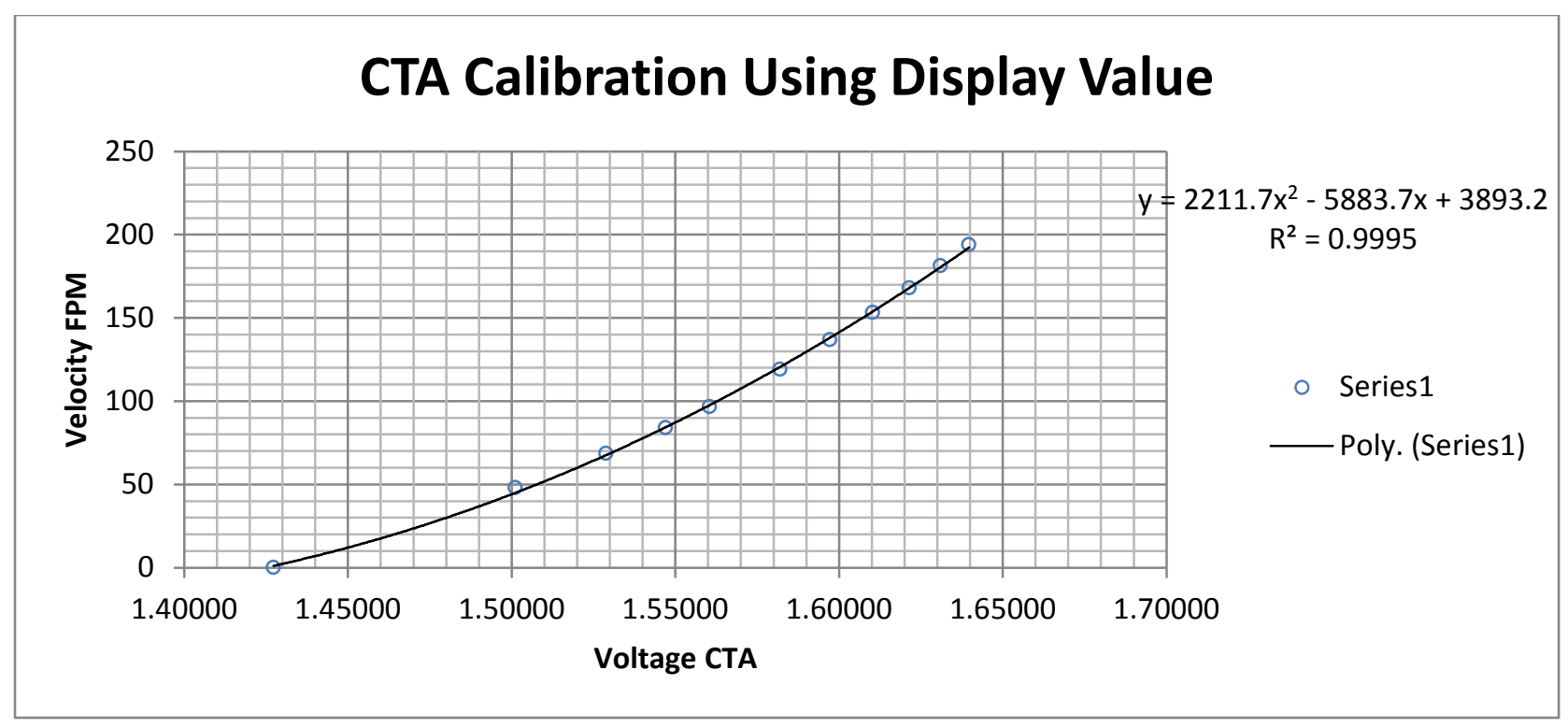

Figure 11-3. CTA calibration curve.

The equation present above in Figure 11-3 was entered in the National Instruments Signal Express program to correct correlate measured voltage to velocity in $\mathrm{fpm}$.

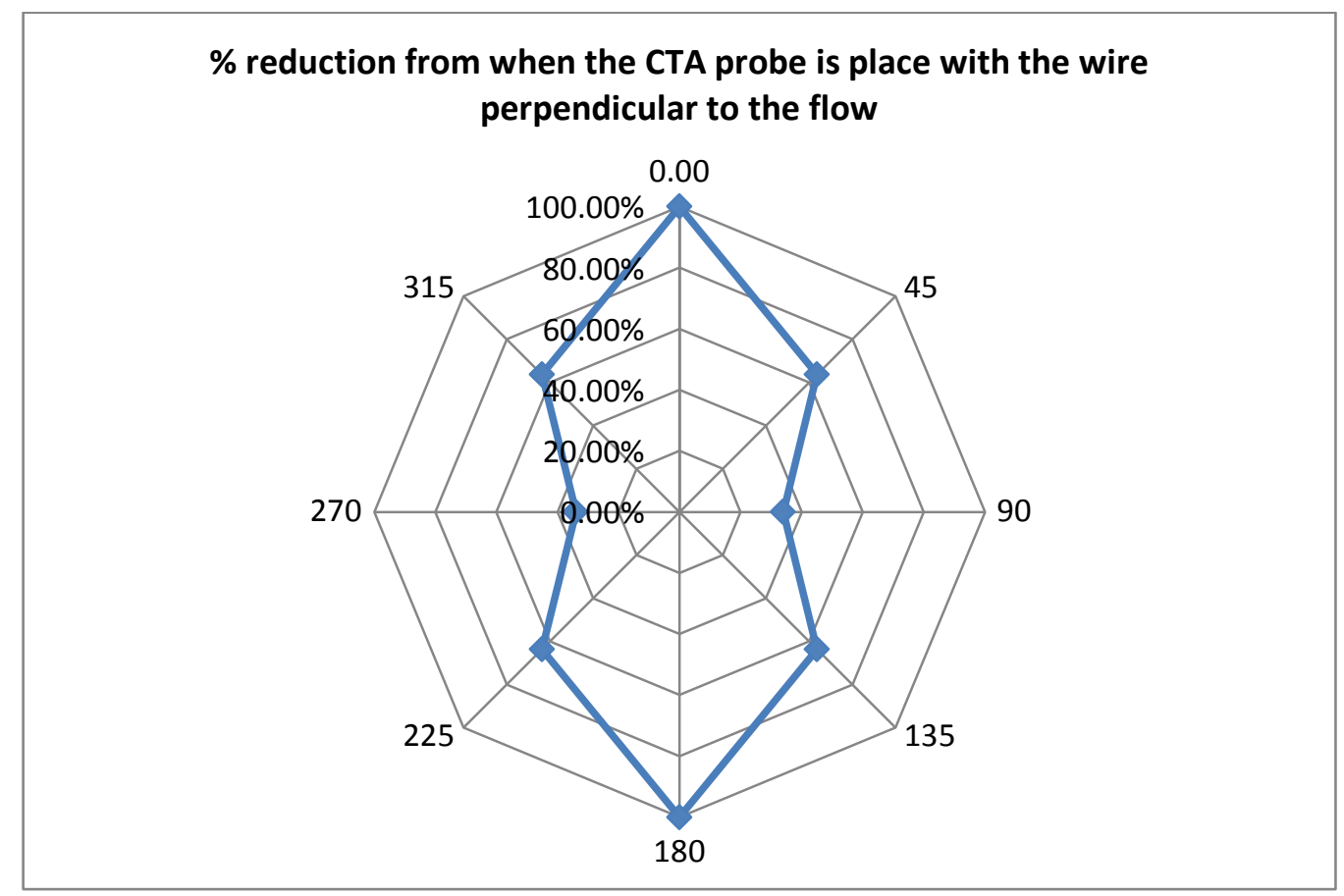

Figure 11-4. Directional sensitivity of the CTA when rotated about its axis.

The directional sensitivity of the CTA was measured by rotating the CTA along the axis of the probe at 45 degree intervals. The reduction in calculated velocity from the CTA for each interval 
around the axis of the CTA is show in Figure 11-4. The CTA probe was found to have a minimal response of approximately $18 \%$ when the probe was oriented 90 degrees to the direction of the flow and a response of approximately $45 \%$ when the probe oriented at a 45 degree angle to the direction of flow. The percent response was calculated as the measured velocity at an abnormally position (45, 90, 225,270, and 315 degrees) divided by the measured velocity when the probe was positioned "normally" with the wire perpendicular to the flow (0 and 180 degrees).0 